Portland State University

PDXScholar

$1-1-1985$

\title{
An assessment of a training program designed to teach staff nurses in an acute care facility to transfer nursing process theory to practice
}

C. Frances Johnson

Portland State University

Follow this and additional works at: https://pdxscholar.library.pdx.edu/open_access_etds Let us know how access to this document benefits you.

\section{Recommended Citation}

Johnson, C. Frances, "An assessment of a training program designed to teach staff nurses in an acute care facility to transfer nursing process theory to practice" (1985). Dissertations and Theses. Paper 417. https://doi.org/10.15760/etd.417

This Dissertation is brought to you for free and open access. It has been accepted for inclusion in Dissertations and Theses by an authorized administrator of PDXScholar. Please contact us if we can make this document more accessible: pdxscholar@pdx.edu. 
AN ASSESSMENT OF A TRAINING PROGRAM DESIGNED TO TEACH

STAFF NURSES IN AN ACUTE CARE FACILITY

TO TRANSFER NURSING PROCESS THEORY

TO PRACTICE

by

CELIA FRANCES JOHNSON

A dissertation submitted in partial fulfillment of the

requirements for the degree of

\author{
DOCTOR OF EDUCATION \\ in \\ COMMUNITY COLLEGE EDUCATION
}

Portland State University

(C) 1985 Celia Frances Johnson 
TO THE OFFICE OF GRADUATE STUDIES AND RESEARCH:

The members of the Committee approve the dissertation of Celia Frances Johnson presented June 12, 1985.

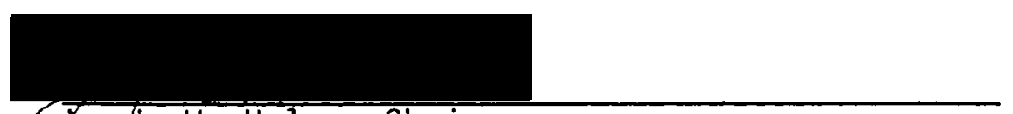

CXoyde W. Hales, Chairman

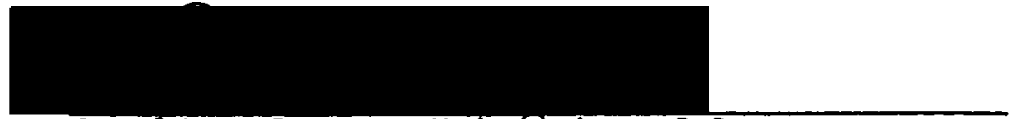

Gerald K. Bogen - Univer ity of Oregon

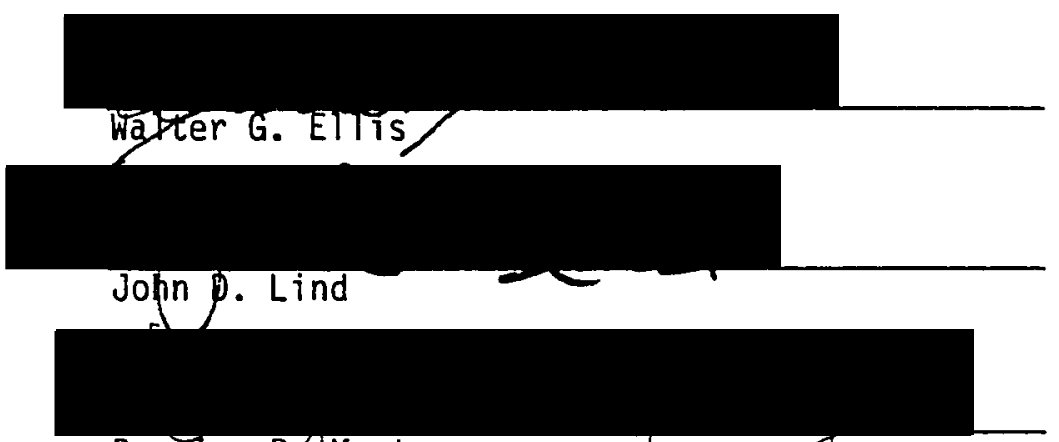

Douğlas D.jMontgomery

APPROVED:

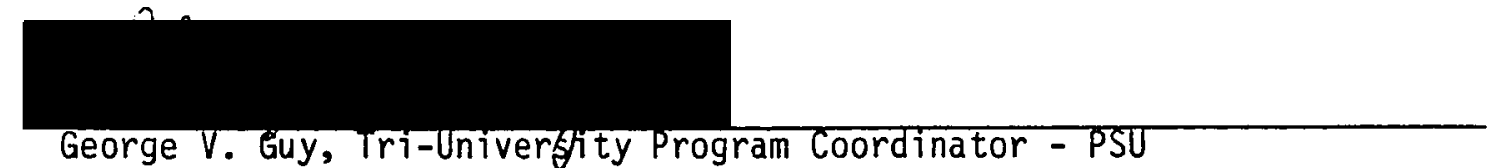

George V. Guy, Tri-University Program Coordinator - PSU

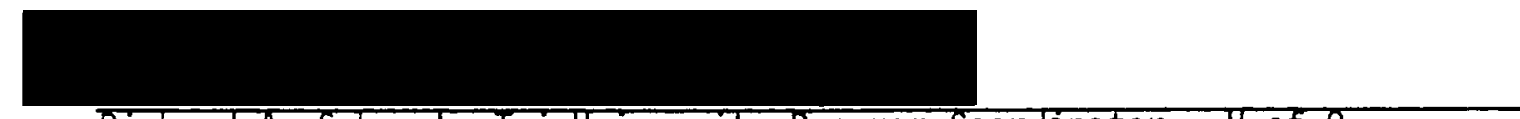

Richard A. Schmuck, Tri-University Program Coordinator - U of 0

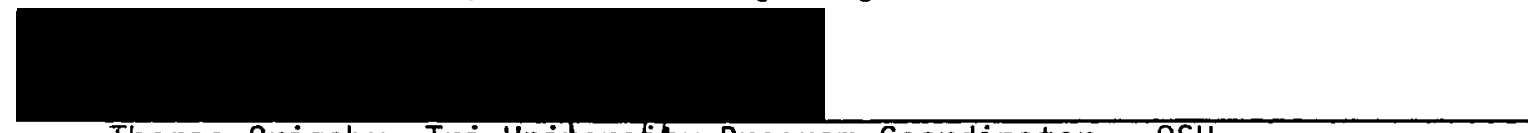

Thomas Grigsby, Tri-Universilty Program Coordinator - OSU

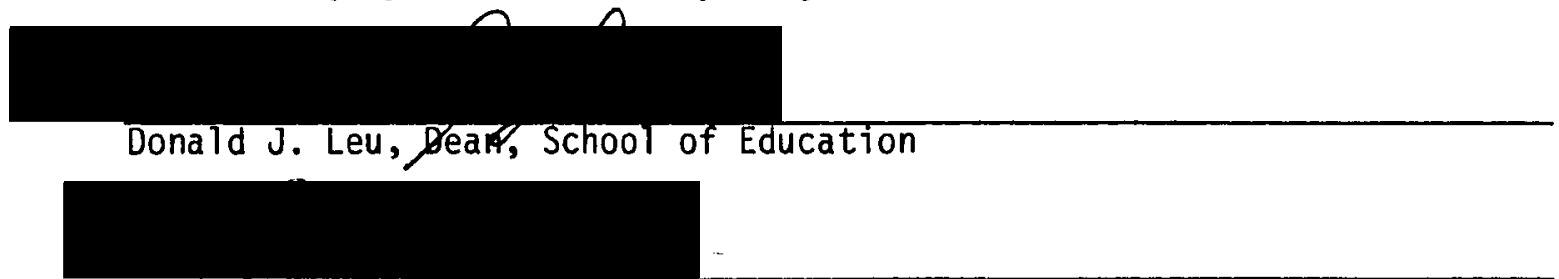

Jim $F$. Heath, Dean of Graduate Studies and Research 
AN ABSTRACT OF THE DISSERATION OF Celia Frances Johnson for the Doctor of Education in Community College Education presented June 12, 1985.

Title: An Assessment of a Training Program Designed to Teach Staff Nurses in an Acute Care Facility to Transfer Nursing Process Theory to Practice.

APPROVED BY MEMBERS OF THE DISSERTATION COMMITTEE:

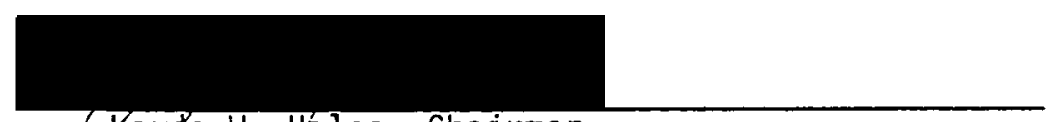

Qoyde W. Háles, Chairman

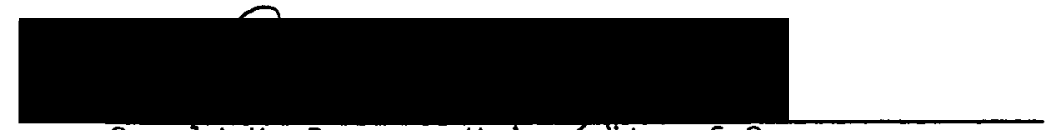

Gerald K. Bogen - University of Oregon

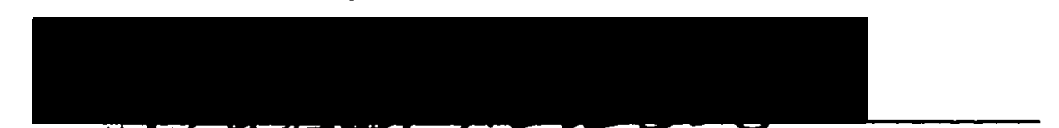

Wayter G. EITIS

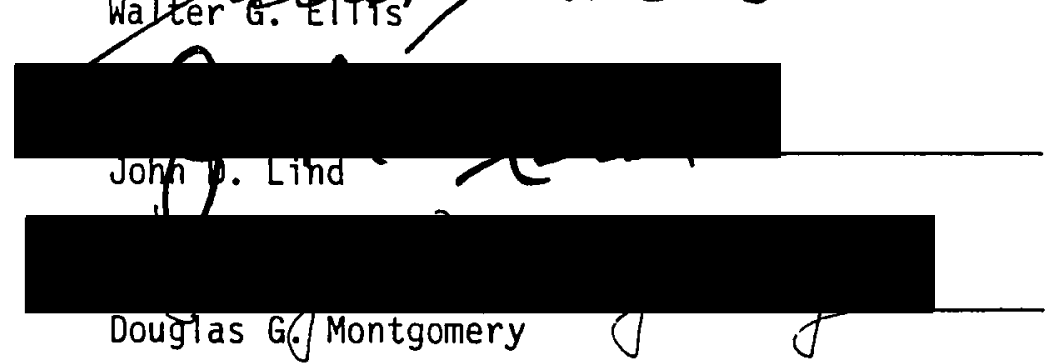

A training program was developed to teach registered nurses in an acute care facility to learn nursing process theory and to transfer that theory to nursing practice. A total sample of 102 newly-hired registered nurses participated in this program, were pre-tested and post-tested, and completed a questionnaire which provided demographic and attitudinal 
data related to the nursing process as a model for nursing care. An audit sample of 82 nurses from the total sample were audited one month after the training program to collect data on documentation in patients' charts of their utilization of nursing process; 246 audits were completed. Concommittantly, an audit was performed on these charts to determine total nursing staff's compliance with requirements that the nursing process be used and documented in patients' charts. Therefore, the purpose of this study was twofold: to evaluate the effectiveness of the inservice program and to evaluate the utilization of nursing process by the entire nursing staff. Secondarily, the relation of age, experience, and type of nursing education with measured performance behavior was investigated.

The following results emerged from the analys is of the audit sample. A significant increase in knowledge of nursing process occurred between pre-testing and post-testing $(\underline{t}=3.22 ; \underline{p}=.002)$, and the patients' charts revealed that $78 \%$ of the appropriate nursing process items were completed. Analyses of variance were performed on type of nursing education using pre-test, post-test, change scores, understanding, and percent completion as dependent variables. Significant differences were found on the pre-test (with the mean for LPN's being less than the mean for BSN's) and post-test (with the mean for LPN's being less than the means for ADN's and BSN's). Analyses of variance were performed on the change scores and percent complete, using age and experience as independent variables; no significant difference was found. 
For the total sample, analyses of variance were performed on type of nursing education, age, and experience, using the pre-test, posttest, and understanding as dependent variables. Analyses of covariance were also performed on these variables, using the pre-test as a covariate and the post-test as the dependent variable. For type of nursing education, the only significant difference was on self-perceived understanding, with the mean for ADN's being less than the mean for BSN's. Significant differences were found for age and experience on the post-test and the post-test with the pre-test as a covariate. On the post-test, the mean for the over 40 group was less than the means for the younger two groups; no significant pair-wise mean comparison was found with the adjusted scores. On the experience variable, the mean for the Under Six Years group was higher than the means for the other groups; this was also true of the adjusted means.

The chart audits yielded the following results. Percent completed for the total nursing staff on the items of the Nursing Assessment form ranged from a low of 52.0 on "Is all information filled in?" to a high of 91.5 on "Is there evidence that the patient's immediate needs were assessed by a Registered Nurse?" The percent complete on the items of the Problem List--Nursing ranged from a low of 4.3 on "Is there evidence that problems have been resolved?" to a high of 53.5 on "Does each problem have a Roman numeral as a designator?" Percent completed for the Patient Progress Notes ranged from a low of 64.6 on "Is there documentation of discharge planning for the patient when necessary?" to a high of 98.8 on three items ("Are dates and specific times indicated 
with comments for each shift, followed by signatures with titles?" "Are nursing interventions recorded accurately?" "Are pertinent observations and communications recorded using S.0.P.A. format?"). On 76.4 percent of the charts, there was evidence of "documentation of one or two items flowing from the plan on this sheet," the one question on the Flow Sheet.

Results indicated that the nurses who attended this training program evidenced an understanding of nursing process theory and documented their implementation of the process into nursing practice. Despite differences in age, experience, and educational programs which appeared to be statistically significant, the performances of nurses who had attended this training program showed no significant differences in practice. 


\section{ACKNOWLEDGMENTS}

I wish to extend my sincere gratitude to the following people. Without their assistance and support, this project would not have been possible.

My thanks to the members of my dissertation committee: John Lind, Walter Ellis, Douglas Montgomery, and Gerald Bogen, for their patience. A special recognition is owed to my chairman, Loyde Hales, who gave so generously of his time and expertise and who never failed to be kind and caring during the long process.

I also want to acknowledge the staff of Bess Kaiser Medical Center who provided the data for this study.

My final and warmest thank-you is to my sister, Rae Tally, who never for one moment doubted that I could obtain my degree and who constantly encouraged me to think the same. 
TABLE OF CONTENTS

PAGE

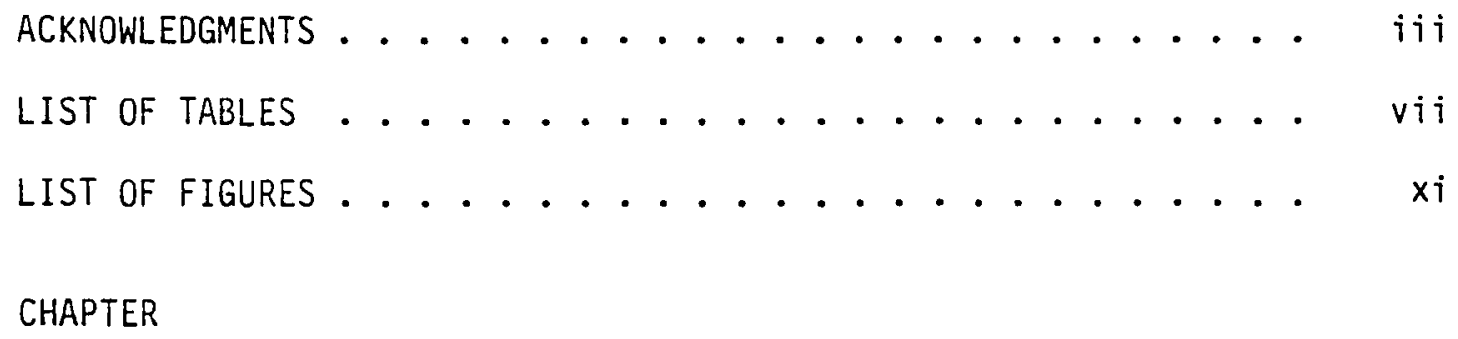

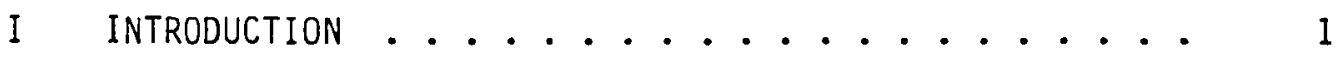

Background .................... 1

In-Service Training of Nurses ....... 3

Problem Identification ........... 6

Significance of the Study .......... 9

II REVIEW OF THE LITERATURE . . . . . . . . . . . 11

The Nursing Process .......... 12

III DESIGN OF THE STUDY .......................... 33

Sample Characteristics ......... 35

Description of the Nursing Process Class . . . . 41

Research Procedures .......... 44

Instrument Construction ......... 45

Training of the Auditors ......... 46

The Collection Procedure .......... . 47

Test Development ............. 51

Statistical Methods ............ 52 
Limitations ................ 53

IV ANALYSIS AND PRESENTATION OF THE DATA . . . . . . . 55

Questions Asked ............. 55

Understanding of Nursing Process by Newly-Employed Nurses.............. 56

Application and Documentation of the Nursing Process by Newly-Employed Nurses . . . . 59

Total Nursing Staff Compliance with Nursing Process Requirements ........ 59

Total Nursing Staff Compliance by Clinical Area . 69

Relationship Between Type of Nursing Education and Nursing Process............

Total Sample

Audit Sample

Relationship Between Age and Knowledge and Use of Nursing Process............

Total Sample Audit Sample

Relationship Between Experience and Knowledge and Use of Nursing Process . . . . . . . .

Total Sample Audit Sample

$\checkmark$ SUMMARY, CONCLUSIONS, AND RECOMMENDATIONS FOR FURTHER

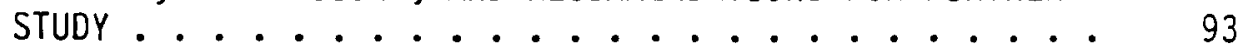

Summary ................ 93

Introduction

Problem

Purpose of the Study

The Sample Instrument Construction Methodology

Results 
PAGE

Discussion and Conciusions....... . . 103

Total Staff Utilization of Nursing Process

Clinical Arena Utilization

Nursing Education and the Nursing Process

Age and the Nursing Process

Experience and the Nursing Process

Concluding Statements

Recommendations for Further Study . . . . . 113

REFERENCES .................... 117

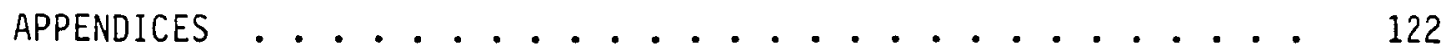




\section{LIST OF TABLES}

TABLE

PAGE

I Crosstabulation of Age Groups by Type of Nursing

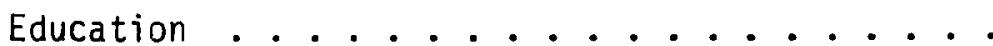

II Crosstabulation of Years of Nursing Experience by

Type of Nursing Education . . . . . . . 33

III Crosstabulation of Years of Nursing Experience by

Previous Nursing Processing Class ...... 39

IV Crosstabulation of Years of Nursing Education by Prior

Nursing Process Class .......... . . 40

V Age of Patients ....................... 41

VI Means and Standard Deviations for the Total and Audit

Samples on Five Dependent Variables . . . . . 57

VII Ninety-Five Percent Confidence Intervals for Population

Means Estimated from Five Dependent Variable

Measures of the Audit and Total Samples . . . .

VIII Pre-Test - Post-Test Change Scores for the Audited Sample................ 59

IX Analysis of Staff RN Utilization of the Nursing

Assessment Form .............. 61

$X \quad$ Ninety-Five Percent Confidence Intervals for Population

Percent Completion for Each Question on the Nursing Assessment Form ........... 
XI Analysis of Staff RN Utilization of the Problem ListNursing ...............

XII Ninety-Five Percent Confidence Intervals for Population

Percent Completion for Each Question on the

Problem List-Nursing Form ......... 64

XII Analysis of Staff RN Utilization of the Progress Notes 66

XIV Ninety-Five Percent Confidence Intervals for Population

Percent Completion for Each Question on the

Progress Note ................ 67

XV Analysis of Staff RN Utilization of the Flow Sheet . . 68

XVI Ninety-Five Percent Confidence Intervals for Population

Percent Completion for the Question on the Flow Sheet ................

XVII For Each Item on the Nursing Assessment Form, Percent

Completed by Clinical Arena, Calculated Chi-

Square and Probability......... 70

XVIII For Each Item on the Problem List-Nursing, Percent

Completed by Clinical Arena, Calculated Chi-

Square, and Probability ..........

XIX For Each Item on the Progress Notes, Percent Completed

by Clinical Arena, Calculated Chi-Square, and

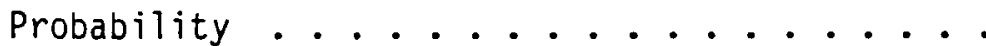


XX Percent Completed by Clinical Arena, Calculated ChiSquare, and Associated Probability on the Flow Sheet .................

XXI Means and Standard Deviations for type of Nursing Education: Total Sample......... 76

XXII Analyses of Variance on Type of Nursing Education with Achievement and Understanding as the Dependent Variables for Total Samples ....... = 77

XXIII Means and Standard Deviations for type of Nursing Education, Audited Sample . . . . . . .

XXIV Analyses of Variance on Type of Nursing Education, Audited Sample................. 80

XXV Means and Standard Deviations on the Pre-test, Posttest, and Understanding Scores Partitioned by Age

XXVI Analyses of Variance for the Total Sample on Age with Achievement and Understanding as Dependent Variables ................

XXVII Analysis of Variance for the Audited Sample on Age with

Achievement Tests Change Scores and Percent

Complete on Audits as Dependent Variables . . . .

XXVIII Means and Standard Deviations on the Pre-Test, Posttest, and Understanding Scores for the Total Sample Partitioned by Experience . . . . . . 
XXIX Analysis of Variance for the Total Sample on Experience with Achievement and Understanding as Dependent Variables ................

XXX Analysis of Variance for the Audited Sample on Experience, with Achievement Change Score and Percent Complete on Audits as Dependent Variables . . . 


\section{LIST OF FIGURES}

FIGURE

PAGE

1. A Model for Nursing Process ............ 19 


\section{CHAPTER I}

\section{INTRODUCTION}

"Nursing process" is a term used to describe the thoughts and resultant behaviors that nurses use in delivery of nursing care to patients. It is the communication process involving the nurse and the patient. It is dynamic and interactional. Each nurse performs the nursing process differently depending upon background, experience, schooling, knowledge, values and goals, all of which act together to develop individual nursing process style. Each patient the nurse encounters is different, and the application of the nursing process must be tailored to meet the needs of the individual patient in the style of the nurse providing the nursing care (Yura \& Walsh, 1973).

\section{BACKGROUND}

The scope of nursing practice has greatly expanded in the last forty years, increasing both the responsibility and accountability of the nurse in the role of care provider. It is no longer acceptable to view medical care as the prime focus of patient care; nursing care must now be included (Harris, 1979). The chart of the individual patient must reflect the activities of the nurse as nursing care is delivered. Charting needs to document the nursing assessment, diagnosis, planning, implementation and evaluation stages of the nursing process (Brown, 1979). The nursing process becomes a framework for nursing practice. 
Scientific knowledge, clinical expertise, and utilization of the nursing process are the elements that enable a nurse to deliver the quality care that is the ultimate goal of the direct care provider (Mauksch \& David, 1972).

Nurses often do not document in the patient's chart evidence of the use of the nursing process as the basis for care given. This has been cited in nursing literature over time as a persistent problem almost universal in scope (Neilson, 1978). At Bess Kaiser Medical Center (BKMC), the accuracy of the charge has been attested to by periodic chart audit where the following deficits have been repeatedly evident:

1. incomplete use of existing tools for documentation in patients' charts;

2. lack of evidence that nursing diagnosis has been formulated as the final step in the assessment stage;

3. lack of documentation that a nursing care plan has been constructed as a guide to delivery of nursing care;

4. consistent lack of documentation of the evaluation stage of the nursing process in the patient's charts;

5. lack of documented evidence of resolution of patient problems on the Problem List-Nursing form; and

6. lack of effective discharge summary noted to document evidence of the use of the nursing process during the hospital stay of the patient, to include discharge planning.

These deficits were frequently discussed during management staff meetings of the Medical Records and Quality Assurance committees. 
The management team of the inpatient nursing service department at BKMC is responsible for defining, formulating, implementing, supervising practice, and evaluating the effectiveness of policies and procedures for all inpatient nursing personnel. The parameters of the structure for and scope of nursing practice within the hospital are set by these policies and procedures, supplemented by those of hospital administration.

\section{IN-SERVICE TRAINING OF NURSES}

The enormity of the economics of such a proposed in-service training progran require justification. The supporting data for such justification are stated succinctly in the policy manual as the statement of philosophy of the Department of In-patient Nursing Service at this Medical Center:

Nursing Care at Bess Kaiser Medical Center is individualized according to the patients' needs but within the realm of accepted standards of care. Each staff member is accountable for his/her own actions while providing that care. A variety of models of care delivery may be used in the hospital but each has as its basis, adherence to the nursing process. Heaith promotion and teaching are both essential components of care at Bess Kaiser Medical Center. There is an awareness of the economics of health care and effort is put into managing limited resources while maintaining a standard of excellence in practice.

Emphasis is given to developing human resources and appropriately utilizing various staff members. Democratic or participative management is practiced (Inpatient Nursing Service, 1983 , p. 3).

Compliance with the expectation that nursing has, as one of its major responsibilities, the definition and development of standards of 
practice in relation to organizational goals, i.e., the provision of quality patient-focused health care, further substantiates the justification of this training program.

The mission defined and the justifications qualified, in 1980 the Director of Medical Center Education, in conjunction with other nursing management team members, developed a curriculum and implemented a series of three two-hour teaching sessions to comply with the recommendations of the nursing management team. The forms used in patients' charts to document nursing care given from the iime of admission to discharge from the hospital were the focal points of the curriculum development. Each form with attendant instructions for proper use was carefully described, and a didactic presentation of each individual stage of the nursing process was given.

The classes in 1980 began with the first step in the process, the Assessment Stage. The Nursing Assessment Form is the tool used to document pertinent data about the patient upon admission to the hospital. This form acts as a guide for the nurse in the process of assessing the patients' needs and is the vehicle for documentation of formulation of the nursing diagnosis.

Methods to facilitate good assessment skills, directions for effective interviewing techniques, consideration of factors affecting patients' responses, (e.g., privacy, fear, environmental factors, etc.) were discussed. Identification of what constitutes a nursing diagnosis and its relationship to a medical diagnosis were presented; and case studies, role playing, and question and answer sessions were implemented 
to give the class participants a chance to become comfortable with the content of the curriculum and to be able to implement what they had learned on the operations level.

The Problem List-Nursing, a form used to document nursing diagnoses and patient needs arising from the problems listed, was used in case studies reviewed by small groups in the classes. The Patient Progress Note, a form used to document nursing orders and plans of care, was used in conjunction with teaching the second stage of the nursing process, the Planning Stage, and the third step or Implementation Stage. The fourth necessary form, the Flow Sheet, was used with the Patient Progress Note to evidence continuity of plans of care to document the final stage of the process, the Evaluation Stage. The content of the classes and the participative response of the nurses attending combined to structure the teaching/learning process of the nursing process classes.

All members of the management team were instructed in the use of the provided class materials during a one-day workshop which was conducted before staff RN classes began. All participants were pre- and post-tested as a part of the class.

The classes were mandatory for all staff RN's and were repeated until all members of the RN staff working full-time and those working 20 hours or more per week had completed the series.

A mandatory four-hour nursing process class was integrated into the existing professional orientation for all new RN personnel and continues as current practice.

Post-tests from all the classes, as reported by Johnson (1982), 
revealed that there existed a wide range of understanding of the nursing process and what constitutes its effective operationalization among the PN staff. This conclusion was also applicable to test results from the management team.

\section{PROBLEM IDENTIFICATION}

Members of the nursing management team were directed by the Associate Hospital Administrator responsible for inpatient nursing services to monitor their individual unit staff members' use of the nursing process. They were to reinforce those factors emphasized in the teaching sessions, i.e., use of existing tools, formulation of nursing diagnoses, construction of nursing care plans, and documentation of the implementation and evaluation stages of the nursing process in patients' charts.

The purpose of the classes was to raise the level of compliance by the staff RN's in documentation of the nursing process, as a basis of nursing care given, to conform to current inpatient nursing policy. The Department of Medical Center Education personnel began and continue to perform spot audits on randomly-selected units and charts. Initial results of this informal system of auditing, however, were conflicting and produced no data by which to measure the success or failure of the nursing process classes. No method existed to objectively measure the rate of compliance by the staff RN's.

Since the results of these training classes had not been measured and since past practices of inadequate documentation of nursing care 
given in many patients' charts continued to be a problem, the researcher conducted an earlier study. The purpose of the study was to systematically collect data to evaluate objectively the degree to which staff RN's were operationalizing and documenting the use of the nursing process as a basis of nursing care given (Johnson, 1982).

The results of this study produced a number of recommendations, including continuation of nursing process classes for all new personnel and review and redesign of those forms being underutilized (with help from the RN's currently uring the forms). Other recommendations included continued scheduling of in-service classes on the use of each of the four forms in units underutilizing them, continued regular reenforcement of the use of nursing diagnoses by unit coordinators, the use of monthly concurrent audits over all clinical arenas with feedback to the staff RN's of the results of the findings, quarterly award recognition to clinical arenas and/or units evidencing the most effective use of the nursing process and finally, a repeat of the original study as a follow-through for comparison.

The recommendations from the original study were implemented over a period of eight months. Priority was given to (1) revision of the thenexisting forms for documentation, (2) strategies for improving in-service classes (i.e., consideration of the frequency and formality of the training program, methods of updating the curriculum content, etc.), and (3) reinforcement of the use of nursing diagnosis by unit coordinators.

The original study was undertaken for purposes of estimation in 
that no reliable data had been collected previously on this subject.

The analysis of the data compiled from examinations and audits of the study is presented and crganized around each of the following major research questions:

1. Does the current training program used at Bess Kaiser Medical Center teach newly-employed staff nurses how to transfer nursing process theory to practice?

2. Do the new? y-employed staff nurses apply and document the nursing process in patients' charts?

3. What is the compliance of the total nursing staff with the requirement that they apply and document the nursing process in patients' charts?

A second component of this study, presented in tabular comparisons, is the analysis of data from the samples to determine the extent to which the following three variables relate to knowledge of and effectiveness in the use of the nursing process: type of nursing preparation, age, and experience. Each of these variables was tested for its impact on the following set of questions:

1. Do nurses differ in their knowledge of the nursing process prior to the beginning of in-service training?

2. Do nurses differ in their knowledge of the nursing process upon completion of in-service training?

3. Do nurses differ in their change scores on common items from pre-test to post-test?

4. Do nurses differ in their perceptions of their understanding 
of the nursing process?

5. Do nurses differ in their compliance with nursing process directives as determined by chart audits?

\section{SIGNIFICANCE OF THE STUDY}

The scope of nursing practice has greatly expanded in the past forty years, increasing both the responsibility and accountability of the nurse in the role of care provider. It is no longer acceptable to view medical care as the prime focus of patient care; nursing care must now be included (Harris, 1979). The chart of the individual patient must reflect the activities of the nurse as nursing care is delivered. Charting needs to document the nursing assessment, diagnosis, planning, implementation and evaluation stages of nursing process (Brown, 1979).

The nursing process becomes the framework for nursing practice. Nurses, however, often either do not understand the concept of the model of the nursing process or do not use it. Moreover, learning the steps of the process does not necessarily equip a nurse to operationalize the process. Nursing requires a strong cognitive process as well as developed skills. The effective teaching of the theoretical model in conjunction with the realities of the operations of nursing practice are felt by many in the profession to be lacking.

Patterns of practice become quickly and firmly established in newly-graduated nurses, with little regard to the theoretical model that has been thrust at them as part of their curriculum, in isolation from practice, during their nursing education. The operations of practice 
become the model of care, and the concepts of the nursing process go underutilized, if they are applied at all (Hammond, 1978).

Experienced nurses who have functioned without formal instruction in either the nursing process model or its application as the core of nursing practice lack the cognitive skills to utilize it (Johnson, 1982).

Much of the current literature documents a concern for the lack of utilization of the nursing process as a model of nursing practice. Many of the academicians in nursing schools focus on the dire consequences that may result in the nursing profession, i.e., the demise of nursing as a discrete occupation (Mauksch \& David, 1972) as a result of this deficit. A great deal is written about the seriousness of the widening gap between nursing education and nursing content, but there is little documentation of the successfur application of solutions to the acknowledged problem.

A study such as this, which is directed toward remedial aspects of the instruction in and application of nursing process, could significantly impact the educational process of nurses. The application of audit education principles as the basic tenet for the teaching of the nursing process to registered nurses would be unique.

Nursing requires a conscious cognitive process; nurses must be proactive. The use of the combined knowledge and skills learned during the educational process of the nurse is the issue here. To evaluate the effectiveness of an in-service training program to achieve transfer of these components of nursing education practice is the objective of this study. 


\section{CHAPTER II}

\section{REVIEW OF THE LITERATURE}

A review of the literature in this area reveals that there has been a growing awareness of the inadequacies of nursing practices. The criteria of a good quality of care are poorly defined. Historically, the medical model has been the guide to nursing practice. Medical thinking has prominently shaped the structure of nursing education. The medical profession has generated sophisticated models and has rapidly enlarged the scope of medical practice. Altschul (1978) points out that "nurses are unlikely to progress far in the wake of doctors and are now in a position to create models of their own" (p. 336). No longer is it enough for nurses to merely understand the concepts of anatomy and physiology.

The attention of the nursing profession is now being refocused onto the intellectual and interpersonal or social skills that are the vital keys to the practice of nursing. This means that nursing care is developed and planned to the needs of the patient and not solely to a medical disease/classification model (Mackie \& Welch, 1982).

Nurses are now studying the operation of other disciplines such as psychology, sociology, anthropology, business, politics, and economics. As a consequence, new ideas about the nursing profession, the scope of practice, and nursing interventions in clinical practice have surfaced. A more rational approach to nursing practice has evolved: the nursing 
process. Butherus (1978) speaks of the nursing process as "an orderly, systematic procedure by which nurses can determine the patients' problems, implement the plan, and later, evaluate the outcome" (p. 31). Several assumptions are inherent when one speaks of any process, but certainly the terms ongoing and cyclic are two that are most evident. The dynamic communication process between the nurse and the patient which fashions the behavior of both parties goes considerably beyond the static task-oriented education of the nurse. Yura and Waish (1973) contend that

The goal of the science of nursing is defined as understanding, while the art of nursing is defined as skill. The art and science of nursing are integral parts of the nursing process. Science suggests knowledge, or intellectualization; art suggests action (p. 16).

\section{THE NURSING PROCESS}

The nursing process model upon which the researcher developed the curriculum for the classes consists of four phases: assessment, planning, implementation, and evaluation.

Assessment, the first phase of the model, begins with the nurse's identifying and obtaining data about the patient, frequently referred to as gathering a nursing history. This process is intended to enable the nurse to recognize and designate problems relating to weliness and iliness of the patient. Identification of the patient's problem is the first step toward resolution of the problem. Yura and Walsh (1973) emphasize that 
the nurse's function is to assess wellness or illness and its extent. In some instances, this ability may mean the difference between life and death for the client. In contrast to goals of other members of the health profession, the nurse does involve herself with basic human needs that affect the total person rather than one aspect, one problem, or a limited segment of need fulfillment. The objective is to meet all basic human needs ( $p .72$ ).

The nurse, in assessing the needs of the patient, must be aware that a need and a problem are not necessarily the same. A need usually denotes a deficit or lack of something and is not necessarily a problem. A problem may well develop if a patient's need goes unattended or only partially filled. If the purpose of this phase of the nursing process is to assess data about the patient which will be the basis on which nursing care is both directed and delivered, the nurse must be concerned with the two major objectives of all nursing care. The first is that nursing care should primarily be directed toward maintaining a state of wellness for the patient. The second objective is that, where wellness is not a realistic option, nursing care will be directed toward maximizing functions and capabilities of the patient (Carlson, Craft, and McGuire, 1982).

The nursing history is taken to obtain needed data about the patient from which the nurse will formulate a nursing diagnosis. To make a proper nursing assessment, the nurse must have both a knowledge of normal human functions (major pathologic and psychopathologic conditions) and the ability to adjust the framework of reference to include the uniqueness of individual patients, their cultural, emotional, sociological, educational, and religious expectations and 
training. The nurse will measure body functions, collect specimens as appropriate, and begin a relationship with the patient based on concern and interest. The skilled nurse will also add the components of mutual trust and respect to this relationship.

When the nursing history is completed, the nurse will analyze the accumulated data and formulate nursing diagnoses as appropriate. Nursing diagnosis is the final step of the assessment phase of the nursing process.

Nursing diagnosis, as it appears in the literature, has numerous definitions. Carlson, Craft and McGuire (1982, p. 57) published a table of Definitions of Nursing Diagnosis that began with Abdellah (1960) and ended with Gordon (1976). The definitions were all similar in that they referred to the problems presented by the patient. Gordon (1976) expanded her definitions to include both actual and potential health problems; this is more in line with the wellness factor associated with nursing assessment described previously. She defines nursing diagnosis as "actual or potential health problems which nurses by virtue of their education and experience are capable and licensed to treat" ( $p .5)$.

There can be no doubt that use of nursing diagnosis increases both the accountability and responsibility of the individual nurse's practice. The nurse must not only maintain a current knowledge base, but must also be aware of the never-ending changes in the health care delivery system that directly or indirectly impact the practice of nursing. This is especially important as it relates to the legal issues governing licensure and practice issues of nurses. Most states have 
revised their Nurse Practice Acts to include directions for use of the term diagnosis, but standards of practice differ from one state to another (Carlson, Craft, and McGuire, 1982).

As with most other components of nursing practice, there are numerous opinions and theories as to both definition of and direction for formulation of a nursing diagnosis. Carlson, Craft and McGuire (1982) use as an example of the process of diagnosis the works of Judge and Zuidema (1968) and Bircher (1975).

Judge and Zuidema (1968, p. 12) have identified the elements of diagnosis as a logical series of six steps: (1) observe, (2) describe, (3) interpret, (4) verify, (5) decide, and (6) act.

Bircher (1975, p. 13) divided the process into 10 steps:

noticing, (2) describing, (3) labeling, (4) grouping, (5) identifying significant relationships, (6) noting critical attributes, (7) selecting an organizing principle, (8) developing criteria, (9) developing a taxonomy, and (10) diagnosing.

The researcher believes that both models represent the essentials for directing the process of formulating a nursing diagnosis. The realities of the current state of the art indicate that nurses today utilize the first five steps of the Bircher Model. The last five steps are utilized much less frequently. Many factors account for this, not the least of which are (1) the lack of an existing taxonomy that is acceptable to the practicing nurse, and (2) the education process of the nurse in which nursing diagnosis is frequently taught in academic concepts rather than in practical specifics. Until these and other 
existing deficits are remedied, techniques for instructing nurses in the formulation of a nursing diagnosis might well be geared to the more general process defined by Judge and Zuidema (1968).

The key to successful formulation of a nursing diagnosis is that the nurse realize that the problem or need is not a one-time phenomenon, but rather a dynamic process which mirrors the dynamic state of the patients and their adaptive abilities.

The nursing diagnosis is a vital component of nursing care and, as stated by Yura and Walsh (1973),

This diagnosis specifically indicates that: a) no problems exist which demand the intervention of the nurse or another member of the health team, or b) the precise identification of all problems that had to be resolved so that the client could experience the wellness optimum for him. Problems will be stated in terms of client problems, and result when basic human needs are either not met or are met inadequately ( $p .92)$.

The nursing diagnosis is the conclusion of the assessment phase of the nursing process.

Planning, the second phase of nursing, has two major purposes: to assign priority to diagnosed problems, and (2) to designate specific actions, to determine who will perform them, and to decide what the expected outcomes will be. A major part of the nurse's care plan design, which incorporates the goal-setting and priority-setting mentioned above, is provision of the methodology for accomplishing these goals. The patient and/or family must be active participants in the formulation of the planning phase. The goals need to be individualized for that patient. Anything less than such joint planning lessens the 
probability of achieving the expected outcomes. The planning phase concludes with the development of the nursing care plan. It is in this plan that nursing interventions are carefully defined and directed through the writing of nursing orders. Then the third phase of the nursing process, implementation, begins (Johnson, 1982).

Implementation, the third phase of the nursing process model, is destined to succeed or fail contingent on the competencies of the nurse. She must be competent in three general skill areas: intellectual, interpersonal, and technical.

With the nursing care plan as a blueprint, implementation may rest solely with the nurse or in cooperation with other health team members and ancillary personnel. The decision-making and observation skills of the nurse strongly impact the success of interventions applied. Communication and supervisory skills are major components of success in the implementation of the plan. The ability to judge the importance of new data as it becomes available, to exercise innovative and creative abilities, to be proactive rather than reactive, and to promote adaptation of both patients and other staff to accomplish the defined outcomes are paramount to a successful implementation of nursing process. The completion of the nursing interventions leads to the final phase of the nursing process: evaluation (Ashworth, 1980).

Evaluation, the fourth phase of nursing process, has three major purposes: (1) to indicate the accuracy of the outcomes of nursing interventions during the implementation phase, (2) to validate the occurrence of the expected outcomes, and (3) to direct the necessity for 
reassessing the four phases of the nursing process in relation to the individual patient's nursing care needs.

The evaluation should always be based in terms of how the patient responded to the nursing plan of care. Evaluation, to be successfur, must always be purposeful and analytical. It must be goal-directed if it is to truthfully reflect the patient-focused intent of the nursing process model. It should be an intellectual activity that examines the successes, failures, and, if applicable, the omissions during the other three phases of the nursing process. Evaluation should be performed by both the patient and the nurse, for the dynamics of the process necessitate the participation of all agents involved--the provider and the providee. It is only in this manner that the cyclic nature of the nursing process is evidenced and the objective of meeting the patient's nursing care needs is realized (Lewis, 1974). The nursing process as previously described by this researcher is summarized in Figure 1.

If the nursing process is an orderly systematic procedure comprised of a planned series of actions to maintain patients' wellness, it is also a system within a system. Yura and Walsh (1973) describe nursing as a "subsystem of the healthcare system" and imply that "a general system theory provides a good reference for structure of the nursing process and framework for the study of nursing" (p. 36). One of the bases of the general systems theory is that it provides a structure whereby unconnected parts may be integrated into an organized whole. Nursing operates cooperatively as one of many subsystems to carry out the purpose of the healthcare system. The purpose, process, and content of 


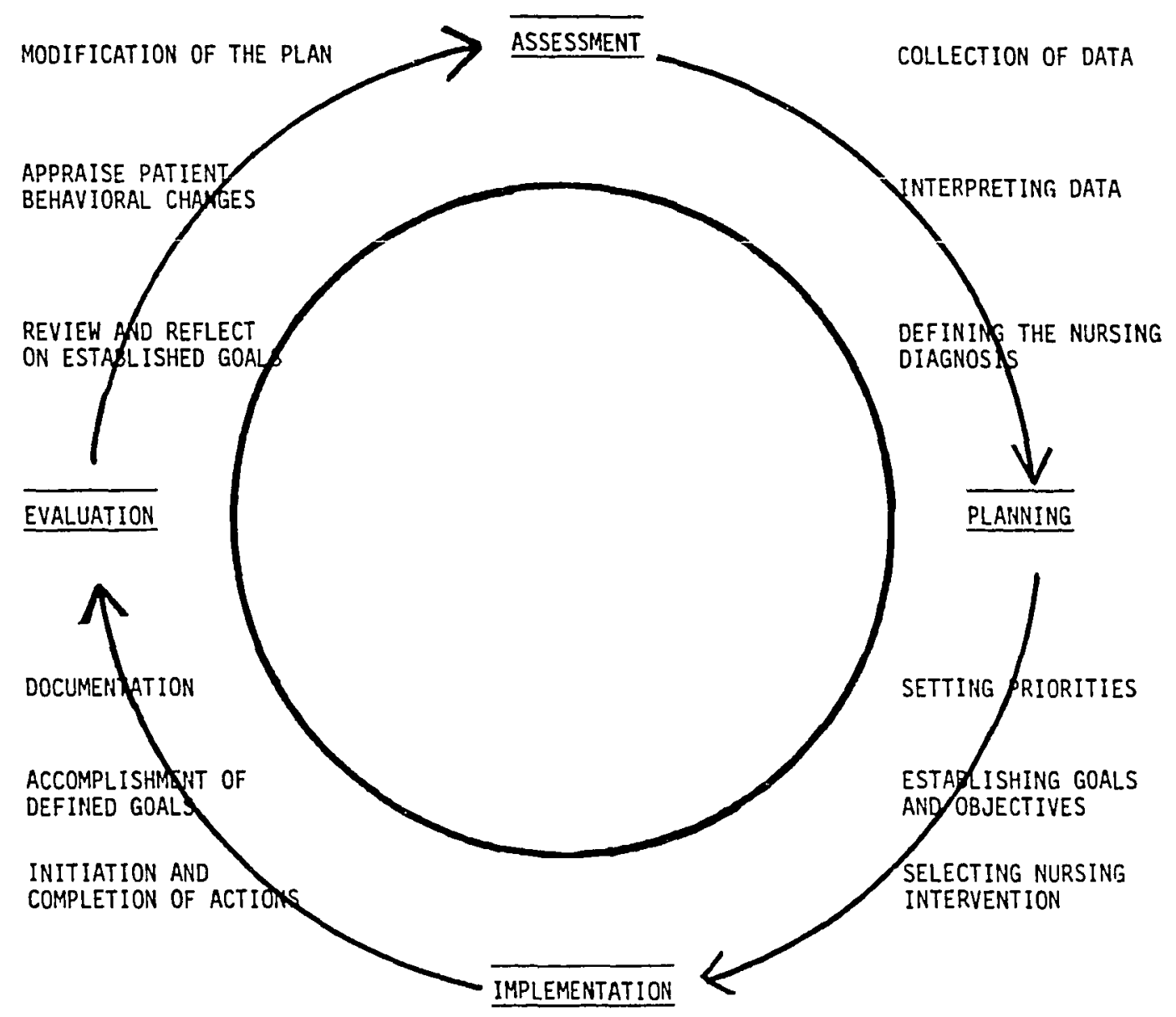

Figure 1. A model for nursing process. 
nursing are interactional and combine with the behavior of patients to create an organized whole.

A review of the literature shows that many nursing process models exist. Walker and Nicholson (1980) contend that the most valuable models are those that generate the best cognitive processes to guide the nurse in structuring optimal nursing care outcomes. They posited a criteria for evaluating nursing process models that should:

1. incorporate an underlying knowledge base in making judgments inherent in the nursing process;

2. be as dynamic as practice itself; that is, the model should permit dynamic movement back and forth between steps in the process;

3. be applicable to nursing in general, not only to specific clinical settings;

4. be compatible with ethical standards for nursing practice;

5. be consistent with scientific findings on human behavior in health and illness (p. 9).

Although the formats may vary slightly one from the other, all nursing process models contain assessment, planning, implementation, and evaluation phases. The concept of a model of nursing process is being increasingly accepted, but there is still much resistance to its use and some disagreement as to its value.

The concept of nursing process is abstract and has meaning for use on the operations level only when applied to clinical practice. Theoretical models taught in classrooms often are too unrealistic to be 
applied to patient care. Moreover, simply learning the steps of the nursing process does not necessarily equip a nurse to operationalize the process. Many nurses feel that the nursing process is unrealistic and bolster their arguments by citing how long nursing survived without it. Lewis (1974) attended to this resistance by referring to the nursing process as

a key to the kind of care which characterizes professional nursing and can give assurance that nursing care is designed to meet the needs of the patient ( $p .12)$.

She added that the central focus of nursing must be therapeutic and must contribute to the wholeness of humankind, possible only when a "knowledgeable, purposeful series of thoughts and actions" (p. 13) [the nursing process] is the vehicle.

Boylan (1982) stated that "one of the things the nursing process has highlighted is the nursing model of care, within which nursing decisions take place" (p. 1561). The enormity of this concept's significance has yet to be recognized by many nurses. The nursing process is in essence a decision-making process, and by its very nature it accents the responsibility and accountability of the professional nurse. It also emphasizes the professional components of nursing, the areas of special knowledge, and the skills and talents that constitute nursing experience. The idea of the professional nurse as a responsible provider is the cornerstone of nursing practice. The nurse must know precisely what is being done and why and must make responsible decisions based on accurate information in the best interest of the patient (Yura 
and Walsh, 1973).

Mauksch \& David (1972) predicted "the demise of nursing as a discrete occupation unless nurses adopt the nursing process as a way of professional life" (p. 1). Th,ay cite a lack of a visible, autonomously effective practice and changes in consumer expectations and value as causes for concern. Aspinwall (1976) stated unequivocably that the nursing process can be no stronger than any of its individual components. She believes that nursing requires a conscious cognitive process and is not merely a matter of reaction. Her emphasis is placed on the importance of nursing diagnosis, the last step of the assessment stage of the nursing process.

The use of the cumbined knowledge and skills of the nurse to collect, assess, and correlate data to optimize planning of care has not been effectively taught and contributes to the resistance of practicing nurses to using the nursing process. Bartos \& Knight (1978) stressed that the nursing process is "a viable system that helps the nurse develop and use a practical, systematic means of recording patient care" (p. 48). The authors consider immediate and direct recording of the nursing process a prescription for survival. The educational process for nurses must include not only the theory of the process, but a practical method of documenting the process in patients' records as wel1. Lack of such skills contributes to inadequate knowledge of and commitment to the nursing process.

Since the nursing process offers a number of possible benefits, why is it not more widely used? Ashworth (1980), a British nursing 
administrator, asked this question of nurses in her own country and then of nurses in America. She speaks to an essential part of the nursing process: setting priorities so that most essential things get done. Like her nursing counterparts in America, she knows that effective care can be possible even where resources are limited. She stated, "If the care plan shows what needs to be done, it may be easier to demonstrate what cannot be done with the available resources and so make a better case for more resources" (p. 27).

The answer to the question of why nursing process is not more widely used may be found in the workload of daily nursing duties. Any activity that requires extra effort and represents a change from traditional procedure often generates disinterest. Nurses are not motivated to accept change and often feel punished by the addition of "extra work." Unfortunately, the nurses' educational process has contributed to this attitude in the past by teaching ideal, theoretically-laden models that do not fit into the real operations of working nurses. Reluctance to cope with change is not peculiar to nursing, but is undoubtedly a factor that contributes to ineffective use of the nursing process (Johnson, 1982).

Inadequate tools with which to operationalize nursing process is one of the outstanding reasons cited by nurses for underutilization of the process (Johnson, 1982). Inadequate record forms, proviuiing little space for documentation, poorly constructed tools that obstruct rather than facilitate effective use and documentation of nursing process, and a plethora of various standing-order forms that contribute to confusion 
and underutilization rank high on the complaint list. Inadequate in-servicing in the proper use of existing tools for current staff members and all new employees are additional problems.

A nurse's ability to translate knowledge into performance appears to be facilitated by prior observation of models performing the target behaviors (Kramer, Holaday, \& Hoeffer, 1981 , p. 34).

This observation, reinforced by the commonsense approach to education-that how you teach directly effects the assimilation by the learner of what you teach--may be another factor affecting resistance by nurses to use of the nursing process.

It has been observed that the nursing process is often not applied in practice because it is taught in isolation from nursing content. Many nurses are still being educated to be reactive rather than proactive. They are action-oriented, and though they observe well, they fail to analyze their observations. This behavior impedes appropriate problem-solving operations. Hammond (1978) voices this sentiment, stating that "empirical rather than theoretical knowledge was the cornerstone of the nurses' education--that is, nurses are being taught to act, not to think" (p. 46).

One cannot read the literature on the nursing process as the basis for nursing practice without being aware that the scope of nursing practice is changing at a rapid rate. A major component of nursing care today is patient education. Traditionally, the social structure of the hospital placed the patient in a dependent child status, with physicians and nurses assuming authoritarian parental roles, telling the patient 
what they thought the patient needed to know. The quality of the learning experience was often poor and the patient's participation negligible. Pittenger and Gooding (1971) said:

Man is not a passive recipient of the environment--a blank tablet to be written on. Neither is he a mystical force that defies scientific study and description. Man is the consequence of a human organism being involved in a dynamic interaction with his environment (p. 50).

Malcolm Knowles (1970) stated in his book, The Modern Practice of Adult Education, that the learning-teaching transaction is the mutual responsibility of the learner and the teacher. Consider these thoughts in relation to the expanded scope of practice of today's nurse. Patient teaching is now a primary responsibility of the nursing staff. This is a change from the traditional medical model where the physician was the primary source of education for the patient.

Health care professionals have traditionally focused on the plan of care for patients and have regarded the patient as a passive recipient rather than an active participant in the planning process. RutkowskiConway (1982) spoke to practicing nurses everywhere when she stated, "Patients cannot be expected to comply with the regimens that they don't understand" (p. 451). Participation of the patient in the nursing process is a prime component for successful completion of the established goals of care plans.

Compliance with therapeutic objectives frequently requires a patient to integrate new behaviors and significantly modify lifestyle to accomodate the disease process or a change in functional capacities as a result of illness (Steckel, Funnell \& Dragovan, 1979). 
Providing a patient with data and the means to increase knowledge of seif care doesn't necessarily mean that the patient will benefit from the teaching. Daniels and Kochar (1979) found "that there is no clear relationship in the literature between a person's knowledge of the disease process (and treatment) and adherence rates" (p. 237). Andragogy is defined by knowles (1970) as the art and science of teaching adults, and he has made some assumptions about adults on which andragogy is based. He believes

(1) that maturity tends to make one a self-directed human being,

(2) that experiences become resources for learning,

(3) that readiness to learn is oriented to the tasks of one's surroundings and social role, and

(4) that problem-centered learning is the focal point of adult learning (p.52).

Nurses involved with patient teaching would probably take issue with Knowles' assumption on adult self-direction. Patients often expect direction in the learning process and just as frequently refuse to control what is taught. Nurses whose own professional education was directed toward reactive rather than proactive behavior and whose problem-solving skills are limited are destined to fail in the role of patient educator (Johnson, 1982).

Just as the nursing process stresses the individual assessment of patient problems and needs, the teaching process should include an assessment and diagnosis of learning needs. Together, the nurse and the physician should develop a program built on the assessment to be shared 
with the patient. The patient's participation in the teaching/learning process will serve as an indicator of progress in the evaluation phase of the teaching process. The teaching process overlaid on the nursing process is the key to the nurse's success in the expanded responsibilities as a patient educator.

Just as the timing of treatments or administration of medicines is important to a successful behavioral response from a patient, so is the time designated for the learning experience. Knowles (1970) stated that when an adult is at the "readiness to learn" point, there comes "a teachable moment" (p. 72). This is where the most effective learning takes place. Hospital nurse/instructor/educators must monitor carefully their roles as program builders and resource persons and must carefully assess the individual patient's "readiness to learn" frame of reference. FitzHugh (1976) stated,

As a program builder, the instructor's responsibility is to ensure that the requested learning experience takes place. As a resource person, the instructor's responsibility is to offer specific content relevant to prearranged objectives ( $p .4)$.

Is the role of the nurse/instructor/educator a realistic expectation of the staff nurse today? Or is this another example of an ideal theoretical model that will not fit into the real operations of working nurses? There is no doubt that it will require extra effort, and it certainly represents change from traditional procedure. Teaching, as a subunit of the nursing nursing process, is a catalyst in the dynamic international communication process involving the nurse and the patient. Lillisand and Korff (1983) speak directly to the care of 
nursing with the statement, "When one measures the effectiveness of nursing process, one measures the quality of nursing care" (p. 9). This is a particularly relevant statement when one considers that the major portion of a hospital's production is nursing care.

Collaboration between nurse and patient is a powerful concept. It imparts strength to the nursing process as outlined by the American Nurses' Association Standards of Practice, which recommend that the client be actively involved in as many aspects of his care as possible (Roberts, 1982, p. 485).

It is critical that the nurse perceive the status of the individual patient. This is usually only possible when the patient or the patient's immediate family share perceptions of the patient's status. It is a combination of the patient's and the nurse's shared perceptual base that shapes the quality of patient care planning. Roberts (1982) stated, "It is suggested that patients may not communicate to the nurse those problems which are perceived as irrelevant, emotionally uncomfortable, or unresolvable by nursing intervention" ( $p$. 481).

Nurses who exclude the patient from the formulation in their plans of care may miss a crucial teaching event. When the patient fails to realize that the nursing plan of care may have answers to health care problems and the ability to resolve them, quality care planning is not possible. Disparity between the patient's identification of a problem and the nurse's perception of the problem rule out effective assessment, planning, and implementation of nursing care (Carlson, Craft, and McGuire, 1982).

It comes then as no surprise that the literature supports increased 
collaboration between the nurses and the patient; the results are the more effective delivery of health care. Nurses, as they attempt to meet better standards of nursing practice, will have to become more flexible than their all-too-often traditional educational process has trained them to be. The improvement of interviewing and communication techniques to facilitate integrating patient collaboration into the individual plans of care is a good place to start. Educators will have an important role in this process.

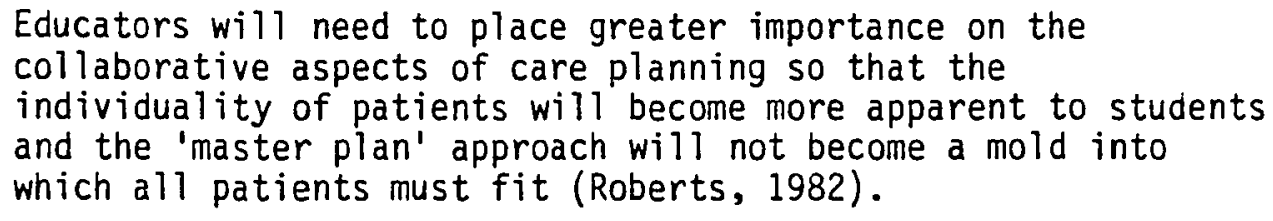

Effective use of the nursing process by the professional nurse can help to humanize the often depersonalized environment of the hospital. Nurses cannot isolate the physical needs from the emotional needs of the patients, nor can they effectively plan nursing care without encouraging the sharing of knowledge, attitudes, feelings, and beliefs by the patient. Such collaborative actions produce not only better care for patients but greater effectiveness for the nursing profession.

The complexity of the assessment stage of the nursing process makes it difficult to do well. The better the knowledge base of the nurse Joing the assessment, the better the assessment will be. The success of the nursing process begins here. If the assessment is poor, the rest of the process is dcomed to failure for the assessment is the base on which all else is built. Assessment is not merely the collection of data-- 
that is only one component of the process. The second compcnent, the judgment of the significance of the information and its significance relative to the planning and implementation phases of the nursing process is even more important. Boylan (1982) describes modern nursing practice well when he stated:

The mental process which is required for the nursing process is bounded by three fundamental principles:

1. The medical diagnosis should not dominate the care but is simply one piece of information which we should bear in mind.

2. People are different and the profile of care needs of a patient will be unique and will change as he changes.

3. Man is a functionally interdependent organism and problems in one body system are likely to cause problems in others. Also, man's social, physical and emotional areas of need interact and are interdependent (p. 1444).

Add these fundamental processes to another facet of practice:

Perhaps even more fundamental to nursing, skills in communication need to be taught. For the future, the concepts of continuity, control and problem solving are linked as fundamental aspects of nursing (Wilson-Barnett, 1982, p. 45).

This provides the rationale for nursing process as a framework for professional nursing practice.

If the chart of the individual patient is to reflect the activities of the nurse as care is delivered, the nursing process must become an attitudinal component of nursing practice. "So where is the link between attitude change and the nursing process?" (Davis, 1982, p. 18). The answer to the question must come from nurses. Davis (1982) 
responded with the following statement:

Those who have undergone this metamorphosis have an obligation to spread the message to their colleagues: now we have introduced the nursing process and it is better for all, but we have adopted a new framework on which our nursing care is based and this has raised both the standard of care and degree of job satisfaction (p. 18).

It goes without saying, however, that the key to successful implementation of the nursing process in any acute care institution lies with the nursing management of the institution.

Nursing management must understand the philosophy of the nursing process and allow it to be implemented in a flexible manner, so that each clinical specialty can adopt the philosophy to its own particular needs. Irrespective of the approach, methodology and documentation that a clinical area develops, there must be certain guidelines that are adhered to and monitored by the staff themselves (Mackie \& Welch, 1982, p. 1758).

The visible and autonomous practice referred to by Mauksch and David (1972) may well prove to be a prescription for survival for nursing as a discrete profession. Nurses are indeed in a position to create models of practice of their own, and nursing process models stand as examples of their efforts. Resistance to and conflict of values over nursing notwithstanding, it would appear that a more rational approach to the complexities of nursing practice has surfaced.

In summary, the nursing literature supports the position that a model for nursing practice is needed (Altschul, 1978) and that nursing process is a viable model for nursing practice (Butherus, 1978; Mackie and Welch, 1982; Yura and Walsh, 1973). Various scholars have provided 
a careful description of the components of nursing process (Ashworth, 1980; Bartos and Knight, 1978; Butherus, 1978). Despite its wide acceptance, however, the literature clearly indicates that there is a major gap between nursing process theory and the application of the theory on the operations level (Aspinwall, 1976; Ashworth, 1980; Goodwin, 1980).

The quality of performance using the nursing process must be the focus of a collaborative approach by nursing educators and nursing management (Johnson, 1982). Quality Assurance and Quality Control are necessary components of successful utilization of the nursing process. Definition of criteria on which to structure standards of performance that combine the philosophy of the nursing process and the realities of nursing operations need to be developed.

Therefore, development of monitors to measure the effectiveness by which the nurse delivers and documents care, and reality-based construction of auditing tools to measure over time effectiveness are vital components of both the training and practice arenas. These are the vehicles of successful implementation of the nursing process into practice.

The next section defines data collection activities which were used to evaluate knowledge and appropriate action from a special educational program designed to improve record-keeping practices by nurses. 


\section{CHAPTER III}

\section{DESIGN OF THE STUDY}

To determine the degree to which staff RN's are operationalizing the nursing process as taught in orientation classes, the researcher designed a study to procure data that would permit measurement of the extent of learning transfer to nursing practice.

The research setting was a 225-bed general hospital in Portland, Oregon. The facility is a designated Health Maintenance Organization (HMO) and one of two acute care hospitals which, in conjunction with nine outpatient medical clinics and four dental clinics, provides health care to approximately 280,000 people in the Portland Metropolitan area. This health care plan has one unique characteristic which separates it from other health care plans in the area and which impacts the delivery of health care services: it is a comprehensive prepaid health care program. Participants do not pay for services received on the typical fee-for-service basis; rather, they select the type of health care membership plan coverage they want and then pay their premiums on a monthly basis. Enrollment is usually handled in blocks rather than on an individual membership basis.

This health care program is one component of a multi-state program. The structure consists of four corporations whose major functions are: (1) marketing, (2) provision of outpatient health care services, (3) provision of inpatient health care services, and (4) provision of 
outpatient dental services.

The hospital in which this study was performed has divided its nursing clinical arenas into: (1) medical/surgical, (2) critical care, (3) maternal/child, and (4) surgical services. Nursing Administration is decentralized, with each clinical arena administered by a nurse clinical specialist. In addition, two other nurses function as members of the nursing administrative team: an Assistant Director of Nursing Systems and a Director of Medical Center Education. The researcher is the Director of Medical Center Education and is responsible for education and training activities for all hospital staff personnel, the exception being MD's. The inpatient nursing service comprises the largest component of hospital staff, and as such, is the primary responsibility of this department.

The sample consisted of 102 recently-hired staff nurses who participated in the professional orientation program. These nurses were all hired in a twelve-month time frame, and each nurse participated in a four-hour nursing process class taught by the researcher. All nurses were pre- and post-tested in a single group study. Eighty-two nurses from the group of 102 were audited; the audit provided the data used for this study.

Four members of the group were hired for management positions and do not document nursing process activity in charts as part of their detail job performance. Sixteen nurses performed their duties in specialty units, i.e., neonatal intensive care, labor and delivery, operating and recovery rooms, and the emergency department. These 
departments do not use the standard inpatient chart format and chart audit; thus, it was not possible for them to use the audit tool designated for this study. The remaining 82 nurses, then, comprised the sample. Further description of the sample is listed below.

\section{SAMPLE CHARACTERISTICS}

The sample consisted of 102 recently-hired staff nurses who participated in the professional orientation program as is required of all nurses who are new to the facility. Categorized by type of nursing education, the distribution of nurses was: 7 (6.9\%) Licensed Practical Nurses (LPN's), 39 (38.2\%) Associate Degree Nurses (ADN's), 20 (19.6\%) Diploma Nurses (DIP's), and 36 (35.3\%) Baccalaureate Science Nurses (BSN's) (see Table 1). All the nurses had been hired to work in a 17 three of the major clinical arenas: Medical/Surgical, Maternal/Child, and Critical Care. The sample contained four nurses hired for management positions. The sample, therefore, represented the range in educational preparation typically found in the acute care facilities in most communities.

A licensed practical nurse (LPN) is an individual who has completed a one-year training program in nursing practices and has demonstrated a basic knowledge of the social and physical sciences in planning and giving nursing care. The practice settings for a practical licensed

nurse may occur in two general settings: (1) a stable nursing situation, i.e., a residential or intermediate care facility where minimal supervision by a registered nurse (RN) or physician (MD) who is 
on the premises or readily available by phone is available; and (2) a complex nursing situation, i.e., an acute care facility or skilled nursing facility, where direct supervision is available by an RN or MD who is in the immediate area where patient care is being provided.

A registered nurse (RN) is an individual who has demonstrated the application of knowledge drawn from in-depth education in social and physical sciences in assessing, planning, ordering, giving, delegating, teaching, and supervising care which promotes the person's optimum health and independence. Currently there are three levels of entry into the practice of nursing for registered nurses: ADN, requiring two years of training at a community college level; DIP, requiring three years of training that is hospital-sponsored; and BSN, requiring four years of training in a college or university setting. The major difference among the programs is that the scope of liberal arts and social science courses taught increases as one proceeds from ADN to DIP to BSN. BSN programs tend to have better and more in-depth training in theory and concepts and less emphasis on the skills development related to nursing practice. DIP programs are hospital-sponsored and emphasize the psychomotor aspects and technical skills of nursing practice. ADN programs have less time involved in the training process and emphasize both cognition and skills development but in less depth than either of the other two programs. Upon graduation from nursing school, regardless of the type of training, all students must take State Board of Nursing Examinations to become registered nurses. In most instances, at this level of entry into pracice there is no difference in expectations of 
practice abilities between the groups, nor is there a differential wage paid to members of either group.

All members of the sample were required to fill out a Characteristics of Nurse Sample Form (see Appendix E). Data collected from these forms were analyzed and used to provide both demographic and attitudinal responses from the participants.

The total sample was divided into four age groups: $14(13.7 \%)$ were over 44 years, $15(14.7 \%)$ were in the $35-44$ age group, $68(66.7 \%)$ were in the 25-34 age group, and 5 (4.9\%) were under 25 years of age, as shown in Table $I$.

TABLE I

CROSSTABULATION OF AGE GROUPS BY

TYPE OF NURSING EDUCATION

$(n=102)$

\begin{tabular}{|c|c|c|c|c|c|c|c|c|c|c|}
\hline \multirow{3}{*}{$\begin{array}{l}\text { Age in } \\
\text { Years }\end{array}$} & \multicolumn{10}{|c|}{ Nursing Education } \\
\hline & \multicolumn{2}{|c|}{ LPN } & \multicolumn{2}{|r|}{ ADN } & \multicolumn{2}{|r|}{ DIP } & \multicolumn{2}{|r|}{ BSN } & \multicolumn{2}{|r|}{ TOTAL } \\
\hline & $f$ & $\%$ & $f$ & $\%$ & $f$ & $\%$ & $f$ & $\%$ & $f$ & $\%$ \\
\hline Over 44 & 2 & $(2.0)$ & 2 & $(2.0)$ & 8 & $(7.8)$ & 2 & $(2.0)$ & 14 & $(13.7)$ \\
\hline $35-44$ & 2 & $(2.0)$ & 6 & $(5.9)$ & 2 & $(2.0)$ & 5 & $(4.9)$ & 15 & (14.7) \\
\hline $25-34$ & 3 & $(2.9)$ & 29 & $(28.4)$ & 10 & $(9.8)$ & 26 & $(25.5)$ & 68 & $(66.7)$ \\
\hline Under 25 & 0 & $(0.0)$ & 2 & $(2.0)$ & 0 & $(0.0)$ & 3 & $(2.9)$ & 5 & $(4.9)$ \\
\hline Total & 7 & $(6.9)$ & 39 & $(38.2)$ & 20 & $(19.6)$ & 36 & $(35.3)$ & 102 & $(100.0)$ \\
\hline
\end{tabular}


Nursing experience in years for the total sample was divided into three groups: $18(17.6 \%)$ had more than ten years of nursing experience, 31 (30.4\%) had between six and ten years of experience, and $53(52.0 \%)$ had less than six years of nursing experience (see Table II).

TABLE II

CROSSTABULATION OF YEARS OF NURSING EXPERIENCE BY TYPE OF NURSING EDUCATION

\begin{tabular}{|c|c|c|c|c|c|c|c|c|c|c|}
\hline \multirow[b]{3}{*}{$\begin{array}{c}\text { Experience } \\
\text { in Years }\end{array}$} & \multicolumn{10}{|c|}{ Nursing Education } \\
\hline & \multicolumn{2}{|c|}{ LPN } & \multicolumn{2}{|r|}{ ADN } & \multicolumn{2}{|r|}{ DIP } & \multicolumn{2}{|r|}{ BSN } & \multicolumn{2}{|r|}{ TOTAL } \\
\hline & $f$ & $\%$ & $f$ & $\%$ & $f$ & $\%$ & $f$ & $\%$ & $f$ & $\%$ \\
\hline Over 10 & 1 & $(1.0)$ & 4 & (3.9) & 11 & $(10.8)$ & 2 & $(2.0)$ & 18 & $(17.6)$ \\
\hline $6-10$ & 5 & $(4.9)$ & 7 & $(6.9)$ & 4 & (3.9) & 15 & (14.7) & 31 & $(30.4)$ \\
\hline Under 6 & 1 & $(1.0)$ & 28 & $(27.5)$ & 5 & $(4.9)$ & 19 & $(18.6)$ & 53 & $(52.0)$ \\
\hline Total & 7 & $(6.9)$ & 39 & $(38.2)$ & 20 & $(19.6)$ & 36 & $(35.3)$ & 102 & $(100.0)$ \\
\hline
\end{tabular}

Crosstabulations of years of nursing experience and type of nursing education were accomplished using attendance at a prior nursing process class as a variable; these crosstabulations were performed on the total sample, and the results are compiled in Table III. The statistical hypothesis of independence was rejected $\left(x^{2}=7.26 ; p=.03\right)$. The more experienced the nurse, the less likely she was to have had a previous 
TABLE III

$$
\begin{gathered}
\text { CROSSTABULATION OF YEARS OF NURSING EXPERIENCE } \\
\text { BY PREVIOUS NURSING PROCESSING CLASS } \\
(n=102)
\end{gathered}
$$

\begin{tabular}{|c|c|c|c|c|c|c|}
\hline \multirow{3}{*}{$\begin{array}{l}\text { Nursing } \\
\text { Experience } \\
\text { in Years }\end{array}$} & \multicolumn{6}{|c|}{ Previous Nursing Process Class } \\
\hline & \multicolumn{2}{|c|}{ Yes } & \multicolumn{2}{|c|}{ No } & \multicolumn{2}{|c|}{ Total } \\
\hline & $f$ & $\%$ & $f$ & $\%$ & $f$ & $\%$ \\
\hline Over 10 & 7 & $(6.9)$ & 11 & $(10.8)$ & 18 & $(17.6)$ \\
\hline $6-10$ & 16 & $(15.7)$ & 15 & $(14.7)$ & 31 & $(30.4)$ \\
\hline Under 6 & 38 & $(37.2)$ & 15 & $(14.7)$ & 53 & $(52.0)$ \\
\hline Total & 61 & $(59.8)$ & 41 & $(40.2)$ & 102 & $(100.0)$ \\
\hline
\end{tabular}

nursing process class.

A crosstabulation of type of nursing education by prior nursing process class is shown in Table IV. The statistical hypothesis of independence was rejected $\left(x^{2}=16.72 ; p=.00\right)$. As the level of professional preparation increased, the percent of the sample who had attended a previous nursing process class increased. Only $14 \%$ of the LPN's had had a previous nursing process class, whereas $83 \%$ of the BSN's had attended one (see Table IV). 
TABLE IV

CROSSTABULATION OF TYPE OF NURSING EDUCATION

BY PRIOR NURSING PROCESS CLASS

\begin{tabular}{|c|c|c|c|c|c|c|c|c|c|c|}
\hline \multirow{3}{*}{$\begin{array}{c}\text { Prior Nursing } \\
\text { Process } \\
\text { Class }\end{array}$} & \multicolumn{10}{|c|}{ Education } \\
\hline & \multicolumn{2}{|c|}{ LPN } & \multicolumn{2}{|c|}{ ADN } & \multicolumn{2}{|c|}{ DIP } & \multicolumn{2}{|c|}{ BSN } & \multicolumn{2}{|c|}{ TOTAL } \\
\hline & $f$ & $\%$ & $f$ & $\%$ & $f$ & $\%$ & $f$ & $\%$ & $f$ & $\%$ \\
\hline Yes & 1 & $(1.0)$ & 21 & $(20.6)$ & 9 & $(8.8)$ & 30 & $(29.4)$ & 41 & $(40.2)$ \\
\hline No & 6 & $(5.9)$ & 18 & $(17.6)$ & 11 & $(10.8)$ & 6 & $(5.9)$ & 61 & $(59.8)$ \\
\hline Total & 7 & $(6.9)$ & 39 & $(38.2)$ & 20 & $(19.6)$ & 36 & $(35.3)$ & 102 & $(100.0)$ \\
\hline
\end{tabular}

The age of patients used in the study covered a wide range, as illustrated in Table $V$. This was a direct result of the inclusion of charts from all major clinical arenas. The relative frequency of ages is characteristic of the daily admission figures and indicates the size of the specialty units. The $41.4 \%$ figure of age 60 and above indicates the increasing trend of utilization by older populations and reflects the existence of chronic diseases in the population of charts audited. This is significant data for the nurse in utilizing the nursing process as the framework on which nursing care is structured. Long-term goals and discharge planning are vital components of the nursing care plan if successful and meaningful nursing care is to occur. 
TABLE V

AGE OF PATIENTS

\begin{tabular}{|c|c|c|}
\hline $\begin{array}{l}\text { Age in } \\
\text { Years }\end{array}$ & Frequency & $\begin{array}{l}\text { Relative } \\
\text { Frequency }\end{array}$ \\
\hline $0-9$ & 23 & 9.3 \\
\hline $10-19$ & 13 & 5.3 \\
\hline $20-29$ & 41 & 16.7 \\
\hline $30-39$ & 26 & 10.6 \\
\hline $40-49$ & 15 & 6.1 \\
\hline $50-59$ & 26 & 10.6 \\
\hline $60-69$ & 36 & 14.6 \\
\hline $70-79$ & 44 & 17.9 \\
\hline $80-89$ & 11 & 4.5 \\
\hline $90-95$ & 4 & 1.6 \\
\hline Over 95 & 7 & 2.8 \\
\hline Total & 246 & 100.0 \\
\hline
\end{tabular}

DESCRIPTION OF THE NURSING PROCESS CLASS

The nursing process class was designed to meet the objectives of the Department of Inpatient Nursing Services at Bess Kaiser Medical Center, that staff nurses use nursing process as a model for the planning and delivery of quality, patient-focused health care and 
document utilization of nursing process in the patients' charts. The Director of Medical Center Education, in conjunction with other nursing management team members, developed a curriculum and implemented a class in nursing process to comply with the recommendations of the nursing management team. The class is four hours in duration and is mandatory for all RN's and LPN's in the facility. The objectives of the class are that nurses, at the completion of the class, will be able to:

1. Express an awareness of the relationship between the nursing process and delivery of nursing care.

2. Describe the components of the nursing process.

3. Distinguish between a medical diagnosis and a nursing diagnosis.

4. Utilize interviewing techniques to obtain pertinent patient information for the care plan.*

5. Distinguish between the terms "patient goal" and "patient problem." *

6. Describe long and short range goals in terms of patient behavior and outcome. *

7. Utilize assessment information to establish short term goals.*

8. Develop nursing actions needed to accomplish the short range goal. *

9. Reassess the patient to evaluate effectiveness of nursing. *

* LPN will do this in cooperation with the RN. 
10. Document the nursing process through utilization of the nursing care plans and other appropriate forms.

11. Integrate the nursing process into the unit's delivery of health care."

12. Assume responsibility and accountability for the nursing care delivered. *

The forms used in patients' charts to document nursing care given from the time of admission to discharge from the hospital were the focal points of the curriculum development. Each form with attendant instructions for proper use was carefully described, and a didactic presentation of each individual stage of the nursing process was given.

The classes began with the first step in the process, the Assessment Stage. The Nursing Assessment Form is the tool used to document pertinent data about the patient upon admission to the hospital. This form acts as a guide for the nurse in the process of assessing the patients' needs and is the vehicle for documentation of formulation of the nursing diagnosis.

Methods to facilitate good assessment skills, directions for effective interviewing techniques, consideration of factors affecting patients' responses (e.g., privacy, fear, environmental factors, etc.) were discussed. Identification of what constitutes a nursing diagnosis and its relationship to a medical diagnosis were presented; and case studies, role playing, and question and answer sessions were implemented to give the class participants a chance to become comfortable with the content of the curriculum and to be able to implement what they had 
learned on the operations level.

The Problem List-Nursing, a form used to document nursing diagnoses and patient needs arising from the problems listed, was used in case studies reviewed by small groups in the classes. The Patient Progress Note, a form used to document nursing orders and plans of care, was used in conjunction with teaching the second stage of the nursing process, the Planning Stage, and the third step or Implementation Stage. The fourth necessary form, the Flow Sheet, was used with the Patient Progress Note to evidence continuity of plans of care to document the final stage of the process, the Evaluation Stage. The content of the classes and the participative response of the nurses attending combined to structure the teaching/learning process of the nursing process classes.

A11 participants were pre- and post-tested as a part of the class.

\section{RESEARCH PROCEDURES}

Data were collected from a sample of 102 nurses. The parameters used were:

1. All nurses attended a four-hour nursing processing class taught by the researcher, Director of the Department of Medical Center Education.

2. All class participants were pre- and post-tested on class materials. 
3. An information sheet was completed on all nurses to compile quantifiable data relative to the study, i.e., type of education, experience, date of graduation, etc.

4. An auditing tool was used which defined data collected for Yes and No answers for all cases.

5. Charts were audited on all participants in the post nursing process class at four weeks (audit sample only).

\section{INSTRUMENT CONSTRUCTION}

The auditing tool was designed specifically for this study. Construction of the tool was based on the four forms employed to facilitate the use and documentation of the nursing process by staff nurses (see Appendices A-D). The parameters defined by existing inpatient nursing policies were carefully examined and questions were constructed to document that staff nurses' behaviors were congruent with these poiticies.

The portion of the audit tool pertaining to the Nursing Assessment Form was constructed to obtain data about completeness of information filled in, evidence of formulation of nursing diagnoses, nursing care plans, goals for planning of nursing care, and whether or not the assessment was done and signed for by a RN within a reasonable time frame after the patient was admitted to the hospital. Existing policy requires such documentation eight to ten hours from the time of admission to the unit.

The Problem List-Nursing was studied, and the portion of the audit 
tool devoted to this form was constructed to elicit information about proper documentation of the assessment of the patient's problems. The assessment of a patient's problems on admission, resolution of these problems, evidence of new problems three days after admission, and resolution of any of the recorded problems five days after admission were audited when feasible. Evidence of the use of nursing diagnoses were also recorded, as well as the assigning of an appropriate Roman numeral to each designated problem, in accordance with existing nursing procedure.

The Patient Progress Notes portion of the audit tool documented accurate recordings of nursing interventions, appropriate use of specific times and dates, appropriate charting methods as defined by existing nursing policy, use of Problem-Oriented Medical Recording (S.0.A.P.) charting, ongoing reassessment of patient's progress, and documentation of discharge planning when necessary.

The final portion of the audit tool focused on the Flow Sheet to determine whether the staff RN's were documenting the implementation of specific items of the nursing care plan on this sheet. All questions were constructed to be answered by a Yes or No reply to facilitate objective gathering and analysis of the data.

\section{TRAINING OF THE AUDITORS}

As previously stated, all 12 of the nursing process classes were taught by the researcher. Instructors from the Medical Center Education Department (M.C.E.) were required to: (1) audit at least one class, and 
(2) be familiar with existing charting protocols and forms used by the staff RN's to document the use of nursing process activities.

Audits were scheduled to be performed during the fourth week following completion of the nursing process class. The researcher and instructors from M.C.E. completed three separate audits on each RN who had attended the nursing process class.

To ensure standardization of the audit process, the researcher educated all instructors in the rationale for use of both the existing forms and the tool designed specifically for this audit. The case study approach was followed to illustrate use of the audit tool. The researcher, as a second step of the instruction process, accompanied each instructor and supervised the audit of three charts of staff RN's in the sample. All completed audit tools were reviewed by the researcher for completeness and accuracy.

THE COLLECTION PROCEDURE

The researcher was responsible for design and implementation of the study and coordination of all factors related to it. Members of the Department of Medical Center Education were instructed in use of the audit tool. The following parameters were used during the auditing process to: (1) determine the effectiveness of the methods used to teach the nursing process to staff RN's by analysis of pre- and posttest results; and (2) evaluate the degree of transfer of learning to nursing practice by new staff RN's: 
a. The nurse will complete a Nursing Assessment Form on a new $y$-admitted patient.

b. The nurse will formulate and document a nursing diagnosis on the Problem List-Nursing.

c. The nurse will evidence formulation of specific goals on the Nursing Assessment Form.

d. The nurse will document the formulation of specific goals on the Nursing Assessment Form.

e. The nurse will document the evaluation of the effectiveness or lack of same of a plan of care designed by the nurse on the Patient Progress Notes.

f. The nurse will evidence documentation of implementation by the nurse of specific items of the nursing care plan on the Flow Sheet.

An audit was performed four weeks after completion of the nursing process class for each nurse in the sample population. The auditor examined three charts that evidenced the individual nurse's charting. Many of the nurses who had been hired to work the night shift had finished their orientation period on the day shift and were working on their assigned shifts. In these cases, it was frequently observed that the Nursing Assessment Form was not used by these nurses and that no documentation existed for the purpose of their audits. This is acceptable practice for nurses working on the night shift due to the emergent admission status of the patient. The form will be completed as soon as the patient's condition allows. 
The Nursing Assessinent Form is used to obtain data on the patient at the time of admission to the unit. Appropriate use of this form necessitates participation by the patient and/or family in the datagathering process. Patients admitted during the night shift are usually direct admissions from the operating room or the emergency department, and the urgency of the existing condition for which they are admitted frequently precludes adequate utilization of the Nursing Assessment Form.

The Patient Progress Note is, in most cases, the vehicle by which night nurses document their assessments, plans of care, nursing interventions and evaluations of the patient's response to care. Proper documentation of items one, two, and three of category $C$ on the audit tool include answers to the following questions:

1. Are dates and specific times indicated with comments for each shift, followed by signatures with titles?

2. Are pertinent observations and communications recorded using the S.0.A.P. format?

3. Are nursing interventions recorded accurately? The responses would validate evidence of effective use of the nursing process by a night nurse, given the constraints of emergency or urgent admissions.

Members of the Department of Medical Center Education were instructed by the researcher to mark N.A. (Not Applicable) at time of admission on the audit tool when there was no evidence of utilization of the Nursing Assessment Form by a night nurse, when appropriate. This 
was a singular exception, and utilization of the three remaining forms by nurses working the night shift was audited over all cases.

Nurses who were hired to work in the float pool, in the resource pool, or in an on-call status presented another problem to the auditing process. These nurses were assigned throughout the hospital in a relief or float status and were scheduled to work on units as the acuity of the patient census demanded. One nurse might work on two or three units during an assigned shift for short periods of time to relieve or assist scheduled staff. Under these circumstances, nonutilization of the Nursing Assessment Form and Problem List-Nursing would be acceptable practice. The same procedure of using N.A. was utilized by the auditors when appropriate. The erratic scheduling of nurses assigned to this category necessitated flexibility in the number of audits performed. It was not unusual for an "on-cal1" nurse to work one or two shifts within a month. This was a factor in the number of audits performed; four were preferable, but three were acceptable. These schedules and the assignments during a shift worked were carefully monitored with assistance from records in the Staffing office to validate appropriate usage of the N.A. category when auditing these nurses' chartings.

The monthly audits were scheduled and coordinated by the researcher. On completion of each audit, the researcher reviewed all the tools for completeness and accuracy. All charts were carefully scrutinized by the auditors and the researcher to maintain the original parameters set for audit criteria as previously described. 


\section{TEST DEVELOPMENT}

The pre- and post-tests were developed by the researcher to indicate the level of knowledge of each nurse participant relative to the nursing process both before and after instruction by the researcher.

Questions on both tests were developed with the four phases of the nursing process as the core of the examination. The unique aspects of each individual phase as well as their interrelationships were the focus of test design. The logical flow of the thought process associated with application of the individual phases was emphasized.

The goal of the class was to raise the level of compliance by the staff RN's in documentation of the nursing process, as a basis of nursing care given, to conform to current inpatient nursing policy. The objectives of the class were: (1) to teach the individual nurse what nursing process is, and (2) to teach the nurse how to implement nursing process into nursing practice. The test questions were constructed to assess the nurses' understanding of the nursing process before and after instruction.

The pre-test contained five questions which, with all answers correct, would provide a score of 12 points. The number of correct answers by the nurse student would indicate the level of understanding of the conceptual model of the nursing process before instruction by the researcher (see Appendix F).

The post-test contained 15 questions, with a possible correct score of 22 points. The five questions used for the pre-test were repeated in the construction of the post-test (see Appendix G). With the exception 
of the first question on each test, all of the questions on both tests used a multiple choice format. The students were instructed by the researcher prior to administration of both the pre-test and the posttest that there was a right and a wrong answer for each question. The first question on each test was a matching-items format with eight components to the question.

\section{STATISTICAL METHODS}

For the total sample and for levels within the total sample of type of nursing education, age, and experience, means and standard deviations were calculated on the pre-test, post-test, and self-perceived understanding scores. For the audit sample and for levels within the audit sample of type of nursing education, means and standard deviations were calculated on the pre-test, post-test, self-perceived understanding, post-test common scores, and percent complete on the audits. For the total and audit sample means, $95 \%$ confidence intervals were constructed. For the audit sample, a related samples t-test was performed on the pre-test, post-test common items scores, with alpha set at .05 .

For the total sample, analyses of variances were performed on the pre-test, post-test, and self-perceived understanding scores, using type of nursing education, age, and experience as independent variables. Analyses of variance and covariance were performed for the total sample on the post-test, using the pre-test as a covariate, with type of nursing education, age, and experience as independent variables. Alpha 
was set at .05 for each test. Scheffé's test was used for pair-wise mean comparisons as appropriate.

For the audit sample, analyses of variance were performed on the pre-test, post-test, self-perceived understanding, change scores, and percent correct on audit, using type of nursing education as an independent variable. Using age and experience as independent variables, analyses of variance were also performed for the audit sample on change scores and percent correct of the audit. Scheffé's test was used as appropriate. Alpha was set at .05 for each statistical test.

For each of the items on the four audit forms, the percent of the total number of audited charts which had completed entries was calculated. A 95\% confidence interval for the population percent was then calculated for each of the item percents. Crosstabulation and chisquare by clinical arena were performed on each item of the four forms, using an alpha level of .05 for each statistical test.

\section{LIMITATIONS}

In this study, a single-group design was used. Criterion measures of the dependent variables included: (1) pre-test of knowledge of nursing process; (2) post-test of knowledge of nursing process; and (3) post-treatment measure of application of nursing process procedures in clinical practice (chart audits). Thus, this was a quasi-experimental study with the internal and external validity problems associated with this type of research design.

Factors which impinge on the internal validity of single-group 
studies include maturation, experience, pre-testing, instrumentation, sampling bias, and mortality. Since an adult sample was used and the training period was relatively short, maturation of the sample is unlikely to influence the results. Experiences of the nurses outside of the classroom might partially explain the results obtained, but their impact is likely to be small because there existed no systematic evaluation feedback to the nurses of their use of nursing process. All subjects completed the study; thus, mortality was not a factor in the results. The pre-test could have influenced the post-test results; the pre-test was considered to be a part of the training and thus did not impact the internal validity. Changes in instrumentation over time are a potential threat. The use of selection-type tests controlled this variable for the achievement variable. The care used in training the auditors and the independent verification of the audits by the researcher provided adequate control over instrumentation. From an internal validity perspective, the use of all newly-employed nurses negated the sampling validity problem. Thus, although the single-group design poses internal validity threats, the characteristics of this study provided additional controls over most of these variables. External validity threats are present. In generalizing the results of this study to other hospital settings, the characteristics of the nursing sample, the hospital setting in which this study was conducted, and the qualifications and enthusiasm of the instructor must be carefully considered. 
CHAPTER IV

ANALYSIS AND PRESENTATION OF THE DATA

QUESTIONS ASKED

The analysis of the data compiled from examinations and audits is presented and organized around each of the following major research questions:

1. Does the current training process used at Bess Kaiser Medical Center teach newly-employed staff nurses how to transfer nursing process theory to practice?

2. Do the newly-employed staff nurses apply and document the nursing process in patients' charts?

3. What is the compliance of the total nursing staff with the requirement that they apply and document the nursing process in patients' charts?

A second component of this study, presented in tabular comparisons, is the analysis of data from the samples to determine the extent to which the following three variables relate to knowledge of and effectiveness in the use of the nursing process: type of nursing preparation, age, and experience. Each of these variables was tested for its impact on the following set of questions:

1. Do nurses differ in their knowledge of the nursing process prior to the beginning of in-service training? 
2. Do nurses differ in their knowledge of the nursing process upon completion of in-service training?

3. Do nurses differ in their change scores on common items from pre-test to post-test?

4. Do nurses differ in their perceptions of their understanding of the nursing process?

5. Do nurses differ in their compliance with nursing process directives as determined by chart audits?

UNDERSTANDING OF NURSING PROCESS BY NEWLY-EMPLOYED NURSES

The total sample of newly-employed nurses $(n=102)$ was partitioned into two subsamples: (1) the audit sample $(n=82)$, and (2) those whose job assignments did not permit auditing their patients' charts for compliance with nursing process procedures $(n=20)$. Although the major focus of the first two research questions was on the audit group, selected performance characteristics of the total sample were also examined because of the potential influence of the configuration of the total group on the performance of group members.

Four variables were examined in attempting to answer the question, "Does the current training program used at Bess Kaiser Medical Center teach newly-employed staff nurses how to transfer nursing process theory to practice?" The pre-test, the post-test, and self-perceived understanding means and standard deviations for both the audit and the total sample are presented in Table VI. 
TABLE VI

MEANS AND STANDARD DEVIATIONS FOR THE TOTAL AND AUDIT SAMPLES

ON FIVE DEPENDENT VARIABLES

\begin{tabular}{|c|c|c|c|c|}
\hline \multirow[b]{2}{*}{ Variable } & \multicolumn{2}{|c|}{ Total $(n=102)$} & \multicolumn{2}{|c|}{ Audit $(n=82)$} \\
\hline & Mean & S.D. & Mean & S.D. \\
\hline Pre-test & 9.7843 & 2.2761 & 10.0854 & 1.8539 \\
\hline $\begin{array}{l}\text { Post-test } \\
\text { Common }\end{array}$ & - & - & 10.8537 & 1.5879 \\
\hline Post-test & 19.0392 & 3.9600 & 19.6341 & 2.1228 \\
\hline $\begin{array}{l}\text { Percent } \\
\text { Complete }\end{array}$ & - & - & 78.9756 & 14.9154 \\
\hline Understanding & 3.3725 & 1.0617 & 3.3902 & 0.9782 \\
\hline
\end{tabular}

The pre-test mean was 10.09 for the audit sample and 9.78 for the total sample. The post-test mean was 19.63 for the audit sample and 19.04 for the total sample. The mean of the scores for perceived understanding of the nursing process for the audit sample was 3.39; for the total sample it was 3.37. Also presented for the audit sample are the means and standard deviations of the scores of those items on the post-test which served as the pre-test for this study and the percent of items completed on the audit; the means were 10.85 and 78.98 , respectively.

A $95 \%$ confidence interval for the estimated population mean was calculated separately for the pre-test, post-test, post-test common, and understanding scores for the audit sample using the following equation: 


$$
C I=\bar{X} \pm t_{.05}(S . D \cdot \sqrt{N-1})
$$

This was repeated on available measures for the total sample. Also, a 95\% confidence interval was calculated, for the audit sample, for the estimated population percent complete on the audit forms, using the following equation:

$$
C I=P \pm 100(1.96)(\sqrt{p q / N})
$$

The results are shown in Table VII.

\section{TABLE VII}

NINETY-FIVE PERCENT CONFIDENCE INTERVALS FOR POPULATION MEANS ESTIMATED FROM FIVE DEPENDENT VARIABLE MEASURES OF THE

\begin{tabular}{|c|c|c|c|c|}
\hline \multirow[b]{2}{*}{ Variables } & \multicolumn{2}{|c|}{ Audit Sample } & \multicolumn{2}{|c|}{ Total Sample } \\
\hline & Mean & $\begin{array}{l}\text { Confidence } \\
\text { Interval }\end{array}$ & Mean & $\begin{array}{l}\text { Confidence } \\
\text { Interval }\end{array}$ \\
\hline Pre-test & 10.09 & $9.67-10.50$ & 9.78 & $9.33-10.23$ \\
\hline $\begin{array}{c}\text { Post-test } \\
\text { Common }\end{array}$ & 10.85 & $10.50-11.21$ & - & - \\
\hline Post-test & 19.63 & $19.16-20.11$ & 19.04 & $18.26-19.82$ \\
\hline Understanding & 3.39 & $3.17-3.61$ & 3.37 & $3.16-3.58$ \\
\hline
\end{tabular}
AUDIT AND TOTAL SAMPLES

A related samples t-test was used to test the significance of the difference between the pre-test mean and the common-items post-test mean for the audit sample. The statistical hypothesis that the pre-test and 
common-items population means are equal $\left(H_{0}: \mu_{1}=\mu_{2}\right)$ was rejected at the .05 level of confidence $(t=3.22, \underline{p}=.01)$. Therefore, the research hypothesis that the common-items post-test mean is greater than the pre-test mean $\left(H_{1}: \mu_{1} \mu_{2}\right)$ was accepted. These results are shown in Table VIII.

TABLE VIII

PRE-TEST - POST-TEST CHANGE SCORES FOR THE AUDITED SAMPLE

\begin{tabular}{cccccc}
\hline Test & Mean & S.D. & $\underline{t}$ & df & Probability \\
\hline $\begin{array}{c}\text { Pre-test } \\
\begin{array}{c}\text { Post-test } \\
\text { Common }\end{array}\end{array}$ & 10.085 & 1.854 & 3.22 & 81 & $0.002^{\star}$ \\
\hline
\end{tabular}

*The statistical hypothesis was rejected at the .05 level.

APPLICATION AND DOCUMENTATION OF THE NURSING PROCESS BY

NEWLY-EMPLOYED NURSES

Four forms were used in the audit of the charts of selected audit sample patients. For each nurse, the percent of appropriate items completed was calculated. The mean of the percent of completion was 78.98, and the standard deviation was 14.92. This information was presented in Table VI (p.57).

TOTAL NURSING STAFF COMPLIANCE WITH NURSING PROCESS REQUIREMENTS

For each item on the four audit forms, the number of audited 
charts containing complete entries was determined. This information was used to calculate for each iten the percent of the total number of audited charts which had completed entries, and this information was then used in interval estimation of population percents, using the equation:

$$
C I=P \pm(1.96)(100) \sqrt{p q / N}
$$

The extent of staff RN utilization of the Nursing Assessment Form is illustrated in Table IX. Percents for completed items range from a low of 52.0 for Question 1 ("Is all information filled in?") to a high of 91.5 for Question 2 ("Is there evidence that the patient's immediate needs were assessed by a Registered Nurse?"). A 95\% confidence interval for the population estimate of the percent completed on each question of the Nursing Assessment Form is presented in Table $X$. Note that none of the confidence intervals included either 0 or 100.

The extent of staff RN utilization of the Problem List-Nursing is illustrated in Table XI. Percent completed for the items ranged from a low of 4.3 ("Is there documented evidence that problems have been resolved?") to a high of 53.5 ("Does each problem have a Roman numeral as a designator?"). A $95 \%$ confidence interval for the population estimate of the percent of items completed is presented for each question on the Problem List-Nursing in Table XII. None of the confidence intervals included 0 , and only one had an upper limit exceeding $50 \%$. 
TABLE IX

ANALYSIS OF STAFF RN UTILIZATION OF THE NURSING ASSESSMENT FORM

\begin{tabular}{|c|c|c|c|c|c|}
\hline \multirow{2}{*}{\multicolumn{2}{|c|}{ Question }} & \multicolumn{2}{|c|}{ Completed } & \multicolumn{2}{|c|}{ Not Completed } \\
\hline & & Freq. & $\begin{array}{l}\text { Rel. } \\
\text { Freq. } \\
\quad(\%)\end{array}$ & Freq. & $\begin{array}{l}\text { Rel. } \\
\text { Freq. } \\
(\%)\end{array}$ \\
\hline & Is all information filled in? & 128 & 52.0 & 118 & 48.0 \\
\hline 2. & $\begin{array}{l}\text { Is there evidence that the } \\
\text { patient's immediate needs were } \\
\text { assessed by a Registered Nurse? }\end{array}$ & 225 & 91.5 & 21 & 8.5 \\
\hline 3. & $\begin{array}{l}\text { Is there evidence that the } \\
\text { initial assessment form was } \\
\text { completed? }\end{array}$ & 210 & 85.4 & 36 & 14.6 \\
\hline \multirow[t]{2}{*}{4.} & $\begin{array}{l}\text { Is there documented evidence } \\
\text { of a nursing diagnosis on the } \\
\text { initial assessment sheet? }\end{array}$ & 153 & 62.4 & 92 & 37.6 \\
\hline & $\begin{array}{l}\text { Is there documentation of } \\
\text { formulation of a plan of } \\
\text { care on the initial } \\
\text { assessment sheet? }\end{array}$ & 173 & 70.3 & 73 & 29.7 \\
\hline & $\begin{array}{l}\text { Are there goals specified on } \\
\text { the initial assessment sheet? }\end{array}$ & 174 & 70.7 & 72 & 29.3 \\
\hline 6. & $\begin{array}{l}\text { Is assessment sheet signed by } \\
\text { an RN? }\end{array}$ & 216 & 87.8 & 30 & 12.2 \\
\hline
\end{tabular}


TABLE $X$

NINETY-FIVE PERCENT CONFIDENCE INTERVALS FOR POPULATION PERCENT COMPLETION FOR EACH QUESTION ON THE NURSING ASSESSMENT FORM

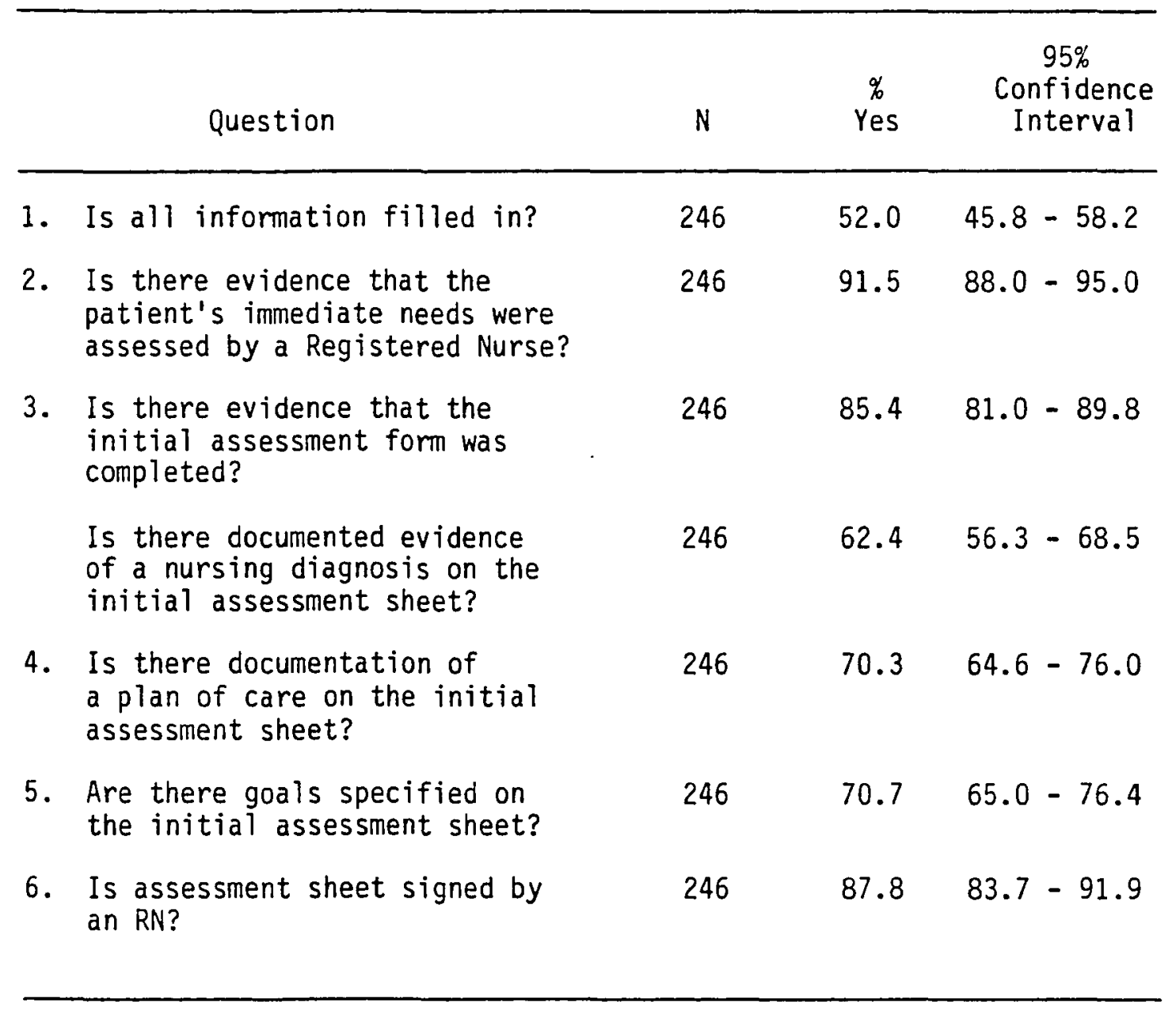


TABLE XI

ANALYSIS OF STAFF RN UTILIZATION OF THE PROBLEM LIST-NURSING

\begin{tabular}{|c|c|c|c|c|}
\hline \multirow[b]{2}{*}{ Question } & \multicolumn{2}{|c|}{ Completed } & \multicolumn{2}{|c|}{ Not Completed } \\
\hline & Freq. & $\begin{array}{l}\text { Rel. } \\
\text { Freq. } \\
\quad(\%)\end{array}$ & Freq. & $\begin{array}{l}\text { Rel. } \\
\text { Freq. } \\
(\%)\end{array}$ \\
\hline $\begin{array}{l}\text { 1. Is there documentation of the } \\
\text { patient's problems on the } \\
\text { Problem List using a nursing } \\
\text { diagnosis? }\end{array}$ & 100 & 41.2 & 143 & 58.8 \\
\hline $\begin{array}{l}\text { 2. Does each problem have a Roman } \\
\text { numeral as a designator? }\end{array}$ & 130 & 53.5 & 113 & 46.5 \\
\hline $\begin{array}{l}\text { 3. Is the nursing diagnosis a } \\
\text { statement of a problem that } \\
\text { may be treated through nursing } \\
\text { interventions? }\end{array}$ & 80 & 32.9 & 163 & 67.1 \\
\hline $\begin{array}{l}\text { 4. Is there documented evidence } \\
\text { that problems have been resolved? }\end{array}$ & 10 & 4.3 & 222 & 95.7 \\
\hline $\begin{array}{l}\text { 5. Is there evidence of new problems } \\
\text { being documented } 3 \text { days after the } \\
\text { admission of the patient? }\end{array}$ & 25 & 16.9 & 123 & 83.1 \\
\hline $\begin{array}{l}\text { 6. Is there evidence of the patient's } \\
\text { problems being resolved } 5 \text { days } \\
\text { after admission? }\end{array}$ & 12 & 10.2 & 106 & 89.9 \\
\hline
\end{tabular}


TABLE XII

NINETY-FIVE PERCENT CONFIDENCE INTERVALS FOR POPULATION PERCENT

COMPLETION FOR EACH QUESTION ON THE PROBLEM LIST-NURSING FORM

\begin{tabular}{|c|c|c|c|}
\hline Question & $N$ & $\begin{array}{c}\% \\
\text { Yes }\end{array}$ & $\begin{array}{l}95 \% \\
\text { Confidence } \\
\text { Interval }\end{array}$ \\
\hline $\begin{array}{l}\text { 1. Is there documentation of the } \\
\text { patient's problems on the } \\
\text { Problem List using a nursing } \\
\text { diagnosis? }\end{array}$ & 246 & 41.2 & $35.1-47.4$ \\
\hline $\begin{array}{l}\text { 2. Does each problem have a Roman } \\
\text { numeral as a designator? }\end{array}$ & 246 & 53.5 & $47.3-59.7$ \\
\hline $\begin{array}{l}\text { 3. Is the nursing diagnosis a } \\
\text { statement of a problem that } \\
\text { may be treated through nursing } \\
\text { intervention? }\end{array}$ & 246 & 32.9 & $27.0-38.8$ \\
\hline $\begin{array}{l}\text { 4. Is there documented evidence } \\
\text { that problems have been resolved? }\end{array}$ & 246 & 4.3 & $1.8-6.7$ \\
\hline $\begin{array}{l}\text { 5. Is there evidence of new problems } \\
\text { being documented } 3 \text { days after the } \\
\text { admission of the patient? }\end{array}$ & 246 & 16.9 & $12.2-21.6$ \\
\hline $\begin{array}{l}\text { 6. Is there evidence of the patient's } \\
\text { problems being resolved } 5 \text { days } \\
\text { after admission? }\end{array}$ & 246 & 10.2 & $6.4-14.0$ \\
\hline
\end{tabular}


Analysis of the utilization of the Patient Progress Notes by staff RN's is illustrated in Table XIII. Percent complete for the items ranged from a low of 64.6 for Question 6 ("Is there documentation of discharge planning for the patient when necessary?") to a high of 98.8 on the first three questions ("Are dates and specific times indicated with comments for each shift, followed by signatures with titles?" "Are pertinent observations and communications recorded using S.O.A.P. format?" "Are nursing interventions recorded accurately?") .

A $95 \%$ confidence interval for the population estimate of the percent completed for each question of the Patient Progress notes is presented in Table XIV. In all six cases, the upper limit of the interval exceeded $70 \%$ and the lower limit exceeded $50 \%$. In three cases, the 1ower limit exceeded $90 \%$.

An analysis of the staff RN's utilization of the Flow Sheet is presented in Table XV. Evidence was found on $76.4 \%$ of the audited charts that there was "documentation of 1 or 2 items flowing from the plan on this sheet." The 95\% confidence interval for the estimated population percent was $71.1-81.7$, as shown in Table XVI. 
TABLE XIII

ANALYSIS OF STAFF RN UTILIZATION OF THE PROGRESS NOTES

\begin{tabular}{|c|c|c|}
\hline & Completed & Not Completed \\
\hline Question & $\begin{array}{cc} & \text { Rel. } \\
& \text { Freq. } \\
\text { Freq. } & (\%)\end{array}$ & $\begin{array}{cc} & \text { Rel. } \\
\text { Freq. } & \\
\text { Freq. } & (\%)\end{array}$ \\
\hline
\end{tabular}

1. Are dates and specific times indicated with comments for each shift, followed by signatures with titles?

2. Are pertinent observations and communications recorded using S.O.A.P. format?

3. Are nursing interventions recorded accurately?

$\begin{array}{llll}243 & 98.8 & 3 & 1.2\end{array}$

$243 \quad 98.8$

$3 \quad 1.2$

4. Is there evidence of newlyassessed problems 3 days after the original assessment done on admission?

5. Is there evidence that the effectiveness of care has been evaluated by day \#5 after admission by the consistent recording of one or two items?

6. Is there documentation of discharge planning for the patient when necessary?

$\begin{array}{rrrr}243 & 98.8 & 3 & 1.2 \\ 131 & 82.4 & 28 & 17.6 \\ 74 & 77.1 & 22 & 22.9\end{array}$

$\begin{array}{llll}112 & 64.4 & 62 & 35.6\end{array}$


TABLE XIV

NINETY-FIVE PERCENT CONFIDENCE INTERVALS FOR POPULATION PERCENT COMPLETION FOR EACH QUESTION ON THE PROGRESS NOTE

\begin{tabular}{|c|c|c|c|c|}
\hline & Question & $\mathrm{N}$ & $\begin{array}{c}\% \\
\text { Yes }\end{array}$ & $\begin{array}{l}95 \% \\
\text { Confidence } \\
\text { Interval }\end{array}$ \\
\hline & $\begin{array}{l}\text { Are dates and specific times } \\
\text { indicated with comments for } \\
\text { each shift, followed by } \\
\text { signatures with titles? }\end{array}$ & 246 & 98.8 & $94.5-100.0$ \\
\hline 2. & $\begin{array}{l}\text { Are pertinent observations } \\
\text { and communications recorded } \\
\text { using } S .0 . A . P \text {. format? }\end{array}$ & 246 & 98.8 & $94.5-100.0$ \\
\hline 3. & $\begin{array}{l}\text { Are nursing interventions } \\
\text { recorded accurately? }\end{array}$ & 246 & 98.8 & $94.5-100.0$ \\
\hline 4. & $\begin{array}{l}\text { Is there evidence of newly- } \\
\text { assessed problems } 3 \text { days after } \\
\text { the original assessment done } \\
\text { on admission? }\end{array}$ & 159 & 82.4 & $76.5-88.3$ \\
\hline 5. & $\begin{array}{l}\text { Is there evidence that the } \\
\text { effectiveness of care has } \\
\text { been evaluated by day } \# 5 \\
\text { after admission by the } \\
\text { consistent recording of } \\
\text { one or two items? }\end{array}$ & 96 & 77.1 & $68.7-85.5$ \\
\hline 6. & $\begin{array}{l}\text { Is there documentation of } \\
\text { discharge planning for the } \\
\text { patient when necessary? }\end{array}$ & 174 & 64.6 & $57.5-71.7$ \\
\hline
\end{tabular}


TABLE XV

ANALYSIS OF STAFF RN UTILIZATION OF THE FL.OW SHEET

\begin{tabular}{lllll}
\hline \multicolumn{1}{c}{ Question } & Completed & $\begin{array}{c}\text { Rel. } \\
\text { Freq. } \\
(\%)\end{array}$ & & $\begin{array}{c}\text { Not Completed } \\
\text { Freq. }\end{array}$ \\
\hline $\begin{array}{l}\text { Is there documentation of one or } \\
(\%)\end{array}$ \\
$\begin{array}{l}\text { two items flowing from the plan } \\
\text { on this sheet? }\end{array}$ & 185 & 76.4 & 57 & 23.6 \\
\hline
\end{tabular}

TABLE XVI

NINETY-FIVE PERCENT CONFIDENCE INTERVAL FOR POPULATION PERCENT COMPLETION FOR THE QUESTION ON THE FLOW SHEET

\begin{tabular}{lccc}
\hline \multicolumn{1}{c}{ Question } & $N$ & $\begin{array}{c}\% \\
\text { Yes }\end{array}$ & $\begin{array}{c}95 \% . \\
\text { Confidence } \\
\text { Interval }\end{array}$ \\
\hline $\begin{array}{l}\text { Is there documentation of one or } \\
\text { two items flowing from the plan } \\
\text { on this sheet? }\end{array}$ & 246 & 76.4 & $71.1-81.7$ \\
\hline
\end{tabular}


TOTAL NURSING STAFF COMPLIANCE BY CLINICAL AREA

A previous study (Johnson, 1981) found that nurses in the three clinical arenas differed in their use of the various components of the nursing process. To reinvestigate this research expectation, a crosstabulation by clinical arena was performed for each of the four forms. For each question on each form the statistical hypothesis that the evaluations are independent of clinical arena was tested at the .05 level of significance. The calculated chi-square and associated probability are reported for each question on each form as a part of this report.

A cross-tabulation of percent completion for each question on the Nursing Assessment Form by clinical arenas is illustrated in Table XVII. For reader convenience, values are reported as percentages; the calculations were performed on the actual cell, of frequencies. Using the .05 level of confidence, the chi-square value for Question 5 was significant; thus, the statistical hypothesis for this question was rejected. A greater proportion of Maternal/Child Nursing Assessment Forms were completed than were the forms for Critical Care and for Medical/Surgical.

A cross-tabulation of percent completed on each question on the Problem List-Nursing by clinical arena is illustrated in Table XVIII. Using the .05 level of significance, the chi-square values for Questions, $1,2,3,5$, and 6 were significant. The statistical hypotheses for these items were rejected. As compared with the other 
TABLE XVII

FOR EACH ITEM ON THE NURSING ASSESSMENT FORM, PERCENT COMPLETED BY CLINICAL ARENA, CALCULATED CHI-SQUARE, AND PROBABILITY

\begin{tabular}{|c|c|c|c|c|c|c|c|c|c|}
\hline \multirow{3}{*}{\multicolumn{2}{|c|}{ Question }} & \multirow{2}{*}{\multicolumn{2}{|c|}{$\begin{array}{l}\text { Critical } \\
\text { Care }\end{array}$}} & \multirow{2}{*}{\multicolumn{2}{|c|}{$\begin{array}{c}\text { Medical- } \\
\text { Surgical } \\
\text { Percent }\end{array}$}} & \multirow{2}{*}{\multicolumn{2}{|c|}{$\frac{\begin{array}{c}\text { Maternal- } \\
\text { Child }\end{array}}{\text { Percent }}$}} & \multirow{3}{*}{$\begin{array}{l}\text { Calculated } \\
\text { Chi-Square }\end{array}$} & \multirow[b]{3}{*}{ Probability } \\
\hline & & & & & & & & & \\
\hline & & Yes & No & Yes & No & Yes & No & & \\
\hline & Is all information filled in? & 52.5 & 47.5 & 47.5 & 52.5 & 58.1 & 41.9 & 2.27633 & .3204 \\
\hline & $\begin{array}{l}\text { Is there evidence that the } \\
\text { patient's immediate needs } \\
\text { were assessed by an RN? }\end{array}$ & 90.0 & 10.0 & 90.8 & 9.2 & 93.0 & 7.0 & 0.43873 & .8030 \\
\hline & $\begin{array}{l}\text { Is there evidence that the } \\
\text { initial assessment form was } \\
\text { completed? }\end{array}$ & 82.5 & 17.5 & 82.5 & 17.5 & 90.7 & 9.3 & 3.00894 & .2221 \\
\hline 4. & $\begin{array}{l}\text { Is there documented evidence } \\
\text { of a nursing diagnosis on the } \\
\text { initial assessment sheet? }\end{array}$ & 65.0 & 35.0 & 62.5 & 37.5 & 61.2 & 38.8 & 0.16983 & .9186 \\
\hline & $\begin{array}{l}\text { Is there documentation of a } \\
\text { formal plan of care on the } \\
\text { initial assessment sheet? }\end{array}$ & 70.0 & 30.0 & 65.8 & 34.2 & 76.7 & 23.3 & 2.86022 & .2393 \\
\hline & $\begin{array}{l}\text { Are there goals specified on } \\
\text { the initial assessment sheet? }\end{array}$ & 72.5 & 27.5 & 63.3 & 36.7 & 80.2 & 19.8 & 6.98305 & $.0305^{\star}$ \\
\hline & $\begin{array}{l}\text { Is assessment sheet signed by } \\
\text { an RN? }\end{array}$ & 85.0 & 15.0 & 87.5 & 12.5 & 89.5 & 10.5 & 0.54468 & .7616 \\
\hline
\end{tabular}

\footnotetext{
* Significant at the .05 level.
} 


\section{TABLE XVIII}

FOR EACH ITEM ON THE PROBLEM LIST-NURSING, PERCENT COMPLETED BY CLINICAL ARENA, CALCULATED CHI-SQUARE, AND PROBABILITY

\begin{tabular}{|c|c|c|c|c|c|c|c|c|}
\hline \multirow[b]{2}{*}{ Question } & \multicolumn{2}{|c|}{$\begin{array}{l}\text { Critical } \\
\text { Care }\end{array}$} & \multicolumn{2}{|c|}{$\frac{\begin{array}{l}\text { Medical- } \\
\text { Surgtcal }\end{array}}{\text { Percent }}$} & \multicolumn{2}{|c|}{$\frac{\begin{array}{c}\text { Maternal- } \\
\text { Child }\end{array}}{\text { Percent }}$} & \multirow{2}{*}{$\begin{array}{l}\text { Calculated } \\
\text { Chi-Square }\end{array}$} & \multirow[b]{2}{*}{ Probability } \\
\hline & Yes & No & Yes & No & Yes & No & & \\
\hline $\begin{array}{l}\text { 1. Is there documentation of the } \\
\text { patient's problems on the } \\
\text { Problem List using a nursing } \\
\text { diagnosis? }\end{array}$ & 46.2 & 53.8 & 29.2 & 70.8 & 56.0 & 44.0 & 15.11894 & $.0005^{\star}$ \\
\hline $\begin{array}{l}\text { 2. Does each problem have a Roman } \\
\text { numeral as a designator? }\end{array}$ & 35.9 & 64.1 & 41.7 & 58.3 & 78.6 & 21.4 & 32.83588 & $.0000^{\star}$ \\
\hline $\begin{array}{l}\text { 3. Is the nursing dfagnosis a } \\
\text { statement of a problem that } \\
\text { may be treated through nursing } \\
\text { intervention? }\end{array}$ & 35.9 & 64.1 & 23.3 & 76.7 & 45.2 & 54.8 & 10.9226 & $.0042^{\star}$ \\
\hline $\begin{array}{l}\text { 5. Is there evidence of new problems } \\
\text { being documented } 3 \text { days after the } \\
\text { admission of the patient? }\end{array}$ & 12.5 & 87.5 & 12.3 & 87.7 & 31.4 & 68.6 & 6.90056 & $.0317^{\star}$ \\
\hline $\begin{array}{l}\text { Is there evidence of the patient's } \\
\text { problems heing resolved } 5 \text { days } \\
\text { after admission? }\end{array}$ & 3.4 & 96.6 & 4.9 & 95.1 & 28.6 & 71.4 & 13.65470 & $.0011^{\star}$ \\
\hline
\end{tabular}

Significant at the .05 lever. 
two arenas, a greater proportion of the charts for the nurses in the Maternal/Child arena

1. indicated documentation of the patients' problems on the Problem List-Nursing using a nursing diagnosis (Question 1);

2. used Roman numerals to identify each problem (Question 2);

3. identified in the nursing diagnosis a problem that may be treated through nursing intervention (Question 3);

4. provided evidence of new problems being documented within three days of admission (Question 5); and

5. provided evidence of the patient's problems having been resolved within five days of admission (Question 6).

A cross-tabulation of percent completed of each question of the Progress Notes is illustrated in Table XIX. There was no significant difference among the arenas on this form.

A cross-tabulation of percent completed on the Flow Sheet is illustrated in Table XX. A significant difference was noted between arenas; the statistical hypothesis was rejected. The Medical-Surgical arena had the lowest percent completion on this form. 
TABLE XIX

FOR EACH ITEM ON THE PROGRESS NOTES, PERCENT COMPLETED BY CLINICAL ARENA, CALCULATED CHI-SQUARE, AND PROBABILITY

\begin{tabular}{|c|c|c|c|c|c|c|c|c|c|}
\hline \multirow{2}{*}{\multicolumn{2}{|c|}{ Question }} & \multicolumn{2}{|c|}{$\begin{array}{l}\text { Critical } \\
\text { Care }\end{array}$} & \multicolumn{2}{|c|}{$\begin{array}{l}\begin{array}{l}\text { Medical- } \\
\text { Surgtcal }\end{array} \\
\text { Percent }\end{array}$} & \multicolumn{2}{|c|}{$\frac{\begin{array}{c}\text { Maternal- } \\
\text { Child }\end{array}}{\text { Percent }}$} & \multirow{2}{*}{$\begin{array}{l}\text { Calculated } \\
\text { Chi-Square }\end{array}$} & \multirow[b]{2}{*}{ Probability } \\
\hline & & Yes & No & Yes & No & Yes & No & & \\
\hline 1. & $\begin{array}{l}\text { Are dates and specific tines } \\
\text { indicated with comments for each } \\
\text { shift, followed by signatures } \\
\text { with titles? }\end{array}$ & 97.5 & 2.5 & 99.2 & 0.8 & 98.8 & 1.2 & 0.69530 & .7063 \\
\hline 2. & $\begin{array}{l}\text { Are pertinent observations and } \\
\text { communications recorded using } \\
\text { SOAP format? }\end{array}$ & 100.0 & & 98.3 & 1.7 & 98.8 & 1.2 & 0.69530 & .7063 \\
\hline 3. & $\begin{array}{l}\text { Are nursing interventions } \\
\text { recorded accurately? }\end{array}$ & 97.5 & 2.5 & 99.2 & 0.8 & 98.8 & 1.2 & 0.69530 & .7063 \\
\hline 5. & $\begin{array}{l}\text { Is there evidence that the } \\
\text { effectiveness of care has been } \\
\text { evaluated by day } 15 \text { after } \\
\text { admission by the consistent } \\
\text { reading of one or two itens? }\end{array}$ & 73.9 & 26.1 & 72.0 & 28.0 & 91.3 & 8.7 & 3.49542 & .1742 \\
\hline & $\begin{array}{l}\text { Is there documentation of discharge } \\
\text { planning for the patient when } \\
\text { necessary? }\end{array}$ & 53.3 & 46.7 & 61.6 & 33.4 & 74.1 & 25.9 & 4. 28800 & .1172 \\
\hline
\end{tabular}


TABLE $X X$

PERCENT COHALETED BY CLINICAL ARENA, CALCULATED CHI-SQUARE, AND

ASSOCIATED PROBABILITY ON THE FLOH SHEET

\begin{tabular}{|c|c|c|c|c|c|c|c|c|}
\hline \multirow[b]{3}{*}{ Question } & \multirow{2}{*}{\multicolumn{2}{|c|}{$\begin{array}{l}\text { Critical } \\
\text { Care }\end{array}$}} & \multirow{2}{*}{\multicolumn{2}{|c|}{$\frac{\begin{array}{l}\text { Medical- } \\
\text { Surgical }\end{array}}{\text { Percent }}$}} & \multirow{2}{*}{\multicolumn{2}{|c|}{$\frac{\begin{array}{c}\text { Maternal- } \\
\text { Child }\end{array}}{\text { Percent }}$}} & \multirow{3}{*}{$\begin{array}{l}\text { Calculated } \\
\text { Chi-Square }\end{array}$} & \multirow[b]{3}{*}{ Probability } \\
\hline & & & & & & & & \\
\hline & Yes & No & Yes & No & Yes & No & & \\
\hline $\begin{array}{l}\text { Is there documentation of one or two } \\
\text { items flowing from the plan on this } \\
\text { sheet? }\end{array}$ & 85.0 & 15.0 & 63.8 & 36.2 & 89.5 & 10.5 & 20.12190 & $.0000^{\star}$ \\
\hline
\end{tabular}

* Significant at the .05 level 
RELATIONSHIP BETWEEN TYPE OF NURSING EDUCATION AND NURSING PROCESS

Is the type of nursing educational preparation related to knowledge and effectiveness in the use of the nursing process? The levels of the independent variable which were used in addressing this question were BSN, ADN, DIP, and LPN. For the total sample, the following dependent variables were examined: pre-test, post-test, and self-perceived level of understanding. For the audit sample, the following dependent variables were examined: pre-test, post-test, common-items on the posttest, understanding, and percent completion. The results for the two samples are reported below.

\section{Total Sample}

Analyses of variance were performed on the type of nursing education, using pre-test, post-test, and understanding as the dependent variables.

The means and standard deviations for type of nursing education of the four groups were computed for the total sample, using the pre-test, post-test and understanding scores as variables. This material is presented in Table XXI. The means on the pre-test ranged from 8.4 (LPN) to 10.3 (BSN). For the post-test, the range was 17.4 (LPN) to 19.5 $(A D N)$. The sum of squares, degrees of freedom, and mean squares for the between- and within-groups are shown in Table XXII.

As a result of the analysis of variance of the pre-test scores, the statistical hypothesis that all population means are equal was not rejected at the .05 level of confidence $(E=1.49 ; p<.22)$. 
TABLE XXI

MEANS AND STANDARD DEVIATIONS FOR TYPE OF NURSING EDUCATION: TOTAL SAMPLE $(n=102)$

\begin{tabular}{llrr}
\hline Variabie & Group & Mean & $\begin{array}{r}\text { Standard } \\
\text { Deviation }\end{array}$ \\
\hline Pre-test & LPN & 8.4286 & 0.9759 \\
& ADN & 9.6154 & 2.6618 \\
& DIP & 9.7000 & 1.4546 \\
Post-test & BSN & 10.2778 & 2.3004 \\
& LPN & 17.4286 & 1.5119 \\
& ADN & 19.4615 & 3.8378 \\
& DIP & 18.5500 & 2.1879 \\
Understanding & BSN & 19.1667 & 5.0398 \\
& LPN & 3.2857 & 1.1127 \\
& ADN & 2.9744 & 1.0384 \\
& DIP & 3.4000 & 1.2732 \\
& BSN & 3.8056 & 0.7863 \\
\hline
\end{tabular}




\section{TABLE XXII}

ANALYSES OF VARIANCE ON TYPE OF NURSING EDUCATION WITH

ACHIEVEMENT AND UNDERSTANDING AS THE

DEPENDENT VARIABLES FOR TOTAL SAMPLE

$(n=102)$

\begin{tabular}{|c|c|c|c|c|c|c|c|c|}
\hline Variable & $S S_{b}$ & $\mathrm{DF}_{\mathrm{b}}$ & $M S_{b}$ & $\mathrm{SS}_{\mathrm{w}}$ & $\mathrm{DF}_{\mathrm{w}}$ & $M S_{W}$ & $\underline{F}$ & $\underline{p}$ \\
\hline Pre-test & 22.89 & 3 & 7.63 & 500.37 & 98 & 5.11 & 1.494 & .221 \\
\hline Post-test & 30.49 & 3 & 10.16 & 1553.36 & 98 & 15.85 & 0.641 & .590 \\
\hline Understanding & 13.00 & 3 & 4.33 & 100.84 & 98 & 1.03 & 4.212 & $.008^{\star}$ \\
\hline $\begin{array}{l}\text { Post-test with } \\
\text { pre-test as } \\
\text { covariant }\end{array}$ & 20.93 & 3 & 6.98 & 1146.37 & 97 & 11.82 & 0.590 & .623 \\
\hline
\end{tabular}

* Rejected at the .05 leve 1

** The covariate was significant $(\underline{F}=35.25 ; \underline{p}=.000)$ 
As a result of the analysis of variance of the post-test scores, the statistical hypothesis that all population means are equal was not rejected at the .05 level of confidence $(\underline{F}=0.64 ; p=.59)$. However, the covariate in the analysis of variance and covariance was significant at the .05 level of confidence $(\underline{F}=35.25 ; \underline{p}<.01)$. As a result, an analysis of variance of the adjusted post-test scores was performed. The statistical hypothesis that all population means are equal was not rejected $(E=0.59 ; p=.63)$.

As a result of the analysis of variance of the self-perceived understanding ratings, the statistical hypothesis that all population means are equal was rejected at the .05 level $(F=4.21 ; p<.01)$. Using the Scheffé test for all pair-wise mean comparisons, the statistical hypothesis that the means for the ADN's and BSN's are equal $\left(H_{0}: \mu_{1}=\mu_{4}\right)$ was rejected. The mean for the BSN's was significantly greater than the mean for the ADN's.

Audit Sample

The means and standard deviations for type of nursing education for the four groups were computed for the audited sample using the pretest, post-test cominon, post-test scores, understanding, and percent complete as dependent variables. These results are presented in Table XXIII. On the pre-test, the mean for the audited sample ranged from 8.3 (LPN) to 10.8 (BSN). On the post-test items which were used as a pretest, the means ranged from 9.2 (LPN) to 11.2 (BSN). On the post-test, the means ranged from 17.2 (LPN) to 20.3 (BSN). On the selfunderstanding question, the means ranged from 3.1 (ADN) to 3.7 (BSN). 
Analyses of variance were performed on the type of nursing educational preparation using pre-test, post-test, change scores (from pre-test to common-items, post-test), understanding, and percent completion as dependent variables. The sums of squares, degrees of freedom, and mean squares for the between- and within-groups are shown in Table XXIV.

TABLE XXIII

MEANS AND STANDARD DEVIATIONS FOR TYPE OF NURSING EDUCATION AUDITED SAMPLE $(N=82)$

\begin{tabular}{lccc}
\hline Variable & Group & Mean & $\begin{array}{c}\text { Standard } \\
\text { Deviation }\end{array}$ \\
\hline Pre-test & LPN & 8.3333 & 1.0328 \\
& ADN & 9.9706 & 2.1530 \\
& DIP & 9.8000 & 1.4736 \\
Post-test Common & BSN & 10.7778 & 1.4763 \\
& LPN & 9.1667 & 2.1370 \\
& ADN & 11.1471 & 1.3514 \\
Post-test & DIP & 10.2667 & 1.6676 \\
& BSN & 11.1852 & 1.4421 \\
& LPN & 17.1667 & 1.4720 \\
& ADN & 20.0294 & 2.0668 \\
Percent Complete & DIP & 18.6000 & 1.9198 \\
& BSN & 20.2593 & 1.8932 \\
& LPN & & \\
& ADN & 91.0000 & 7.3756 \\
& DIP & 78.2647 & 16.3064 \\
& BSN & 81.5333 & 12.8222 \\
& Understanding & 75.7778 & 14.4284 \\
& LPN & 3.6667 & 0.5164 \\
& ADN & 3.0882 & 0.9001 \\
& DIP & 3.3333 & 1.2910 \\
& BSN & 3.7407 & 0.8590 \\
& & & \\
\hline
\end{tabular}




\section{TABLE XXIV}

ANALYSES OF VARIANCE ON TYPE OF NURSING EDUCATION AUDITED SAMPLE

$(n=82)$

\begin{tabular}{|c|c|c|c|c|c|c|c|c|}
\hline Variable & $S S_{b}$ & $\mathrm{DF}_{\mathrm{b}}$ & $M S_{b}$ & $S S_{W}$ & $D F_{W}$ & $M S_{W}$ & $\underline{F}$ & $\underline{P}$ \\
\hline Pre-test & 33.03 & 3 & 11.01 & 245.37 & 78 & 3.15 & 3.500 & $.019^{\star}$ \\
\hline Post-test & 68.44 & 3 & 22.81 & 296.59 & 78 & 3.80 & 5.999 & $.001^{\star}$ \\
\hline $\begin{array}{l}\text { Change Scores } \\
\text { on Common Items }\end{array}$ & 10.57 & 3 & 3.52 & 368.03 & 78 & 4.72 & 0.747 & .527 \\
\hline $\begin{array}{l}\text { \% Complete } \\
\text { on Audit }\end{array}$ & 1258.93 & 3 & 419.64 & 16761.02 & 78 & 214.88 & 1.953 & .128 \\
\hline Understanding & 6.93 & 3 & 2.31 & 70.59 & 78 & 0.905 & 2.551 & .062 \\
\hline
\end{tabular}


As a result of the analysis of the pre-test scores, the statistical hypothesis that all populations means are equal was rejected at the .05 level of confidence $(\underline{F}=3.50 ; P<.02)$. Using a Scheffé test for all pair-wise mean comparisons, one statistical hypothesis was rejected at the .05 level of confidence $\left(H_{0}: \mu_{1}=\mu_{4}\right)$. The pre-test mean for LPN was significantly lower than the mean for BSN.

As a result of the analysis of the post-test scores, the statistical hypothesis that all population means are equal was rejected at the .05 level of confidence $(\underline{F}=6.00 ; \underline{p}<.01)$. Using a Scheffé test for all pair-wise mean comparisons, two statistical hypotheses were rejected at the .05 level of confidence $\left(H_{0}: \mu_{1}=\mu_{2} ; H_{0}: \mu_{1}=\mu_{4}\right)$. The post-test mean for LPN was significantly less than for ADN's and BSN's.

As a result of the analysis of variance of the change scores, the statistical hypothesis that all population means are equal was not rejected at the .05 level of confidence $(\underline{F}=0.75 ; p<.53)$.

As a result of the analysis of variance of the percent complete on audit, the statistical hypothesis that all population means are equal was not rejected at the .05 level of confidence $(\underline{F}=1.95 ; p<.13)$. As a result of the analysis of variance of the understanding scores, the statistical hypothesis that all population means are equal was not rejected at the .05 level of confidence $(\underline{F}=2.55 ; p<.07)$.

RELATIONSHIP BETWEEN AGE AND KNOWLEDGE AND USE OF NURSING PROCESS

Is age related to knowledge of and effectiveness in the use of the nursing process? The levels of the independent variable which were used 
in addressing this question were: Over 44, $35-44,25-34$, and Less 25. For the total sample, the following dependent variables were examined: pre-test, post-test, understanding, and post-test with pretest as covariate. For the audit sample, the following dependent variables were examined: change scores and percent correct on audit. The results for both are reported below.

\section{Total Sample}

The means and standard deviations partitioned by age groups are presented in Table XXV for the pre-test, post-test, and understanding variables for the total sample. The pre-test means on age ranged from 8.6 (Over 44) to 11.4 (Under 25). The post-test means on age ranged from 15.4 (Over 44) to 21.8 (Under 25). For understanding, the means on age ranged from 2.9 (Over 44) to 3.6 (Under 25; 35-44).

Analyses of variance were performed on age groupings using pretest, post-test, understanding, and post-test with pre-test as covariate. The sums of squares, degrees of freedom, and mean squares for the between- and within-groups are shown in Table XXVI.

As a result of analysis of variance of the pre-test scores, the statistical hypothesis that all population means are equal was not rejected at the .05 level of confidence $(\underline{F}=2.16 ; p<.98)$.

As a result of analysis of variance of the post-test scores, the statistical hypothesis that all population means are equal was rejected at the .05 level of confidence $(\underline{F}=5.90 ; \underline{P}<.01)$. Using a Scheffé test for all pair-wise mean comparisons, two statistical hypotheses were rejected at the .05 level of confidence $\left(H_{0}: \mu_{1}=\mu_{4} ; H_{0}: \mu_{2}=\mu_{4}\right)$. The 
TABLE XXV

MEANS AND STANDARD DEVIATIONS ON THE PRE-TEST, POST-TEST, AND UNDERSTANDING SCORES PARTITIONED BY AGE

$(n=102)$

\begin{tabular}{|c|c|c|c|c|c|c|c|}
\hline \multirow{2}{*}{\multicolumn{2}{|c|}{ Group N }} & \multicolumn{3}{|c|}{ Means } & \multicolumn{3}{|c|}{ Standard Deviations } \\
\hline & & $\begin{array}{l}\text { Pre- } \\
\text { test }\end{array}$ & $\begin{array}{l}\text { Post- } \\
\text { test }\end{array}$ & $\begin{array}{l}\text { Under- } \\
\text { standing }\end{array}$ & $\begin{array}{l}\text { Pre- } \\
\text { test }\end{array}$ & $\begin{array}{l}\text { Post- } \\
\text { test }\end{array}$ & $\begin{array}{l}\text { Under- } \\
\text { standing }\end{array}$ \\
\hline Less 25 & 5 & 11.4000 & 21.8000 & 3.6000 & 1.3416 & 0.4472 & 1.1402 \\
\hline $25-34$ & 15 & 9.9118 & 19.6029 & 3.3971 & 2.1492 & 3.0378 & 1.0529 \\
\hline $35-44$ & 68 & 9.7333 & 18.9333 & 3.6000 & 2.2190 & 2.6851 & 0.9103 \\
\hline Over 44 & 14 & 8.6429 & 15.4286 & 2.9286 & 2.8449 & 6.9139 & 1.2067 \\
\hline
\end{tabular}




\section{TABLE $X X V I$}

ANALYSES OF VARIANCE FOR THE TOTAL SAMPLE ON AGE WITH ACHIEVEMENT AND UNDERSTANDING AS DEPENDENT VARIABLES

$$
(n=102)
$$

\begin{tabular}{|c|c|c|c|c|c|c|c|c|}
\hline Variable & $s S_{b}$ & $\mathrm{DF}_{\mathrm{b}}$ & $M S_{b}$ & $\mathrm{SS}_{\mathrm{W}}$ & $D F_{W}$ & $M S_{W}$ & $\underline{F}$ & $\underline{p}$ \\
\hline Pre-test & 32.44 & 3 & 10.81 & 490.82 & 98 & 5.008 & 2.159 & .0978 \\
\hline Post-test & 242.40 & 3 & 80.80 & 1341.44 & 98 & 13.688 & 5.903 & $.0010^{\star}$ \\
\hline Understanding & 3.84 & 3 & 1.28 & 110.01 & 98 & 1.123 & 1.139 & .3373 \\
\hline $\begin{array}{l}\text { Post-test with } \\
\text { pre-test as } \\
\text { covariant }\end{array}$ & 123.00 & 3 & 41.00 & 1044.30 & 97 & 10.766 & 3.808 & $.0130^{\star}$ \\
\hline
\end{tabular}

* Rejected at the .05 level

** The covariate was significant $(\underline{F}=38.691 ; \mathrm{p}<.0001)$ 
mean for Group 4 (Over 44) was lower than the means for Group 1 (Less 25) and Group $2(25-34)$.

The covariate in the analysis of variance and covariance was significant at the .05 level of confidence $(\underline{F}=38.69 ; p<.01)$. As a result, an analysis of variance of the adjusted post-test scores was performed. The statistical hypothesis that all population means are equal was again rejected at the .05 level of confidence $(\underline{F}=3.81$; $\mathrm{p}<.02)$.

The Scheffe test was used in pair-wise mean comparisons of adjusted means, with the confidence level set at .05 . None of the six statistical hypotheses was rejected. No significant difference was found among the pair-wise mean comparisons of adjusted means.

\section{Audit Sample}

For the audit sample, two dependent variables were examined for age differences: change scores and percent complete on audit. As a result of the analysis of variance of the change scores, the statistical hypothesis that all population means are equal was not rejected at the .05 level of confidence $(\underline{F}=.047 ; p<.71)$.

As a result of the analysis of variance of the percent complete on audit, the statistical hypothes is that all population means are equal was not rejected at the .05 level of confidence $(F=0.58 ; p<.64)$. These results are contained in Table XXVII. Since neither analys is produced significant differences, the means and standard deviations are not presented. 


\section{TABLE XXVII}
ANALYSIS OF VARIANCE FOR THE AUDITED SAMPLE ON AGE WITH ACHIEVEMENT TESTS CHANGE SCORES AND PERCENT COMPLETE ON AUDITS AS DEPENDENT VARIABLES
$(n=82)$

\begin{tabular}{lccccc}
\hline Source & $\begin{array}{l}\text { Sum of } \\
\text { Squares }\end{array}$ & df & $\begin{array}{c}\text { Mean } \\
\text { Squares }\end{array}$ & $F$ & $P$ \\
\hline Between & 6.77 & 3 & 2.26 & 0.473 & .702 \\
Within & 371.83 & 78 & 4.77 & & \\
Total & 378.60 & 81 & & & \\
\hline Change Scores & & & \\
\hline Between & 391.24 & 3 & 130.41 & 0.577 \\
Within & 17628.71 & 78 & 226.01 & \\
\hline
\end{tabular}


RELATIONSHIP BETWEEN EXPERIENCE AND KNOWLEDGE AND USE OF NURSING PROCESS

Is experience related to the knowledge of and effectiveness in the use of the nursing process? The levels of the independent variable which were used in addressing this question were: Over 10 years, $6-10$ Years, and Less than 6 Years. For the total sample, the following dependent variables were examined: pre-test, post-test, understanding, and post-test with pre-test as covariate. For the audit sample, the following dependent variables were examined: change scores and percent correct on audit. The results for both samples are reported in this section.

\section{Total Sample}

The means and standard deviations for levels of experience of the total sample are presented in Table XXVIII. The pre-test mean ranged from 8.9 (Over 10 Years) to 10.2 (Under 6 Years); the post-test means ranged from 17.1 (Over 10 Years) to 20.3 (Under 6 Years); and the understanding means ranged from 3.1 (Over 10 Years) to 3.5 (6 - 10 Years).

Analyses of variance were performed on experience in nursing practice using pre-test, post-test, understanding, and post-test with pre-test as covariate as dependent variables. The sums of squares, degrees of freedom, and mean squares for the between- and within-groups are shown in Table XXIX. 
TABLE XXVIII

MEANS AND STANDARD DEVIATIONS ON THE PRE-TEST, POST-TEST, AND UNDERSTANDING SCORES FOR THE TOTAL SAMPLE PARTITIONED BY EXPERIENCE

$(n=102)$

\begin{tabular}{|c|c|c|c|c|c|c|c|}
\hline \multirow[b]{2}{*}{ Group } & \multirow[b]{2}{*}{$N$} & \multicolumn{3}{|c|}{ Means } & \multicolumn{3}{|c|}{ Standard Deviations } \\
\hline & & $\begin{array}{l}\text { Pre- } \\
\text { test }\end{array}$ & $\begin{array}{l}\text { Post } \\
\text { test }\end{array}$ & $\begin{array}{l}\text { Under- } \\
\text { standing }\end{array}$ & $\begin{array}{l}\text { Pre- } \\
\text { test }\end{array}$ & $\begin{array}{l}\text { Post- } \\
\text { test }\end{array}$ & $\begin{array}{l}\text { Under- } \\
\text { standing }\end{array}$ \\
\hline Less 6 & 53 & 10.19 & 20.34 & 3.40 & 1.98 & 1.6165 & 1.06 \\
\hline $6-10$ & 31 & 9.58 & 17.93 & 3.52 & 2.43 & 5.21 & 1.00 \\
\hline Over 10 & 18 & 8.94 & 17.11 & 3.06 & 2.65 & 5.07 & 1.16 \\
\hline
\end{tabular}




\section{TABLE XXIX}

ANALYSIS OF VARIANCE FOR THE TOTAL SAMPLE ON EXPERIENCE

WITH ACHIEVEMENT AND UNDERSTANDING AS

DEPENDENT VARIABLES

$(n=102)$

\begin{tabular}{|c|c|c|c|c|c|c|c|c|}
\hline Variable & $s S_{b}$ & $D F_{b}$ & $M S_{b}$ & $S S_{W}$ & $\mathrm{DF}_{\mathrm{W}}$ & $M S_{W}$ & $\underline{F}$ & $\underline{p}$ \\
\hline Pre-test & 22.65 & 2 & 11.32 & 500.606 & 99 & 5.06 & 2.240 & .1119 \\
\hline Post-test & 194.31 & 2 & 97.15 & 1389.536 & 99 & 14.04 & 6.922 & $.0015^{\star}$ \\
\hline Understanding & 2.48 & 2 & 1.24 & 111.366 & 99 & 1.12 & 1.101 & .3365 \\
\hline $\begin{array}{l}\text { Post-test with } \\
\text { pre-test as } \\
\text { covariant }\end{array}$ & 101.99 & 2 & 50.99 & 1065.310 & 98 & 10.87 & 4.691 & $.0110^{\star}$ \\
\hline
\end{tabular}

* Rejected at the .05 level

** The covariate was significant $(\underline{F}=38.319 ; \mathrm{p}<0.000)$ 
As a result of the analysis of variance of the pre-test scores, the statistical hypothesis that all population means are equal was not rejected at the .05 level of confidence $(\underline{F}=2.24 ; \underline{p}<.12)$.

As a result of the analysis of variance of the post-test scores, the statistical hypothesis that all population means are equal was rejected at the .05 level of confidence $(\underline{F}=6.92 ; \underline{p}<.01)$. Following the analysis of variance, a Scheffé test was applied to all pair-wise mean comparisons using a .05 level of confidence for each comparison. Two statistical hypotheses were rejected: $\left(H_{0}: \mu_{1}=\mu_{2} ; H_{0}: \mu_{1}=\mu_{3}\right)$. Group 1 (Less than 6 Years) had a significantly greater mean than either Group 2 ( 6 - 10 Years) or Group 3 (Over 10 Years).

The covariate in the analys is of variance and covariance was significant at the .05 level of confidence $(\underline{F}=38.32 ; p<.01)$. As a result, an analysis of variance of the adjusted post-test scores was performed. The statistical hypothesis that all population means are equal was rejected at the .05 level of confidence $(F=4.69 ; p<.02)$.

The Scheffé test was performed at the .05 level of confidence on all pair-wise mean comparisons of adjusted means. For these comparisons, the critical value of $\underline{F}$ was 5.42 . The statistical hypothesis that $\mu_{3}=\mu_{2}$ (for the Over 10 Years of Experience and the 6 - 10 Years of Experience groups, respectively) was not rejected ( $\underline{F}=$ 0.1022 ). The statistical hypothesis that $\mu_{3}=\mu_{1}$ (for the Over 10 Years of Experience and the Under 6 Years of Experience groups, respectively) was rejected $(\underline{F}=6.13)$; the adjusted mean for the Over 10 Years group (17.79) was less than the adjusted mean for the Under 6 Years group 
(20.01). The statistical hypothes is that $\mu_{2}=\mu_{1}(6-10$ Years versus Less than 6 Years) was rejected $(\underline{F}=6.50)$; the adjusted mean for the 6

- 10 Years group (18.10) was less than the adjusted mean for the Under 6 Years group (20.01).

As a result of the analysis of variance of the Understanding scores, the statistical hypothes is that all population means are equal was not rejected at the .05 level of confidence $(E=1.10 ; p<.34)$.

\section{Audit Sample}

For the audit sample, two dependent variables were examined for experience differences: change scores and percent complete. As a result of the analysis of variance of the change scores, the statistical hypothesis that all population means are equal was not rejected at the .05 level of confidence $(\underline{F}=0.33 ; p<.72)$. As a result of the analysis of variance of the percent complete on audit, the statistical hypothesis that all population means are equal was not rejected at the .05 level of confidence $(\underline{F}=0.21 ; p<.82)$, as shown in Table $X X X$. Since neither analysis produced significant differences, the means and standard deviations are not presented. 
TABLE $X X X$

ANALYSIS OF VARIANCE FOR THE AUDITED SAMPLE ON EXPERIENCE, WITH ACHIEVEMENT CHANGE SCORE AND PERCENT COMPLETE ON AUDITS AS DEPENDENT VARIABLES

$$
(n=82)
$$

\begin{tabular}{|c|c|c|c|c|c|}
\hline Source & $\begin{array}{l}\text { Sum of } \\
\text { Squares }\end{array}$ & $d f$ & $\begin{array}{l}\text { Mean } \\
\text { Squares }\end{array}$ & $\mathrm{F}$ & $\mathrm{P}$ \\
\hline \multicolumn{6}{|c|}{ Change Scores } \\
\hline Between & 3.1680 & 2 & 1.5840 & 0.3330 & .7175 \\
\hline Write in & 375.4295 & 79 & 4.7523 & & \\
\hline Total & 378.5976 & 81 & & & \\
\hline \multicolumn{6}{|c|}{ Percent Complete } \\
\hline Between & 95.0490 & 2 & 47.5245 & 0.209 & .8115 \\
\hline Write in & 17924.9022 & 79 & 226.8975 & & \\
\hline Total & 18019.9512 & 81 & & & \\
\hline
\end{tabular}




\section{CHAPTER $V$ \\ SUMMARY, CONCLUSIONS, AND RECOMMENDATIONS \\ FOR FURTHER STUDY}

SUMMARY

Introduction

Nursing process is a term used to describe the thoughts and resultant behaviors that nurses use in the delivery of nursing care to patients. It is the communication process involving the nurse and the patient. It is dynamic and interactional. Each nurse performs the nursing process differently; background, experience, schooling, knowledge, values, and goals act together to develop a nurse's style. Each patient the nurse encounters is different, and the application of the nursing process must be tailored to meet the needs of the individual style of the nurse providing the nursing care (Yura and Walsh, 1973). Nursing process is the framework for nursing practice, the model of practice for the professional nurse. However, review of the literature has shown that nursing process is generally unused or ineffectively used in hospitals.

Problem

It was found, in an acute care hospital in Portland, Oregon, that the registered nurses on the staff were not in compliance with existing departmental philosophy, policies, and procedures relative to 
utilization and documentation of use of the nursing process as a basis of nursing care given to patients. The nurses were seemingly either deficit in the concepts of nursing process, or, if they understood, were unable to operationalize the process (Johnson, 1982). Therefore, the researcher, in conjunction with other members of the nursing management team, developed and implemented an inservice training program for all staff nurses. The forms used in the patients' charts to document nursing care given from the time of admission to discharge from the hospital were the focal points of the curriculum development. Nursing process theory and procedures for proper application of theory to practice were the other portion of the curriculum.

Purpose of the Study

Basically, this study was intended to address the following research questions:

1. Does the current training process used at Bess Kaiser Medical Center teach newly-employed staff nurses to transfer nursing process theory to practice?

2. Do the newly-employed staff nurses apply and document the nursing process in patients' charts?

3. What is the compliance of the total nursing staff with the requirement that they apply and document the nursing process in patients' charts?

A second component of this study, presented in tabular comparisons, is the analysis of data from the samples to determine the extent to which the following three variables relate to knowledge of and 
effectiveness in the use of the nursing process: type of nursing preparation, age, and experience. Each of these variables was tested for its impact on the following set of questions:

1. Do nurses differ in their knowledge of the nursing process prior to the beginning of in-service training?

2. Do nurses differ in their knowledge of the nursing process upon completion of in-service training?

3. Do nurses differ in their change scores on common items from pre-test to post-test?

4. Do nurses differ in their perceptions of their understanding of the nursing process?

5. Do nurses differ in their compliance with nursing process directives as determined by chart audits?

The Sample

The total sample of newly-employed nurses $(n=102)$ was partitioned into two subsamples: the audit sample $(n=82)$, and those whose job assignments did not permit auditing patients' charts for compliance with nursing process procedures $(n=20)$. All nurse participants attended one of the four-hour nursing process classes taught by the researcher.

The sample was comprised of 95 registered nurses, 39 with Associate Degrees in Nursing, 20 with Diplomas in Nursing, 36 with Baccalaureate Degrees in Nursing, and 7 Licensed Practical Nurses. The ages of the participants were divided into four groups: 14 were over 44 years, 15 were in the 35-44 age group, 68 were in the 25-34 age group, and 5 were under 25 years of age. Nursing experiences of the group ranged from 18 
who had more than 10 years of nursing experience, 31 who had $6-10$ years of nursing experience, and 53 who had less than six years of nursing experience. All the nurses had been hired to work in all three of the major clinical arenas: Medical/Surgical, Maternal/Child, and Critical Care. The sample contained four nurses hired for management positions.

\section{Instrument Construction}

Four instruments were constructed. The auditing tool was designed specifically for this study. Construction of the tool was based on the four forms designed to facilitate the use and documentation of the nursing process by staff nurses. The Characteristics of Nurse Sample form was designed to supply specific demographic data about each nurse and attitudinal responses relative to how the nurse perceived the nursing process as a model for nursing care. Finally, the pre-test and post-test were constructed as evaluative components of the inservice training program; they contained questions for both theoretical and operational nursing application.

\section{Methodology}

All participants attended one of the nursing process workshops designed to teach the basic principles of the nursing process, to acquaint nurses with nursing process procedures and forms used in the hospital, and to help nurses understand the importance of nursing process in patient care. Each participant was administered a Characteristics of Nurse Sample form and a pre-test at the beginning of 
the class and a post-test at the end. For the audit sample of nurses, an audit was performed four weeks after completion of the nursing process class for each nurse in the sample.

The auditor examined three patient charts that contained documentation by the nurses who had responsibility for those charts (total staff nurses) and for completeness by the audit sample nurses of those items which they should have completed. The data yielded the following measures: (1) pre-test, post-test, and perceived understanding scores for all nurse participants and the audit sample; (2) post-test common scores (items of the post-test which comprise the pre-test), difference scores (between the pre-test and the post-test), and percent of appropriate entries completed as determined by the chart audits for the audit sample; and (3) for each item on the audit forms, the number of completed entries on the audited-patient charts as a measure of total nursing staff compliance with the directives concerning nursing process.

Means and standard deviations were calculated on the pre-test, post-test, and understanding variables for the total participating sample and for the audit sample. Means and standard deviations were calculated for the post-test common scores and the percent complete measures of the audit sample. For each calculated mean, a 95\% confidence interval was constructed. A related samples t-test was used to test the significance of the differences between the pre-test mean and the common-items post-test mean.

For each item on the four audit forms, the percent of the total 
number of audited charts which had completed entries was calculated. A 95\% confidence interval for the population percent was then calculated for each of the item percents. Crosstabulation and chi-square by clinical arena were performed on each item of the four forms, using an alpha level of .05 for each statistical test.

For each type of nursing education, means and standard deviations for the total participant sample and the audit sample were computed on the pre-test, post-test, and understanding scores. For each sample, an analysis of variance, followed by Scheffé's test (when appropriate), was performed on each dependent variable.

For the audit sample only, the above procedure was used with two additional dependent variables: post-test common and percent complete. In addition, analysis of variance and covariance was performed on the 1 post-test scores of the total sample, using the pre-test as a covariate. For the audit sample, an analysis of variance was performed on the change scores.

The procedure discussed in the previous paragraph was replicated for the total sample, using age and experience as independent variables. For the audit sample, an analysis of variance was performed on two dependent variables (change scores and percent complete), using age and experience as independent variables.

Results

For the total participating sample, the pre-test mean was 9.78 , the post-test mean was 19.04 , and the understanding mean was 3.37 ; for the 
audit sample, the means were $10.09,10.85$, and 3.39 , respectively. The statistical hypothesis that the pre-test and common-items post-test population means are equal was rejected $(\underline{t}=3.22, \underline{p}<.01)$; for the audit sample, the common-items post-test mean was greater than the pretest mean. For the audit sample, the percent of completion of appropriate items on the nursing process forms was 78.98 .

Percent completed for the total nursing staff on the items of the Nursing Assessment form ranged from a low of 52.0 on "Is all information filled in?" to a high of 91.5 on "Is there evidence that the patient's immediate needs were assessed by a Registered Nurse?" The percent complete on the items of the Problem List-Nursing ranged from a low of 4.3 on "Is there evidence that problems have been resolved?" to a high of 53.5 on "Does each problem have a Roman numeral as a designator?" percent completed for the Patient Progress Notes ranged from a low of 64.6 on "Is there documentation of discharge planning for the patient when necessary?" to a high of 98.8 on the first three items ("Are dates and specific times indicated with comments for each shift, followed by signatures with titles?" "Are pertinent observations and communications recorded using S.O.A.P. format?" and "Are nursing interventions recorded accurately?"). On 76.4 percent of the charts, there was evidence of "documentation of one or two items flowing from the plan on this sheet," the one question on the Flow Sheet.

The percent completed on each item of each form was calculated for each clinical arena. On the Nursing Assessment form, the percent completed ranged from 52.5 to 90.0 for the Critical Care nurses, from 
47.5 to 90.8 for the Medical/Surgical nurses, and from 58.1 to 93.0 for Maternal/Child nurses. For each group, the low completion item was "Is all information filled in?" and the high completion item was "Is there evidence that the patient's immediate needs were assessed by an RN?" The onty significant difference among the groups on this form was on Item 6 ("Are there goals specified on the initial assessment sheet?"), with Medical/Surgical having the lowest percent (63.3) and Maternal/Child having the highest percent (80.2).

On the Problem List-Nursing, the percent completed ranged from 2.6 to 46.2 for Critical Care nurses, from 3.6 to 41.7 for Medical/Surgical nurses, and from 6.2 to 78.6 for Maternal/Child nurses. For all three groups, the smallest percent completion was on Item 4 ("Is there documented evidence that problems have been resolved?"). For the Critical Care nurses, the greatest compliance was on Item 1 ("Is there documentation of the patient's problems on the Problem List-Nursing using a nursing diagnosis?"); for the other two arenas, the greatest compliance was on Item 2 ("Does each problem have a Roman numeral as a designator?").

Significant differences among arenas were found on five items: "Is there documentation of the patient's problems on the Problem ListNursing using a nursing diagnosis?", with the Maternal/Child arena having the highest percent (56.0) and the Medical/Surgical having the lowest (29.2); "Does each problem have a Roman numeral as a designator?", with the Maternal/Child arena having the highest percent (78.6) and the Critical Care arena having the lowest (35.9); "Is a 
nursing diagnosis a statement of a problem that may be treated through nursing intervention?", with the Maternal/Child arena having the highest percent (45.2) and Medical/Surgical having the lowest (23.3); "Is there evidence of new problems being documented 3 days after the admission of the patient?", with the Maternal/Child arena having the highest percent (31.4) and the other two arenas being about the same (approximately $12 \%)$; and "Is there evidence of the patient's problems being resolved 5 days after admission?", with a $28.6 \%$ compliance for the Maternal/Child arena and $3.4 \%$ for the Critical Care arena.

On the Progress Notes form, the percent completed ranged from 53.3 to 100 for the Critical Care arena, from 61.6 to 99.2 for the Medical/Surgical arena, and from 74.1 to 98.8 for the Maternal/Child arena. For each arena, the lowest percent compliance was "Is there documentation of discharge planning for the patient when necessary?" Although the order varied across arenas, the percents were above 97 for all these groups on the first three items ("Are dates and specific times indicated with comments for each shift, followed by signatures with titles?" "Are pertinent observations and communications recorded using S.0.A.P. format?" and "Are nursing interventions recorded accurately?"). No significant differences by arena were found on the items on this form.

The arenas differed significantly in their "documentation of one or two items flowing from the plan on this sheet" (Flow Sheet), with an $89.5 \%$ compliance by Maternal/child, an $86.5 \%$ compliance by Critical Care nurses, and a $63.8 \%$ compliance by Medical/Surgical nurses. 
Using Type of Nursing Education as the independent variable, the dependent variables data were analyzed separately for the total and audit samples. No significant differences among levels of nursing education were found for the total sample by the analysis of variance of the pre-test and post-test scores and the analysis of covariance. However, there were significant differences among the groups in selfperceived understanding of the nursing process, with the mean for the ADN being significantly lower than the mean for the BSN.

For the audit sample, no significant difference was found on the change scores, percent complete on audit, and self-perceived understanding. Significant differences among the types of nursing education were found on the pre-test and post-test, with the pre-test and post-test means for the LPN's being significantly lower than the respective means for the BSN's, and the post-test mean for the LPN'S being significantly lower than the post-test mean of the ADN's.

Using age levels as the independent variable, the dependent variables data were analyzed separately for the total and audit samples. For the total sample, no significant difference was found on the pretest and self-perceived understanding. The age groups differed significantly on the post-test, with the two older groups having significantly lower means than the youngest group. However, when the pre-test was used as a covariate, the statistical hypothesis was rejected in the analysis of variance and covariance, but no pair-wise mean comparison of the adjusted means was significant. For the audit sample, no significant difference was found on the two dependent variables 
(change scores and percent complete).

Using levels of experience as the independent variable, the dependent variables data were analyzed. For the total sample, no significant difference was found on the pretest and the self-perceived understanding variables. The groups differed significantly on the analysis of variance of the post-test and the analysis of variance and covariance of the post-test with the pretest as a covariate, with the mean (and adjusted mean) of the youngest group being greater than the means (and adjusted means) of the other two groups. For the audit sample, no significant difference was found on the two dependent variables (change scores and percent complete).

\section{DISCUSSION AND CONCLUSIONS}

Does the current training program used at Bess Kaiser Medical Center teach newly-employed staff nurses how to transfer nursing process theory to practice, and do these nurses then apply and document the utilization of nursing process in patients' charts? For the audit sample, the post-test mean was significantly greater than the pre-test mean, indicating that the nurses did acquire additional knowledge about the methodology used in nursing process as it is applied in clinical settings. Also, the audit of the charts of the patients of the participating nurses indicated that they did apply nursing process in their work with the patients (79\% of the appropriate items were documented in the charts). If one extrapolates an overall compliance rate from the tables in the earlier study, Johnson (1982) found that 
there was only a $54.8 \%$ compliance. Thus, these newly-employed nurses are more effectively documenting on their patients' charts the utilization of the nursing process than did the staff nurses in the earlier study. This supports an inference that the nursing process class is influencing the charting behavior of staff nurses; whether this apparent gain will be maintained over time is yet to be detemined. Documentation of practice is an essential component of nursing process. It is the tangible evidence of the cognition and skill of the professional nurse practicing nursing. It is a statement of accountability and responsibility by the nurse. The legalistic environment in which today's nurse practices nursing emphasizes the importance of good documentation in the patients' medical records. The nurse who uses and documents effective use of nursing process while caring for patients meets first the professional obligations of nursing, and second the legal obligations of health care providers today.

Total Staff Utilization of Nursing Process

Nursing Assessment Form. Analyses of the staff RN's utilization of this form revealed that percent completion for the items ranged from 52.0 on Item 1 to 91.5 on Item 2, with one half of these items being 85 percent or higher. This is an improvement from the original study (Johnson, 1980) in which the percent completion ranged from 23.3 on Item 1 to 75.6 on Item 6 . Thus, the immediate needs of the patients being assessed by a registered nurse, completion of the initial assessment form, and signing of the forms by a registered nurse were the highest rates of compliance to existing policies. This was an improvement over 
the results of the original study in which signing the forms was the only practice factor that demonstrated compliance with existing policies. All items showed an improvement from the original study. The least improvement, from $57.4 \%$ to $62.4 \%$, was on Question 3, Part 2, relating to documentation of a nursing diagnosis on the initial assessment sheet. This continues to be a problem and is in part related to the existing taxonomies for nursing diagnoses; none are well designed and as such are not utilized by the practicing nurse.

The nurses in the Maternal/Child arena are less likely to document a nursing diagnosis and the resulting goals on the initial assessment sheet than are nurses from other arenas. This may be attributable to the type of patients serviced in that arena. Normal postpartum patients present fewer problems and are classified in a wellness category. This could explain the disparity between clinical arenas on the utilization of this form. No data are offered in this study to validate that possibility.

Problem List-Nursing. Analyses of the utilization of the Problem List-Nursing form indicated an underutilization of this form. Percent complete on the items ranged from 4.3 on Question 4 to 53.5 on Question 2. This was a decline from the percent complete in the original study, which ranged from 13.5 on Question 5 to 80.6 on Question 2. On only one item, Question 2, "Does each problem have a Roman numeral as a designator?", was the completion rate over 50 percent; and it was lower than the $80.6 \%$ of the original study. The poor construction of this form has been frequently voiced by nurses as obstructive to charting 
practices, and they opt to ignore it or underutilize it.

Patient Progress Note. Analyses of the utilization of the Patient Progress Note demonstrated a relatively high utilization as evidenced by the range in percent of completed items: 64.6 on Question 6 to 98.8 on Questions 1, 2, and 3. There is again evidence of improvement from the original study that demonstrated a range of 45.3 on Question 4 to 93.7 on Question 1 of items completed. Four of the items in the new study were recorded as $82 \%$ or above completed, contrasted with only three in the original study. All items showed an improvement from the original study. One consistent pattern should be noted here that appears in both this and the previous study. A comparison of the percentages for the first three items indicates that some parts of this form are more routinely utilized by the staff RN's. Questions 1,2, and 3 indicate the highest compliance rates to existing policies in both studies.

Flow Sheet. Analyses of the utilization of the Flow Sheet by staff demonstrated a high utilization by staff as evidenced by the $76.4 \%$ compliance rate. This was an improvement from the last study when completion rate was $62.3 \%$.

\section{Clinical Arena Utilization}

Calculated chi-squares and levels of significance for percent completion by clinical arenas for each question on each of the four forms were performed. For the convenience of the reader, values are reported as percentages; the calculations were performed on the cell frequencies.

Using the .05 level of significance, the chi-square values for 
Question 6 on the Nursing Assessment form was significant, thus the statistical hypothesis for this item was rejected. A greater portion of the nurses from the Maternal/Child clinical arena complied with existing policies relative to the utilization of the Nursing Assessment form. Percents of completion from that clinical arena ranged from a low of 61.2 on Question 3, Part 2, to a high of 93.0 on Question 2. This is an improvement from the original study where the range was 46.5 on Question 1 to 65.1 on Question 2. Only on Question 3, Part 2, did other clinical arenas lead in percent compliance of utilization. Critical Care led with 65\%; Medical/Surgical followed, at 62.5\%, and Maternal/Child had 61.2\%. An improvement was noted in all clinical arenas as indicated by the percent completed ranges of 47.5 on Question 1 to 84.9 on Question 6 in the original study.

Calculated chi-squares and levels of significance for percent completion by clinical arena for each question on the Problem ListNursing indicated a higher compliance level by nurses from the Maternal/Child arena. Using the .05 level of significance, the chisquare values for Questions $1,2,3$, and 5 were significant, and the statistical hypotheses for these items were rejected. The range of percents completed for this study were from 2.6 on Question 4 to 78.6 on Question 2. This was less favorable than the ranges on the original study (from a low of 10.6 on Question 5, Part 2, to a high of 83.7 on Question 2).

Calculated chi-squares and levels of significance for percent completion by clinical arena for each question on the Progress Note 
revealed no significant difference between arenas. Compliance rates were improved as evidenced from the percent completion range of 53.3 on Question 6 to a high of 100 on Question 2, compared with a low of 42.9 on Question 4 and a high of 96.8 on Questions 2 and 3 in the previous study.

Calculated chi-square and level of significance for percent completion by clinical arena for the one item on the Flow Sheet indicated better compliance with existing policies by the nurses in the Maternal/Child clinical arena. The ranges of percents completed $(63.8$ to a high of 89.5 ) showed improvement from the ranges in the original study $(58.1-63.5)$.

\section{Nursing Education and the Nursing Process}

Is the type of nursing education related to the knowledge of and effectiveness in the use of the nursing process? There seemed to be few significant relationships between the type of nursing education and demonstrated knowledge and effectiveness in use of the nursing process. There were, however, interesting differences among the groups.

A Scheffe test indicated that there were significant differences between the groups on the pre-test and post-test variables compared with type of education. LPN's scored significantly lower on both tests than the other groups. This reinforces the probability that there is a significant difference between the LPN education process and that of the other groups. The LPN's tended to rate their self-perceived understanding of the nursing process higher than one would expect to find using the test scores as an index of comparison. This may well be 
explained by the findings, which indicate that the LPN participants were in the group of older and more experienced categories. It is an interesting characteristic of practicing nurses to equate experience with knowledge as evidenced by hiring guidelines that frequently demand a specific number of years of experience to qualify for a nursing position.

Though nurses with BSN's scored higher on test items and perceived understanding, they tended to rank lower on percent complete on audit--a performance score. This again may be explained by the fact that the curriculum of the BSN programs are generally more heavily academic-oriented than the other groups, with less focus on directed clinical practices, more cognition and less skills development.

Age and the Nursing Process

Is age related to knowledge of and effectiveness in the use of the nursing process? Analysis of the means indicated that the older age group (those over 44 years old) produced a consistently lower mean throughout both pre- and post-test scores, but there were no significant differences in change scores. An analys is of variance supported by a Scheffe test did indeed indicate that the older group did not do as well on the post-test; older nurses may not be as susceptible to classroom interventions. There was, however, no significant difference between the age groups in the audit sample when analyzing the effectiveness of utilization of nursing process as demonstrated by percent complete on chart audit. The conclusion may well be that older nurses do not do as well on tests but can perform as well as their younger peers. 


\section{Experience and the Nursing Process}

Is experience related to knowledge of and effectiveness in the use of the nursing process? Analyses of the means and standard deviations indicated that the more experienced nurses (the'over 10 years group) produced a lower mean than did the other two groups on both the pre- and post-tests and on understanding for the total sample. The less experienced group (under 6 years) did significantly better than the remaining two groups. Again, however, in the audit sample no significant differences were apparent when analyzing performance by percent complete on chart audit. The conclusion may well be that, as with the age variable, the more experienced nurses do not do as well on tests but can perform as well as the younger, less experienced nurses.

\section{Concluding Statements}

It should be recognized at this time that this study was quasiexperimental in design, lacking a control group. Consequently, it is possible that variables other than independent variables of direct concern to the study contributed to the results obtained. However, given the experimental setting in which the study was conducted and the characteristics of the sample, it is unlikely that most of the internal threats to the validity of the study were in fact operational in this study and contributed directly to the results obtained. For example, maturation in this type of design is a threat; since the sample was an adult group and the duration of treatment was short, maturation is unlikely to have contributed in any significant manner to the results obtained. Contemporary history, those events occuring during the course 
of a study but not a part of the design of the study, could, on the other hand, have played some role. In particular, it is possible that other activities in the job setting, while the nurses were working in the wards, led to their greater awareness and utilization of nursing process. However, this is unlikely to have been a major factor in the results since there was no systematic manner of obtaining information about the nursing process in the clinical settings and since the sample of nurses was divided among several classes taught over the course of one year, thus modifying the impact of any one unusual event. Also, since the intent of this study was to investigate the effectiveness of an inservice training program on the utilization of nursing process, any secondary feedback of a normal type in the regular daily work experiences of the nurses is in fact a part of a program designed to integrate classroom theory and field practice. Thus, although there are a number of potential validity threats resulting from the nature of this study, it is reasonable to cautiously interpret these results as indicative of the effectiveness of this inservice training program. With appropriate recognition of the above limitations, it is possible to generalize with care the results of this study to other hospital settings in which this nursing process class might be placed into operation. This study demonstrated that nurses can be taught to use nursing process in the clinical setting. It also suggests a general procedure which might be used in inservice training at the hospital level or incorporated into the curriculum of the directed clinical practice sessions of schools of nursing. 
The findings of the study indicate that nurses who have attended the nursing process class do evidence an understanding of the theory of nursing process and document the application of this knowledge in patients' charts. Analyses of data collected indicates improved utilization of the nursing process by staff since the original study. Audits indicate that newly-hired nurses who have participated in the training program document both understanding and utilization of the nursing process as they deliver nursing care to patients.

Variables such as type of nursing education, age, and experience, though statistically significant related to performance on tests in the classroom, are generally less apt to be significant relative to the performance of practicing staff nurses. The relationship between the nurse's knowledge and the application of that knowledge using acquired skills has been analyzed in this study from a generalist perspective and as such leaves room for more in-depth analysis at another time: examining the differences within groups in relation to the variables as stated above.

The focus of this study, as previously described at the beginning of this chapter, was aimed at a small population of nurses in a particular hospital. It was a field study and as such had the imposed restraints of existing institutional regulations and the budgetary considerations frequently found in field studies. It is not intended to serve as an educational model for all nurses. The results of this study, however, indicate that this training course did teach these nurses, in this hospital under the imposed conditions of this program, 
to transfer nursing process theory to practice and to document same in the patients' charts. To this researcher, this lends validity to the concern voiced by many authors cited in the literature review of this document (Chapter II) that the educational process for nurses must include not only the theory of nursing process but a practical method of application of the theory to practice. This training program combined those two components, and the results were positive.

Teaching in isolation from practice has been advanced by many of the authors cited in the literature review as one of the potential contributing causes to lack of successful implementation of nursing process into nursing practice. This researcher would raise a subtle point for discussion or perhaps for future study: is the recognized disparity due to inadequate practice mechanisms or inadequate instruction in practice?

\section{RECOMMENDATIONS FOR FURTHER STUDY}

The contentions voiced throughout the literature review presented in Chapter II of this study appear to be substantiated by the researcher's original study and reinforced by the current one. Nursing process models taught in isolation from nursing operations are not an effective way to integrate this concept into nursing practice. Nurses are indeed resistant to changes in practice that they (1) do not understand, or (2) consider impractical at the operations level. Newlygraduated nurses who have learned the conceptual model do not have the skills to implement the process in their practice as independent 
practitioners; and without assistance from their peers, they soon conform to the "old way of doing things." Older nurses who have resisted implementation of the model have frequently done so because they (1) have not understood the model or even the concept of models of practice, and/or (2) have lacked administrative direction and support to learn and implement the model.

Nursing practice is increasing in scope and sophistication. The demands that are being made and will continue to be made on the professional nurse are significant; evidence the revamping of the healthcare delivery system with Diagnostic Related Groupings (DRG's) and Prospective Payment Organizations (PPO's). Nursing education can no longer afford the luxury of training nurses in isolation from the realities of the operations level. Proactive, process thinking must replace the traditional reactive component of nursing education if nurses are to be able to meet the demands of the health care system of the future. Data analysis and decision making are necessary components of the process.

Newly-hired nurses come to an institution with many individual differences: age, experience, education, religious beliefs, personal values, and cultural experiences. They are a diverse population from various geographic areas and with only one common expectation: to practice professional nursing as defined by their professional organization and the state Nurse Practice Act. To what degree do these variables impact the ability of the nurse to utilize nursing process as a model of nursing practice? Further research on this question might 
provide knowledge that would validate the current theories proposed for underutilization of nursing process.

Nursing research that defines problems of both the academic and operational phases of nursing education and presents potential and workable solutions to these problems is a realistic place to start. Educational and training programs, co-sponsored by institutes of learning and health care facilities, developed, implemented, and evaluated by qualified personnel from each arena, is another direction to be explored. Tools for implementing nursing process as the basis of practice must be carefully designed to assist nurses as they practice, rather than obstruct, the flow of operations. Evaluations must be based both on cognition and the behavioral response of the nurse. Audit may be the tool, but the process is monitoring. An ongoing evaluative process is the final objective.

This study should be replicated (including in the sample nurses in the outpatient, ambulatory care, and home health settings) in order to evaluate the effects of the patient-focused intent of the nursing process model.

Evidence regarding the effectiveness of the use of the nursing diagnosis as a vital core component of the plan of care directing nursing practice would be beneficial. Are the explanations frequently advanced, i.e., the lack of a well-defined taxonomy of nursing diagnoses and an inherent resistance by nurses to diagnosis as a component of nursing practice, truly the causes for nurses' underutilization of diagnoses? Is the chasm between nursing education and nursing 
management widening, despite good intentions on both sides, due to lack of collaborative practice? Does the present methodology of teaching nursing process to nurses obstruct the learning process as the search of the literature would indicate? Is the focus on utilization of nursing process so misdirected that the quality of utilization of nursing process is sacrificed in the training program? Many questions have yet to be answered. Yura and Walsh (1973) contend that the purpose of research is to reveal new knowledge and the purpose of problem solving is to solve an existing problem in a particular setting. The nursing process is essentially a problem-solving technique, but it also can be a usefut tool in research.

This researcher would posit that research is often necessary to provide the knowledge on which the decision-making process necessary to solve a problem is based. Experimental evidence of the validity of training programs such as this one would enhance the development of creditable and purposeful nursing operational research. 


\section{REFERENCES}

Abdellah, F., Belland, I., Martin, A., et al, Patient Centered

Approaches to Nursing. New York: The Macmillan Company, 1960.

Aitschul, A. T., A systems approach to the nursing process. Journal of Advanced Nursing, 1978, pp. 333-340.

Ashworth, P., A way to better care. Nursing Mirror, August 28, 1980, pp. 26-27.

Ashworth, P., Problems and solutions. Nursing Mirror, September 4, 1980 , pp. 34-36.

Aspinwall, M. J. Nursing diagnosis--the weak link. Nursing Outlook, July 1976, pp. 433-437.

Aspinwall, M. J., Jambruno, N., and Phoenix, B. The why and how of nursing diagnosis. The American Journal of Maternal Child Nursing, Nov./Dec. 1977, pp. 334-358.

Bartos, L. and Knight, M. R., Documentation of nursing process. Supervisor Nurse, July 1978, pp. 41-47, p. 248.

Billie, D., Practical Approaches to Patient Teaching. Boston: Little, Brown and Co., 1981.

Bircher, A., On the development and classification of diagnoses. Nursing Forum, Vol. 14, 1975, p. 10.

Boylan, A., The nursing process and the role of the registered nurse. Nursing Times, Vol. 78, No. 34, August 25, 1982, pp. 1443-1444.

Boylan, A. The role of the nurse in the future. Nursing Times, Vol. 78, No. 37, Sept. 15, 1982, pp. 1561-1563.

Brown, B. Documentation of ANA Standards. Publication of the American Nurses' Association. New York, 1979.

Browning, M. H. and Minehan, P. L., The Nursing Process in Practice. New York: American Journal of Nursing Company, 1974.

Bruce, J. A., Implementation of nursing diagnosis. Nursing Clinics of North America, 1979,14 (3), 509-515. 
Butherus, C. G., The nursing process: Part I. The Journal of Practical Nursing, October 1978, pp. 15-18.

Butherus, C. G., The nursing process: Part II. The Journal of Practical Nursing, November 1978, pp. 31-39.

Carlson, J., Craft, C., and McGuire, A., Nursing Diagnosis,

Philadelphia: W. B. Saunders, 1982.

Carmack, Desmond, The nursing process: An application of the S.O.A.P.E. model. Nursing Times, April 3, 1980, pp. 37-40.

Committee Records of Quality Assurance and Medical Records Committees, Bess Kaiser Medical Center, Portland, Oregon, 1979-1980.

Crow, J., The nursing process--2: How and why to take a nursing history. Nursing Times, June 23, 1977, pp. 950-957.

Daniels, L. M., and Kochar, M. S., What influences adherence to hypertension therapy. Nursing Forum, 11: 231-245, 1979.

Davis, J., Slow wheel of progress. Nursing Mirror, Vol. 154, No. 3, January 1982, pp. 18-20.

Dickenson, S., The nursing process and the professional status of nursing. Nursing Times, Vo1. 78, No. 16, June 2, 1982, pp. 61-64.

Feild, L., The implementation of nursing diagnosis in clinical practice. Nursing Clinics of North America, 1971, 14 (3), pp. 497-508.

FitzHugh, L. A., Applying andragogy to patient education. CrossReference on Human Resources Management, July-August 1976, $\overline{\mathrm{pp} .}$ 3-6.

Fivars, G. and Gosnel, D., Nursing Evaluation: The Problem and the Process. New York: The Macmitlan Company.

Gebbie, K. and Lanvin, M. classifying nursing diagnoses. American Journal of Nursing, February 1974, pp. 250-253.

Goodwin, J. 0., A cross cultural approach to integrating nursing theory and practice. Nurse Educator, November/December 1980, pp. 15-20.

Gordon, M., Nursing diagnosis and the diagnostic process. The American Journal of Nursing, August 1976, pp. 1298-1300.

Gordon, M., The concept of nursing diagnosis. Nursing clinics of North America, 14 (3), 1979, pp. 487-495.

Gustafson, M. B. Puppets in the nursing process. The Journal for Nursing Leadership and Management, November 1980, pp. 33-36. 
Hagar, L., The nursing process, a tool to individualize care. Nursing Mirror, June 1978, pp. 876-879.

Hammond, M., The nursing process. The American Journal of Nursing, December 1978, pp. 3719-3723.

Harris, R., A strong vote for nursing process. The American Journal of Nursing, November 1979, pp. 1999-2001.

Hegyvary, S. T., Nursing process as the basis for evaluating the quality of nursing care. International Nursing Review, 1979, 26 (4), pp. 113116.

Hilbhourne, J., The patient process. Nursing Times, Vol. 78, No. 16, June 2, 1981, pp. 917-919.

Holt, D., Middleton, R., and Borzonia, A., Making a new record. Nursing Mirror, August 1980, pp. 32-34.

Inpatient Nursing Service, Policy and Procedure Manual, Portland, Oregon: Bess Kaiser MedicaT Center, 1983.

Johnson, C. F., An audit of the utilization of nursing process in an acute care facility by staff RN's. A Research Report, 1982.

Jones, C. The nursing process, individualized care. Nursing Mirror, October 1979, pp. 13-14.

Judge, R. D., and Zuidema, G. D., Physical Diagnosis: A Physiological Approach to the Clinical Examination, 2nd ed. Boston: Little, Brown, and Co., 1968.

Kirwin, B., From the ivory tower to the ward. Nursing Mirror, February 1980, pp. 28-30.

Knowles, M. S., Gearing adult education for the seventies. Journal of Continuing Education in Nursing, 1:11, May 1970, p. 3.

Knowles, M. S., The Modern Practice of Adult Education. New York:

Assoc. Press, 1970 .

Kramer, M., Holaday, B., and Hoeffer, B., The teaching of nursing research--part II: A literature review of teaching strategies. Nurse Educator, March/April 1981, pp. 30-36

Lewis, L. This I believe . - about the nursing process--key to care. The Nursing Process in Practice. American Journal of Nursing Co., New York, 1974, p. 12 . 
Lillesand, K. M. and Korff, S., Nursing process evaluation: a quality assurance tool. Nursing Administration Quarterly, Spring 1983, pp. 914.

Mackie, L. C. R. and Welch, J. W., Quality assurance audit fo the nursing process. Nursing Times, Vol. 78, No. 34, June 1982, pp. 17571758 .

Maran, M. D., Patient allocation vs. task allocation in relation to the nursing process. Nursing Times, March 9, 1978, pp. 413-416.

Marriner, A. The Nursing Process, A Scientific Approach to Nursing Care. St. Louis: C. V. Mosby Company, 1975.

Mauksch, I. C. and David, M. L., Prescription for survival. The American Journal of Nursing, December 1972, pp. 2189-2193.

McKeehan, K. M., Nursing diagnosis in a discharge planning program. Nursing clinics of North America, 1971, 14 (3), pp. 517-523.

Mundinger, M. 0. and Jauron, G. D., Developing a nursing diagnosis. Nursing Outlook, February 1975, pp. 94-98.

Neilson, A. F., Why do we need the nursing process? Nursing Times, November 30, 1978, pp. 1984-1990.

Nichols, M. E. and Wessells, V. G., Nursing Standards and Nursing Process. Wakefield, Ma: Nursing Resources, Inc.

Orlando, I. J., The Discipline and Teaching of Nursing Process. New York: G. P. Putnain's Sons, 1972.

Pittenger, 0 . and Gooding, C. T. Learning Theories in Educational Practice: An Integration of Psychological Theory and Education Philosophy. New York: John wiley \& Sons, 1971.

Policy and Procedure Manual, Inpatient Nursing Service, Bess Kaiser Medical Center, 1979-1983.

Raeder, M. A., Patient care plans and the evaluation of nursing process. The Journal for Nursing Leadership and Management, June 1980, pp. 57-58.

Redman, B. K., The Process of Patient Teaching in Nursing. Third Edition, St. Louis: C. V. Mosby, 1976.

Roberts, C. S. Identifying the real patient problems. Nursing $\mathrm{Cl}$ inics of North America, Vol. 17, No. 3, September 1982, pp. 481-489.

Roy, C. Sister, A diagnostic classification systen for nursing. Nursing Outiook, February 1975, 23 (2), 90-93. 
Roy, C. Sister, Introduction to Nursing: An Adaptation Model.

Englewood Cliffs: Prentice-HalT, Inc., 1976.

Rutkowski-Conway, Barbara, Patient participation in nursing process. Nursing Clinics of North America, Vol. 17, No. 3, September 1982, pp. $451-4$.

Sculco, C., Development of a taxonomy for the nursing process. Journal of Nursing Education, 1978, 17 (6), pp. 41-48.

Shoemaker, J., How nursing diagnosis helps focus your care. R.N. Magazine, August 1979, Pp. 60-65.

Smith, L., A nursing history and data sheet. Nursing Times, April 24, 1980, pp. 20-21.

Steckel, S. B., Funnell, M. M., and Dragovan, A., How nursing care can increase patient adherence rather than patient compliance. Clinical Sessions of the American Nurse Association, 1979.

Thompson, A. The nursing process I: Its value for special hospital patients. Nursing Mirror, March 1, 1979, pp. 20-21.

Walker, L. and Nicholson, R., Criteria for evaluating nursing process models. Nurse Educator, September-October 1980, pp. 8-10.

Walters, E. J., How to do Patient Discharge Planning. Miami, Florida, 1980.

West, A., The nursing process: Patient into person. Nursing Mirror, April 1980, pp. 70-74.

Williamson, F., The nursing process in a community nursing service, Nursing Times, Vol. 78, No. 1, January 6, 1982, pp. 1-3.

Wilson-Barnett, J., A rare chance to break free. Nursing Mirror, Vol. 154, May 26, 1982, pp. 42-45.

Vasey, E. K., Writing your patients' care plan efficiently. Nursing 79, April 1979, pp. 67-71.

Yura, H. and Walsh, M. B., The Nursing Process. Second Edition. New York: Appleton-Century-Criftam, 1973. 
APPENDIX A

MEDICAL/SURGICAL CRITICAL CARE NURSING ASSESSMENT 


\section{KAISER \\ $\therefore$ DUNDATION \\ hospitals}

\section{SMC $\square \quad$ BKMC $\square$}

\section{MEDISURG CRITICAL CARE NURSING ASSESSMENT}

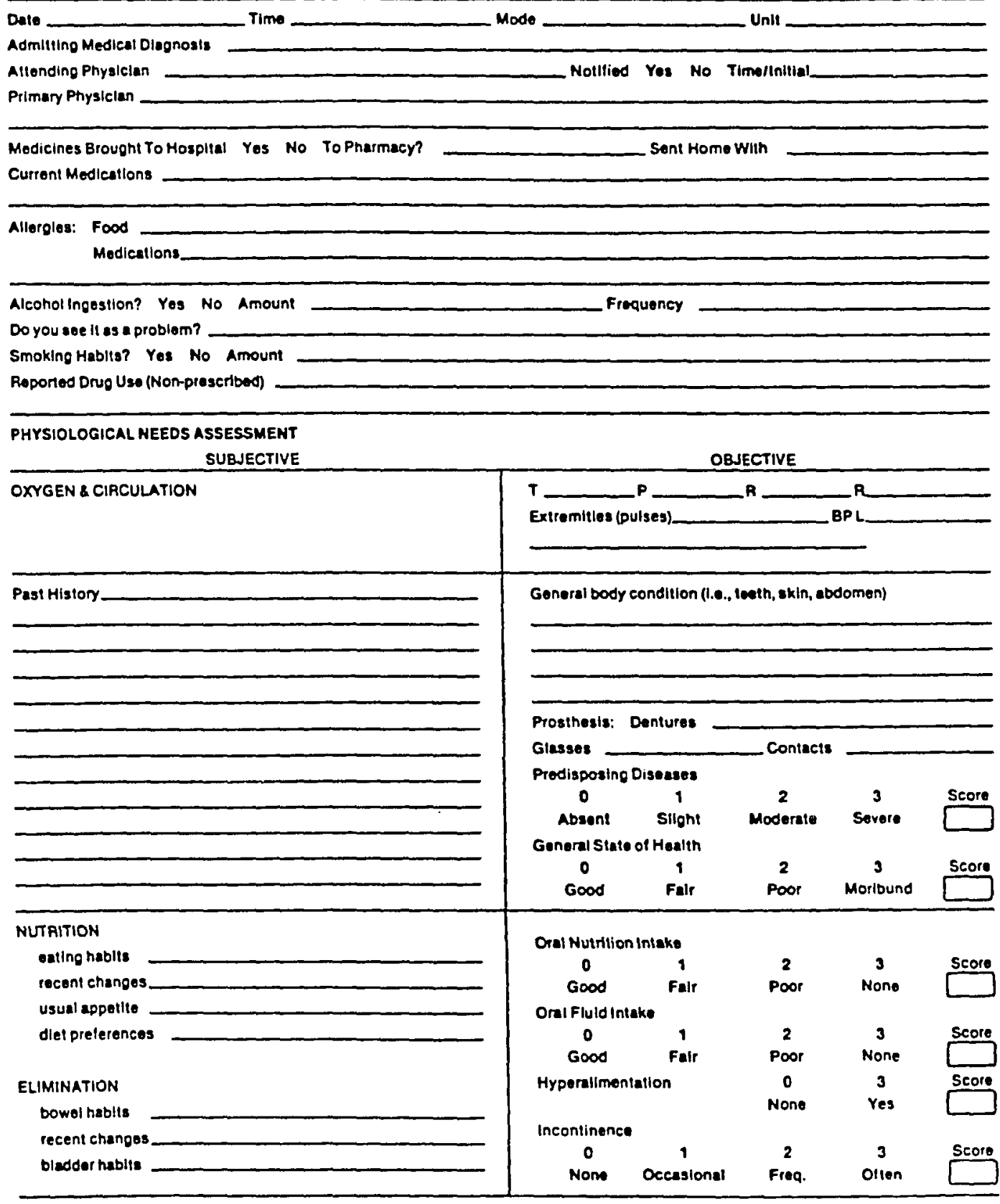




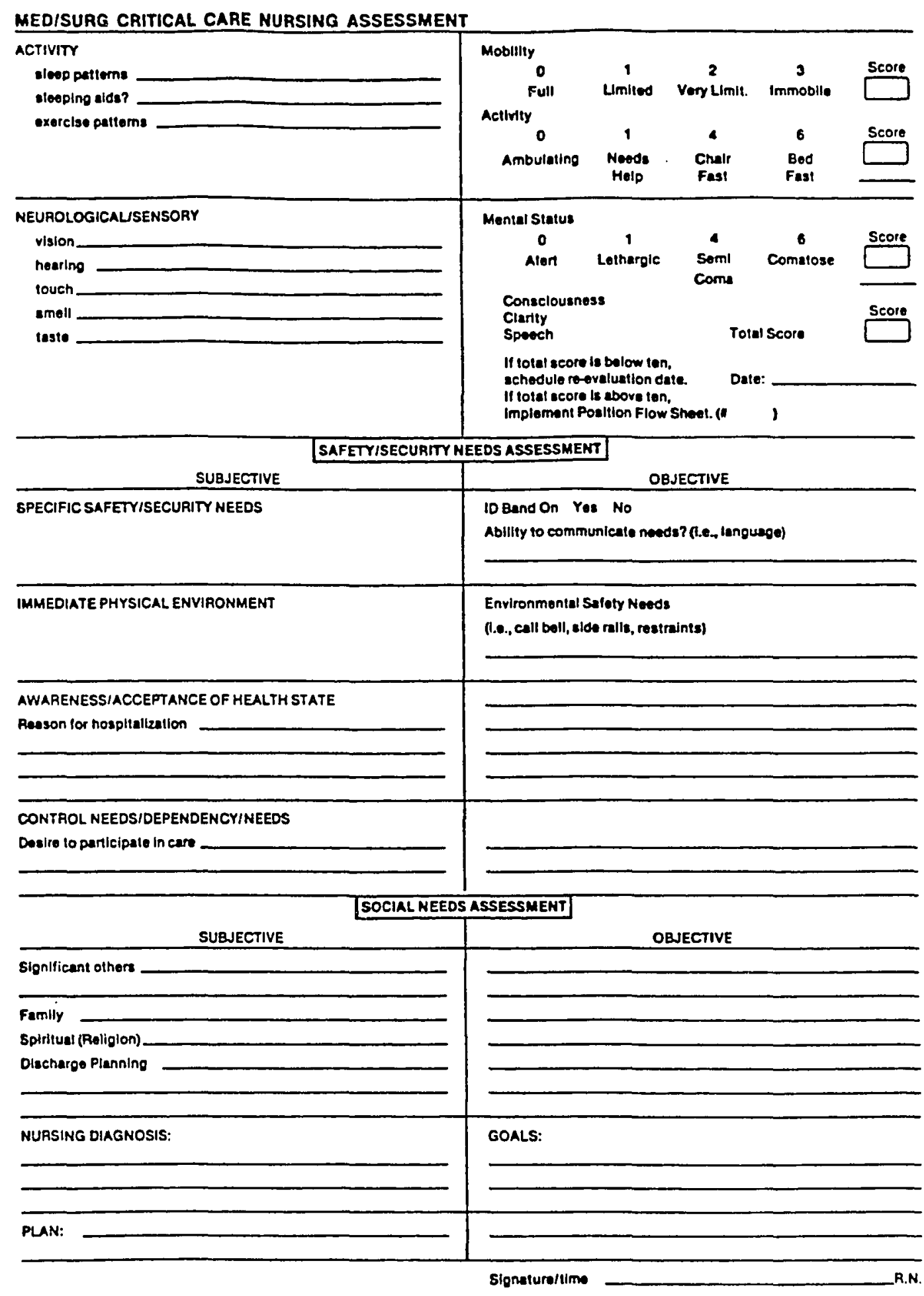




\section{APPENDIX B}

PROBLEM LIST-NURSING 
KAISER

FOUNDATION

PROBLEM LIST-NURSING

$\mathrm{N}-148 \quad 11 / 74$

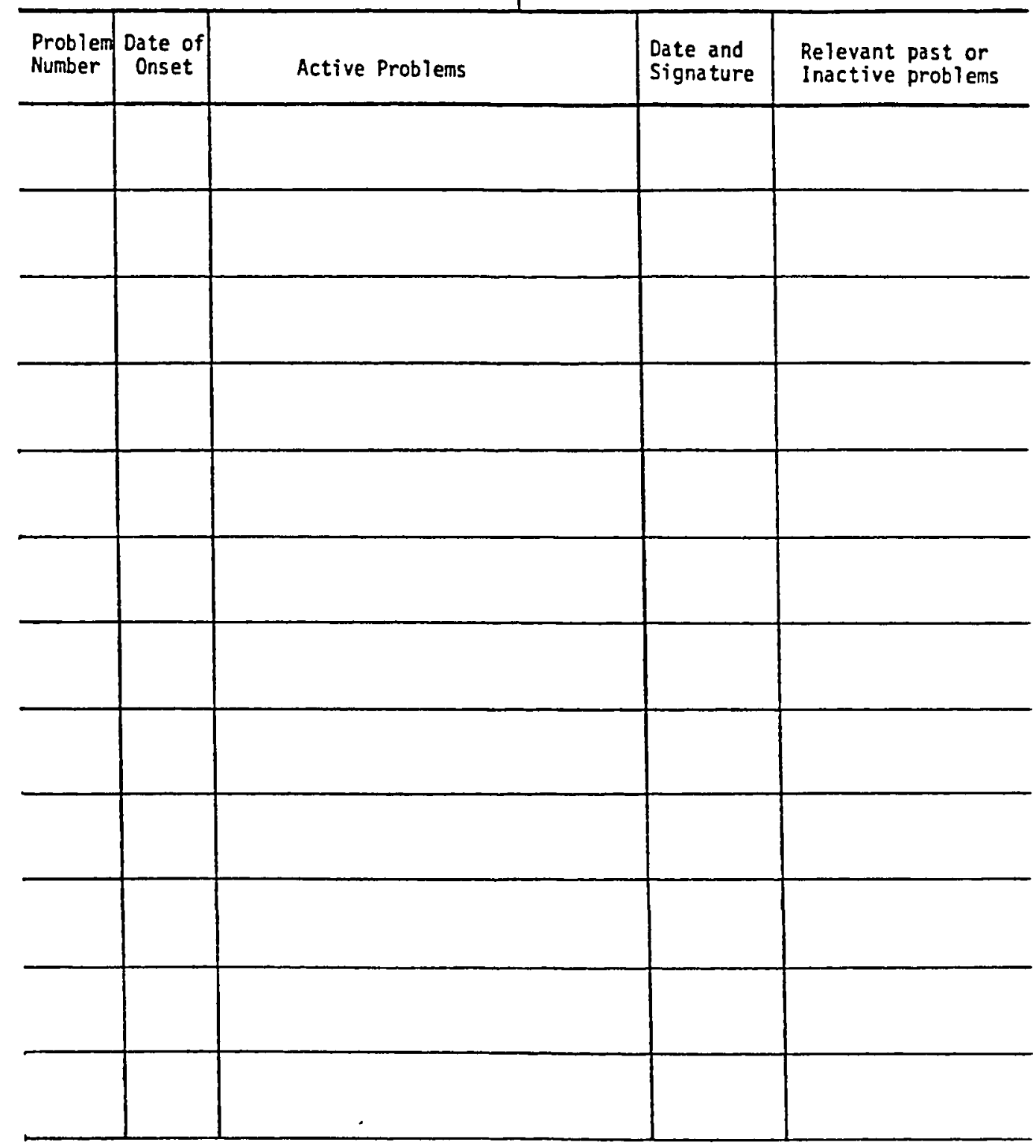


APPENDIX C

PATIENT PROGRESS NOTES 


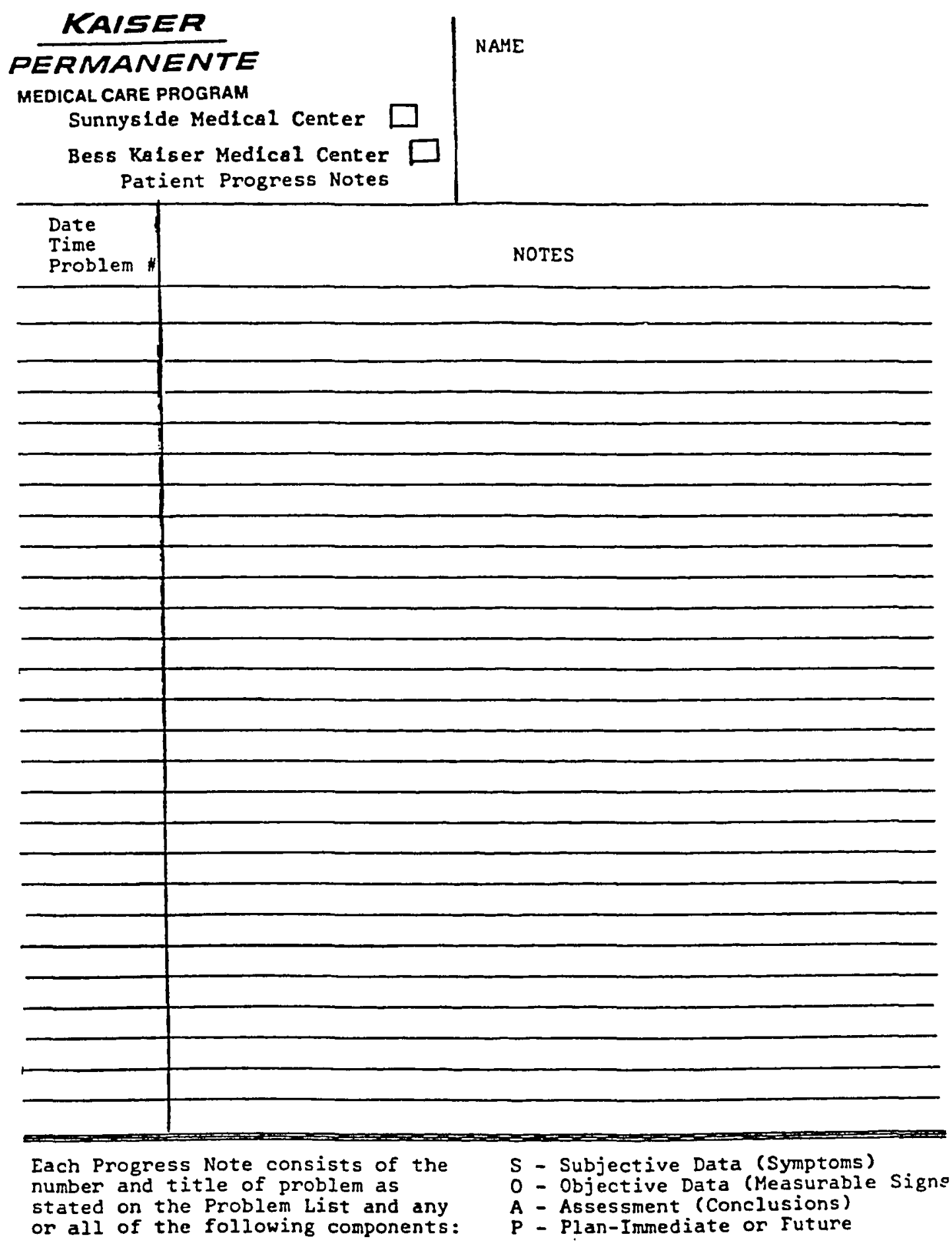




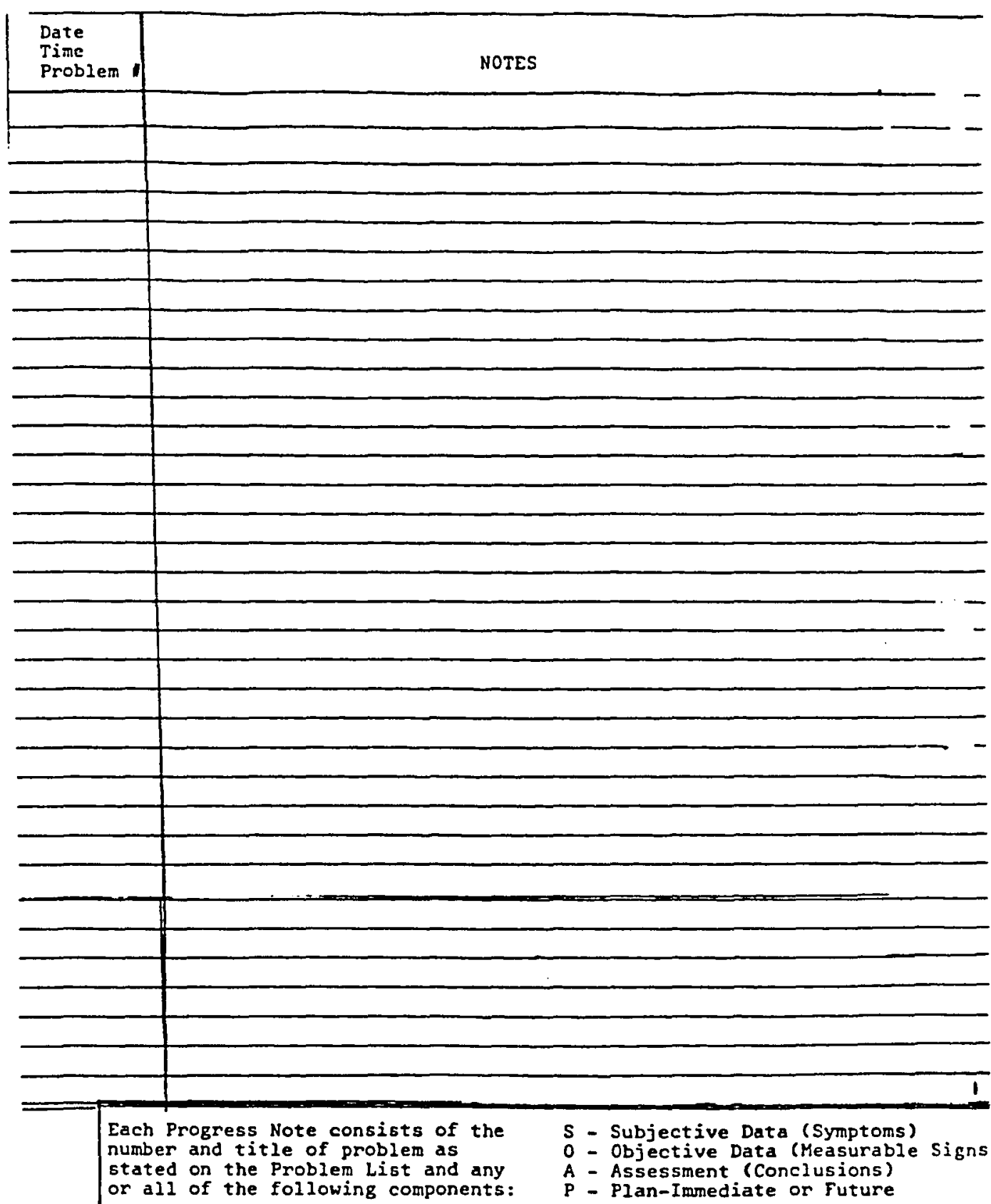


APPENDIX D

FLOW SHEET - NURSING 


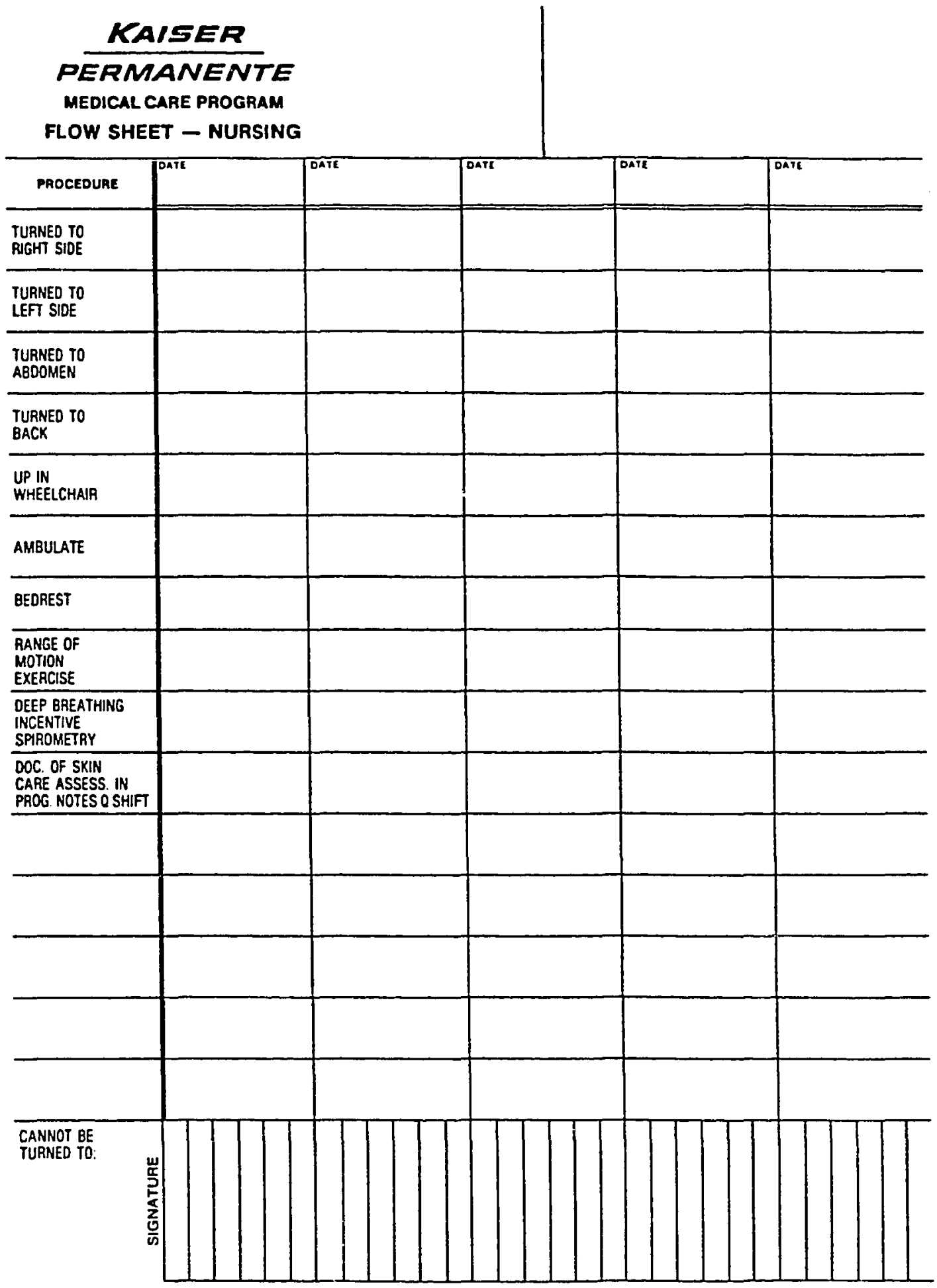




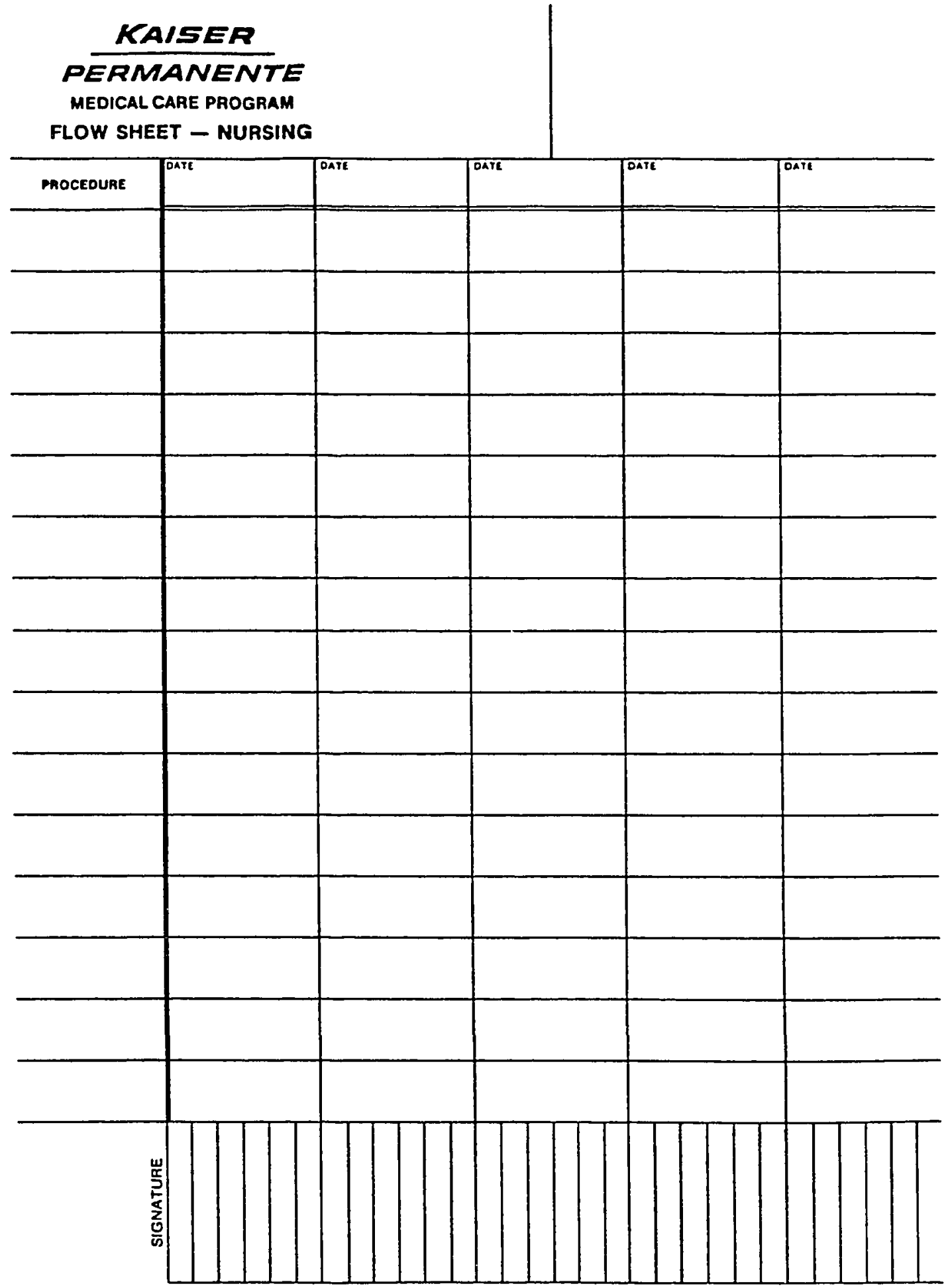


APPENDIX E

CHARACTERISTICS OF NURSE SAMPLE 


\section{CHARACTERISTICS OF NURSE SAMPLE \\ NURSING PROCESS CLASS}

NAME: TODAY'S DATE

SEX: $F$ M

AGE : Under 25 $35-44$ $25-34$ 45 and over

NAME OF NURSING SCHOOL YOU ATTENDED:

LOCATION:

YEAR OF GRADUATION:

TYPE OF PROGRAM: ADN

BSN

DIPLOMA

Graduate Degree Obtained: YES NO

If yes, what: YEARS OF EXPERIENCE IN NURSING where:

Are you:

A full-time employee

A part-time employee

Less than 20 hours a week

What shift have you been hired for? Day Evening Night What clinical arena will you be working in?

Medical-Surgical
Maternal-Child
Critical Care
Other

Have you previously had a formal class in Nursing Process? Yes _No If so, was it while you were in nursing school? Yes_ No 
How would you rate your understanding of the Nursing Process as the framework of Nursing Practice?

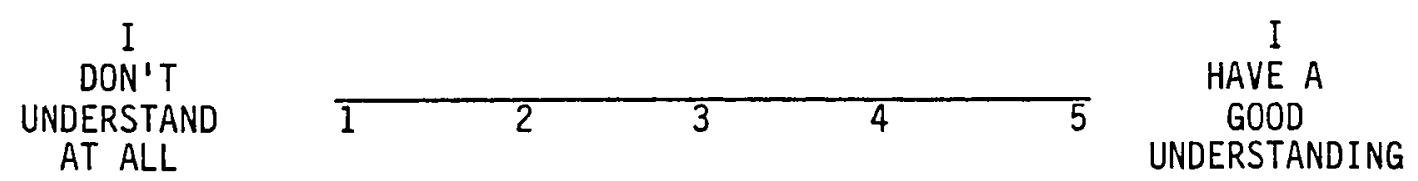

Do you think that the use of the Nursing Process will positively affect nursing care given?

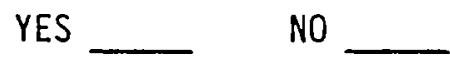

WHY?

Would you be willing to help implement Nursing Process utilization by modeling your nursing practice to your peers?

YES

IF NOT, WHY NOT? 
APPENDIX F

PRE-TEST 
NAME

DATE

1. MATCH THE FOLLOWING:

Nursing Process A. Appraisal of the outcomes of the planned intervention.

Theory

Assessment

Nursing Diagnosis

Implementation

Planning

Evaluation

Care Plan
B. Gathering pertinent data in relationship to a patient's need or problem.

C. Framework for organizing nursing activity.

D. Proposed description and explanation of the underlying principles of a particular phenomena.

E. A judgment based on the nurse's scientific knowledge.

F. A means of determining a course of action to meet the needs of the patient.

G. A means by which the plan is put into action.

H. A written record that gives direction, continuity, and communication between health team members and the patient.

\section{CIRCLE THE BEST ANSWER}

2. The final step in the assessment stage of the nursing process is:

(a) planning nursing interventions

(b) collecting subjective data

(c) formulating a nursing diagnosis

(d) writing a care plan 
3. Nursing Orders are also known as:
(a) nursing actions
(b) nursing interventions
(c) nursing strategies

4. The four phases of the nursing process are:
(a) unrelated
(b) dependent, independent and interrelated
(c) dependent
(d) independent

5. The evaluation stage of the nursing process:
(a) refers to examination of nurse's interventions
(b) refers to the response of the nursing staff
(c) refers to the quality of nursing care given
(d) refers to the patient's response to nursing interventions


APPENDIX G

POST-TEST 
NAME

DATE

1. MATCH THE FOLLOHING:

Nursing Process
Theory
Assessment
Nursing Diagnosis
Implementation
Planning
Evaluation
Care Plan
A. Appraisal of the outcomes of the planned intervention.

B. Gathering pertinent data in relationship to a patient's need or problem.

C. Framework for organizing nursing activity.

D. Proposed description and explanation of the underlying principles of a particular phenomena.

E. A judgment based on the nurse's scientific knowledge.

F. A means of determining a course of action to meet the needs of the patient.

G. A means by which the plan is put into action.

H. A written record that gives direction, continuity, and communication between health team members and the patient.

2. The final step in the assessment stage of the nursing process is:

(a) planning nursing interventions

(b) collecting subjective data

(c) formulating a nursing diagnosis

(d) writing a nursing care plan 
3. The planning phase of the nursing process involves:
(a) establishing expected behavioral outcomes for the patient.
(b) setting priorities of care.
(c) deveioping specific nursing interventions.
(d) prioritizing patient problems.
(e) all of the above.

4. A nursing diagnosis is:

(a) identifying the cause of the patient's medical problems.

(b) a summary of signs and symptoms.

(c) a statement of pathophysiology.

(d) a statement of a problem with which the patient alone can no longer cope.

5. The following is a correct statement of nursing diagnosis:
(a) depression.
(b) anxiety.
(c) insomnia secondary to change in working schedule.
(d) immobility due to pain of arthritis in hips.

6. A short term goal is:
(a) a plan of action.
(b) a nursing diagnosis.
(c) an expected outcome.
(d) progressive day-to-day patient behavior.

7. A long term goal is:
(a) progressive day-to-day patient behavior.
(b) a criterion for discharge.
(c) a nursing diagnosis.
(d) an expected outcome.

8. Nursing orders are also known as:
(a) nursing actions.
(b) nursing interventions.
(c) nursing strategies.
(d) nursing diagnoses. 
NURSING PROCESS

9. Nursing orders:
(a) provide continuity of care from shift to shift.
(b) establish priorities of care.
(c) set goals for the nurse.
(d) (a) and (b) only.

10. A correctly written nursing order contains the following components:
(a) date, content, signature
(b) date, content, action, signature.
(c) a statement of collected data.
(d) none of the above.

11. The content of a nursing order includes:
(a) what should be done.
(b) when it should be done.
(c) who should do it.
(d) (a) and (c) only.

12. The following is a correct example of a nursing order:
(a) ambulate with assistance, two lengths of the corridor, four times a day at $0830,1230,1630$ and 2000.
(b) keep left leg elevated on two pillows when in bed.
(c) force fluids each shift.
(d) encourage patient to test urines daily.

13. The evaluation stage of the nursing process:
(a) refers to examination of the nurse's interventions.
(b) refers to the response of the nursing staff.
(c) refers to the quality of nursing care given.
(d) refers to the patient's response to nursing interventions. 
POST-TEST

14. The evaluative phase may:
(a) validate effective use of nursing interventions.
(b) result in identifying new problems.
(c) identify resolution of problems.
(d) (a) and (c) only.

15. The four phases of the nursing process are:
(a) unrelated.
(b) dependent, independent and interrelated.
(c) dependent.
(d) independent. 
APPENDIX $\mathrm{H}$

AUDIT TOOL 
DATE

TIME

UNIT

Patient Name Chart No. Age Sex

Admitting Medical Diagnosis

Admission Date Discharge Date

Is this the patient's first hospital admission?

Is this the patient's first hospital admission with diagnosis?

\begin{tabular}{l|l|l|l}
\hline A. Nursing Assessment Form & YES & NO & COMMENT \\
\hline $\begin{array}{l}\text { Is all information filled in? } \\
\text { (Not applicable (NA) and/or } \\
\text { Deferred are valid) }\end{array}$ & & & \\
\hline $\begin{array}{l}\text { Is there evidence that the patient's } \\
\text { immediate needs were assessed by a } \\
\text { registered nurse? }\end{array}$ & & & \\
\hline $\begin{array}{l}\text { Is there evidence that the initial } \\
\text { assessment form was completed? }\end{array}$ & & & \\
$\begin{array}{l}\text { Is there documented evidence of a } \\
\text { Nursing Diagnosis on the initial } \\
\text { assessment sheet? }\end{array}$ & & & \\
\hline $\begin{array}{l}\text { Is there documentation of formula- } \\
\text { tion of a plan of care on the } \\
\text { initial assessment ? }\end{array}$ & & & \\
\hline $\begin{array}{l}\text { Are there goals specified on the } \\
\text { initial assessment sheet? }\end{array}$ & & & \\
\hline $\begin{array}{l}\text { Is assessment sheet signed by an } \\
\text { Ting }\end{array}$ & & & \\
\hline
\end{tabular}




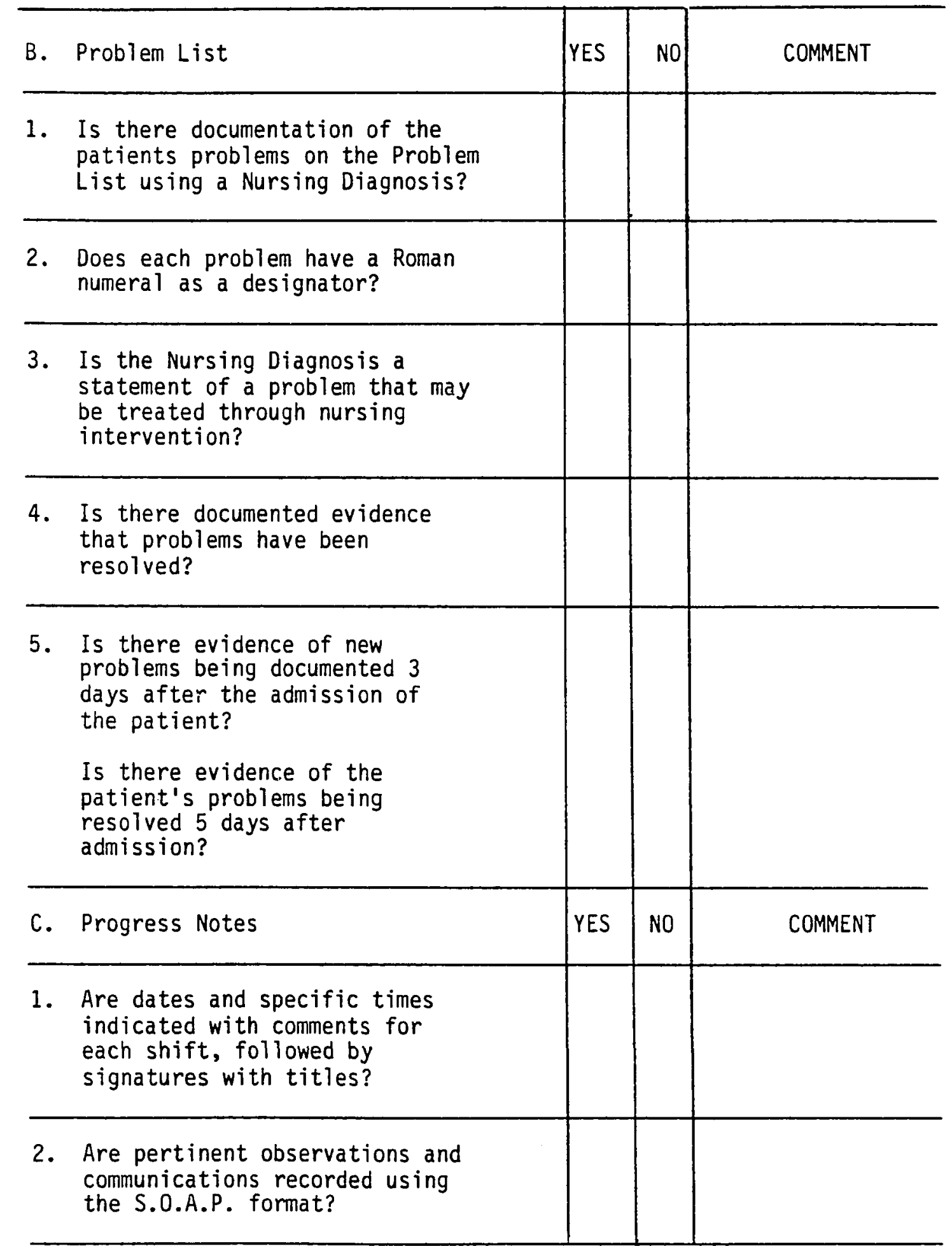




\begin{tabular}{|c|c|c|c|}
\hline $\begin{array}{l}\text { 3. Are nursing interventions } \\
\text { recorded as directed by the } \\
\text { plan of care? }\end{array}$ & & & \\
\hline $\begin{array}{l}\text { 4. Are there indications of a } \\
\text { psycho/social assessment; } \\
\text { i.e., pain, fear, } \\
\text { depression, etc? }\end{array}$ & & & \\
\hline $\begin{array}{l}\text { 5. Is there evidence of newiy- } \\
\text { assessed problems } 3 \text { days } \\
\text { after the original assess- } \\
\text { ment done on admission? }\end{array}$ & & & \\
\hline $\begin{array}{l}\text { 6. Is there evidence that the } \\
\text { effectiveness of care has } \\
\text { been evaluated by day \#5 } \\
\text { after admission by the con- } \\
\text { sistent recording of one } \\
\text { or two items? }\end{array}$ & & & \\
\hline $\begin{array}{l}\text { 7. Is there documentation of } \\
\text { discharge planning for the } \\
\text { patient when necessary? }\end{array}$ & & & \\
\hline D. Flow Sheet & YES & NO & COMMENT \\
\hline $\begin{array}{l}\text { 1. Is there documentation of } \\
1 \text { or } 2 \text { items flowing from } \\
\text { the plan on this sheet? }\end{array}$ & & & \\
\hline
\end{tabular}

Number of YES answers

Number of NO answers

Total Answered 